SILVIA FERNANDES MORGADO D'IPPOLITO

\title{
AVALIAÇÃO DO MÚSCULO PTERIGÓIDEO LATERAL POR MEIO DE RESSONÂNCIA MAGNÉTICA
}

São Paulo 


\section{Silvia Fernandes Morgado D’Ippolito}

\section{Avaliação do músculo pterigóideo lateral por meio de ressonância}

magnética

Dissertação apresentada à Faculdade de Odontologia da Universidade de São Paulo, para obter o título de Mestre, pelo Programa de Pós-Graduação em Odontologia.

Área de Concentração: Diagnóstico Bucal

Orientadora: $\operatorname{Prof}^{\mathrm{a}}{ }^{\mathrm{Dr}}{ }^{\mathrm{a}}$. Marlene Fenyo-Pereira

São Paulo 
Catalogação-na-Publicação

Serviço de Documentação Odontológica

Faculdade de Odontologia da Universidade de São Paulo

D'Ippolito, Silvia F. Morgado

Avaliação do músculo pterigóideo lateral por meio de ressonância magnética / Silvia F. Morgado D'Ippolito; orientador Marlene FenyoPereira. -- São Paulo, 2009.

120p.: tab., fig., graf. ; $30 \mathrm{~cm}$.

Dissertação (Mestrado - Programa de Pós-Graduação em Odontologia. Área de Concentração: Diagnóstico Bucal) -- Faculdade de Odontologia da Universidade de São Paulo.

1. Músculo pterigóide lateral - Articulação temporomandibular Diagnóstico 2. Músculo pterigóide lateral - Ressonância magnética

AUTORIZO A REPRODUÇÃO E DIVULGAÇÃO TOTAL OU PARCIAL DESTE TRABALHO, POR QUALQUER MEIO CONVENCIONAL OU ELETRÔNICO, PARA FINS DE ESTUDO E PESQUISA, DESDE QUE CITADA A FONTE E COMUNICADA AO AUTOR A REFERÊNCIA DA CITAÇÃO.

São Paulo,

Assinatura:

E-mail: 


\section{FOLHA DE APROVAÇÃO}

D'Ippolito SFM. Avaliação do músculo pterigóideo lateral por meio de ressonância magnética [Dissertação de Mestrado]. São Paulo: Faculdade de Odontologia da USP; 2009.

São Paulo, / /

\section{Banca Examinadora}

1) Prof.(a). $\operatorname{Dr}(a)$.

Titulação:

Julgamento:

Assinatura:

2) Prof.(a). Dr (a).

Titulação:

Julgamento:

Assinatura:

3) Prof.(a). Dr (a).

Titulação:

Julgamento:

Assinatura: 
"Só é útil o conhecimento que nos torna melhores" Sócrates 


\section{DEDICATÓRIA}

Aos meus pais, Manoel e Aldina, pelo amor, dedicação, ensinamentos, paciência e educação que me deram, sempre.

Ao meu marido Pippo, pelo amor, companheirismo, respeito e apoio ao longo de toda esta caminhada juntos. 


\section{AGRADECIMENTO ESPECIAL}

À minha orientadora e amiga $\operatorname{Prof}^{\mathrm{a}}$. Dr ${ }^{\mathrm{a}}$. Marlene Fenyo-Pereira, pela dedicação, disponibilidade, ensinamentos, incansável paciência e principalmente por ser essa pessoa maravilhosa, um exemplo de ser humano. Obrigada, Marlene, por ser quem você é. 
Ao Prof. Dr. Jurandyr Panella (in memorian)pela oportunidade e pelo exemplo de dedicação à vida acadêmica 


\section{AGRADECIMENTOS}

A todas minhas amigas que me ajudaram, me apoiaram e me compreenderam.

As minhas queridas amigas da USP Alessandra, Sibele, Rosangela, Patrizia, Ana Lucia, Lila, Thásia e Denise, pela amizade e colaboração.

As minhas irmãs, Emilia e Claudia que estiveram sempre ao meu lado.

Aos meus sobrinhos, pelo carinho sempre.

À Dra Ângela Borri Wolosker pelo apoio, incentivo, ensinamentos e paciência.

Aos Profs. Drs. Israel Chilvarquer e Claudio Freitas pelo aprendizado ao longo dos anos.

À Maria Cecília Forte pela sua ajuda fundamental, amizade e disponibilidade sempre.

À Gisele Santos, meu Anjo da Guarda, sem a qual este trabalho não teria sido realizado.

À Nina pela ajuda, amizade e paciência. 
Aos biomédicos do Serviço de Diagnóstico por Imagem do Hospital São Luiz, pela realização dos exames de Ressonância Magnética, com competência e bom humor.

Aos enfermeiros do Serviço de Diagnóstico por Imagem do Hospital São Luiz, Horácio, Regina e Valéria, entre outros, pela ajuda e boa vontade.

Ao Herbert, pela amizade e incansável disponibilidade aos domingos, sempre com muita alegria.

Aos meus colegas Estagiários da Graduação do período diurno da FOUSP, pelo apoio.

A todos os professores do Departamento de Radiologia da FOUSP, pelos ensinamentos e amizade.

Aos voluntários que se dispuseram a realizar os exames aos domingos.

À Dra Carmen, minha amiga, chefe e exemplo de ética e perseverança.

Ao Balthazar que esteve sempre presente ao meu lado nas longas noites insones.

Ao meu mestre e marido, Prof. Dr. Giuseppe D’Ippolito, pelo exemplo de dedicação e dignidade.

A todos que direta ou indiretamente colaboraram na realização deste trabalho. 
D'Ippolito SM. Avaliação do músculo pterigóideo lateral por meio de ressonância magnética [Dissertação de Mestrado]. São Paulo: Faculdade de Odontologia da USP; 2009.

\section{RESUMO}

O Músculo Pterigóideo Lateral (MPL) desempenha um papel importante nas Desordens Temporomandibulares (DTM), devido à íntima relação deste músculo com a Articulação Temporomandibular (ATM). No entanto, evidências de alterações patológicas dos músculos mastigatórios ainda parecem faltar nas pesquisas da DTM. Este estudo investigou o MPL por meio de Ressonância Magnética (RM) de 50 indivíduos com e sem DTM. Neste trabalho, das 100 ATM analisadas, 35 pacientes com DTM (70 ATM), prevalecendo o gênero feminino e 15 indivíduos sem sinais e sintomas clínicos de DTM (30 ATM) foram incluídos. O MPL foi observado e analisado em diferentes projeções. As imagens sagitais oblíquas e axiais da ATM foram capazes de mostrar os MPL claramente. Hipertrofia, atrofia e contratura do MPL foram as anomalias encontradas. Sinais de DTM, como hipermobilidade, hipomobilidade e deslocamento do disco articular puderam ser observados nas imagens de ATM. Com relação aos sintomas clínicos como dor, sons articulares, cefaléia e limitação nos movimentos mandibulares, foi possível observar que todos os pacientes com DTM apresentavam pelo menos um destes sintomas, sendo as queixas mais presentes dor e estalo; e os pacientes sem DTM também puderam mostrar alterações nas imagens de RM da ATM, como atrofia e contratura muscular, as mais observadas. O reconhecimento das alterações no MPL, podem levar a um diagnóstico mais específico e aumentar o entendimento dos sintomas clínicos e da fisiopatologia da DTM. Estudos futuros são necessários para se continuar avaliando o MPL por meio de RM.

Palavras-chave: músculo pterigóideo lateral - ressonância magnética - articulação tempomandibular 
D'Ippolito SM. Evaluation of the Lateral Pterygoid Muscle by Magnetic Resonance Imaging [Dissertação de Mestrado]. São Paulo: Faculdade de Odontologia da USP; 2009.

\section{ABSTRACT}

The Lateral Pterygoid Muscle (LPM) plays an important role in Temporomandibular Disorders (TMD), due to the close relation of this muscle with the Temporomandibular Joint (TMJ). However, evidence of pathological changes of the masticatory muscles still seems to be lacking in the TMD research. This study investigated the LPM by Magnetic Resonance Imaging (MRI) of 50 subjects with and without TMD. In this work, 100 Temporomandibular joints were analyzed, 35 subjects with TMD (70 TMJs), with the prevalence of female and 15 subjects without clinical signs and symptoms (30 TMJs) were included. The LPM was visible in different projections and analyzed. The oblique sagital and axial images of the TMJ were able to show the LPM clearly. Hipertrophy, atrophy and contracture of the LPM were the abnormalities found. TMD signs, such as hipermobility, hipomobility, disc displacement could be seem in the TMJ images. Related to clinical symptoms like pain, articular sounds, headache, and limitation of mandibular movements, it was possible to observed that all patients with TMD had at least one of these symptoms, pain and click being the most frequent complaint. Patients without TMD could also show alterations in the TMJ MRI, such as atrophy and contracture as the most common. The recognition of LPM alterations may lead to a more specific diagnosis and improvement of understanding of the clinical symptoms and pathophysiology of TMD. Further studies should be necessary to continue evaluating the LPM by MRI.

Keywords: lateral pterygoid muscle - magnetic resonance imaging temporomandibular joint 


\section{LISTA DE ABREVIATURAS E SIGLAS}

\begin{tabular}{|c|c|}
\hline ADA & American Dental Association \\
\hline ATM & Articulação Temporomandibular \\
\hline Bo & Campo Magnético Estático Externo \\
\hline DD & Deslocamento do Disco Articular \\
\hline DDA & Deslocamento Anterior do Disco Articular \\
\hline DP & Densidade de Prótons \\
\hline DTM & Desordem Temporomandibular \\
\hline FFE & Fast Field-echo \\
\hline FOV & Field of View \\
\hline G & Gauss \\
\hline GE & Gradiente Eco \\
\hline $\mathrm{H}$ & Hidrogênio \\
\hline MPL & Músculo Pterigóideo Lateral \\
\hline $\mathrm{RF}$ & Radiofreqüência \\
\hline $\mathrm{RM}$ & Ressonância Magnética \\
\hline $\mathrm{RCR}$ & Razão Contraste-Ruído \\
\hline RSR & Razão Sinal-Ruído \\
\hline SE & Spin Eco \\
\hline SPIR & Spectral Presaturation by Inversion Recovery \\
\hline $\mathrm{T}$ & Tesla \\
\hline $\mathrm{TC}$ & Tomografia Computadorizada \\
\hline TE & Tempo de Eco \\
\hline
\end{tabular}


TI Tempo de inversão

TR Tempo de Repetição

TSE Turbo Spin-echo

T1 Tempo de relaxação T1

T2 Tempo de relaxação T2

VME Vetor de Magnetização Efetiva 


\section{SUMÁRIO}

1 INTRODUÇÃO. 14

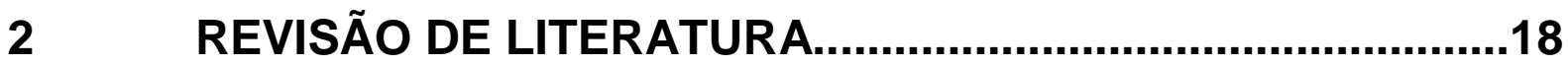

2.1 Anatomia do Músculo Pterigóideo Lateral..........................18

2.2 Princípios Básicos da Ressonância Magnética...................24

2.3 Aplicação da Ressonância Magnética na Avaliação do Músculo Pterigóideo Lateral...............................................39

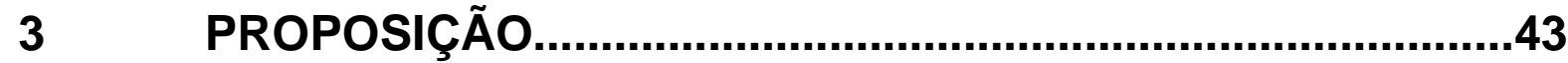

4 MATERIAL E MÉTODOS....................................................4

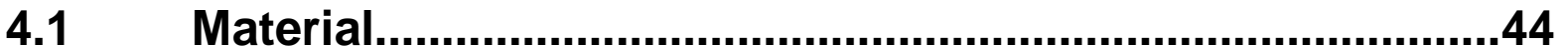

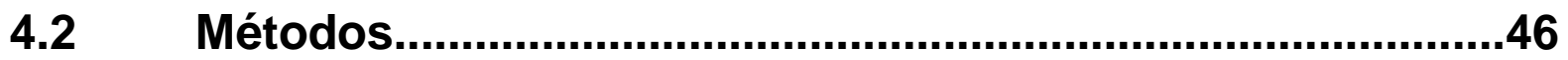

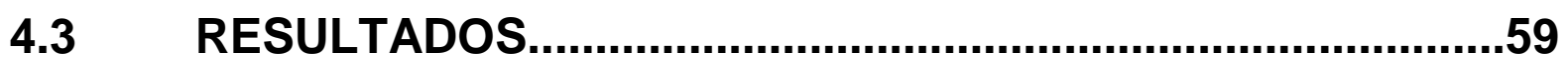

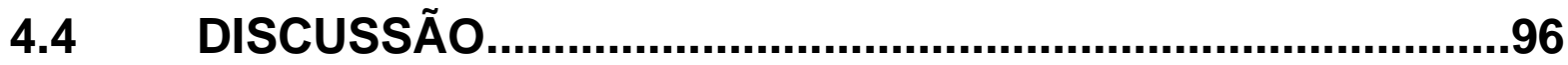

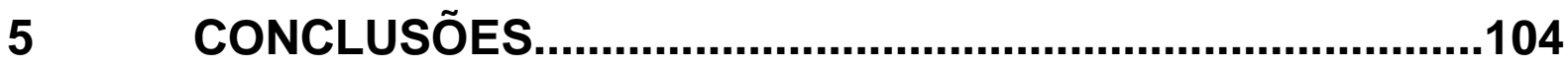

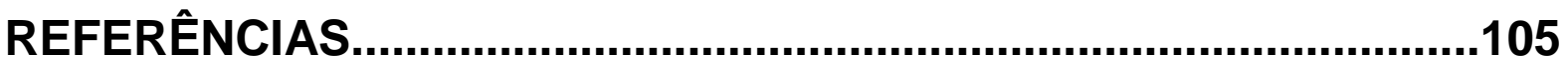

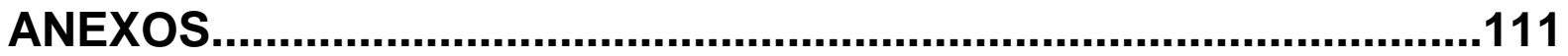

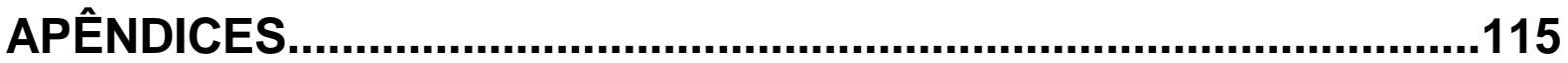




\section{INTRODUÇÃO}

Desordem Temporomandibular (DTM) é um termo complexo que engloba uma série de alterações clínicas envolvendo a Articulação Temporomandibular (ATM), os músculos da mastigação e as estruturas circunvizinhas.

É também chamada de Síndrome de Costen, Disfunção ou Desordem da ATM e Disfunção Temporomandibular ou Craniomandibular, termos considerados atualmente inadequados, segundo a American Dental Association (ADA) (1982), apud Laskin (2008), que adotou o nome de Desordens Temporomandibulares como o mais aceito (LASKIN, 2008; LASKIN, GREENFIELD, GALE, 1983).

A sintomatologia associada à DTM abrange de 40 a $60 \%$ da população adulta, destacando-se sua prevalência no gênero feminino (3:1) (FRICTON; OKESON, 2000; BRUNO, 2004).

Aproximadamente $50 \%$ dos pacientes com DTM procuram tratamento médico e não odontológico. O médico está apto a fazer o diagnóstico e realizar terapias simples para reduzir os sintomas, mas posteriormente o paciente deve ser encaminhado para um odontólogo especialista para avaliação adicional e tratamento (FRICTON; OKESON, 2000; OKESON; DEKANTER, 1996).

Os sinais e sintomas mais comuns da DTM são inicialmente, dor orofacial e na ATM (dor pré-auricular), estalido (click) ou som articular; limitação nos movimentos da mandíbula; alterações nos componentes da ATM, como deslocamento do disco articular e degeneração na cabeça da mandíbula; e alterações nos músculos da mastigação, sintomas que aumentam com a 
mastigação. Posteriormente os sintomas associados são cefaléia, otalgia e dor cervical.

O deslocamento do disco articular é a causa da DTM mais estudada por meio da Ressonância Magnética (RM), por estar associado à dor, estalido, limitação na abertura da boca, otalgia e cefaléia. Por volta de $33 \%$ dos pacientes assintomáticos e $60 \%$ dos sintomáticos apresentam deslocamento do disco articular.

Alteração muscular é outra causa comum da DTM. A energia necessária para mover a mandíbula é dada pelos músculos da mastigação como o masseter, o temporal, o pterigóideo medial e o pterigóideo lateral. O músculo digástrico, apesar de não ser considerado músculo da mastigação também tem papel importante na função da mandíbula.

Os músculos da mastigação podem estar relacionados com a DTM por serem fontes frequentes de dor, provavelmente causada por sobrecarga nos músculos devido a hábitos parafuncionais e distúrbios oclusais (OKESON; DEKANTER, 1996; RAUHALA; OIKARINEN; RAUSTIA, 1999).

Não podemos esquecer o bruxismo, esta atividade parafuncional que sozinha representa uma significante fonte de dor e que acomete aproximadamente $20 \%$ dos pacientes com DTM (RAUHALA; OIKARINEN; RAUSTIA, 1999).

O stress emocional talvez seja a causa mais comum de DTM. O aumento do stress ativa o sistema nervoso autônomo, que estaria associado às alterações musculares (OKESON; DEKANTER, 1996).

Dentre os músculos da mastigação o Músculo Pterigóideo Lateral (MPL), objeto do nosso estudo, se conecta diretamente com a ATM. É o mais curto dos músculos da mastigação, se dispõe horizontalmente e participa dos momentos de abertura, fechamento, lateralidade e protrusão da mandíbula. Uma pequena porção 
das fibras superiores do MPL se insere na cápsula articular e no disco articular da ATM, dando estabilidade ao conjunto e influenciando diretamente na posição do disco articular durante os movimentos da mandíbula.

O MPL está localizado profundamente ao ramo da mandíbula e ao músculo temporal, por este motivo torna-se difícil a sua avaliação (HONG, 1993).

Técnicas radiográficas básicas como a radiografia e a tomografia linear podem ser utilizadas para a avaliação óssea da ATM ou para o acompanhamento da DTM.

A Artrografia, a Tomografia Computadorizada (TC) e a Ressonância Magnética (RM) são usadas para a avaliação dos tecidos moles da articulação. A RM tem boa acurácia na observação tanto de tecidos duros quanto moles (KATZBERG et al., 1996).

A RM é o método de diagnóstico por imagem de escolha para a exploração da ATM, sua anatomia, deslocamento do disco articular, deformidades na cabeça da mandíbula e alterações envolvendo os tecidos moles ao seu redor, como os músculos da mastigação, mas poucos estudos de RM têm se dedicado às alterações no MPL, como hipertrofia, atrofia ou contratura muscular associados ao deslocamento do disco articular com e sem redução, alterações estas que estão relacionadas com os sintomas da DTM, principalmente dor e limitação na abertura da boca (YANG et al., 2002).

Taskaya-Yýlmaz et al. (2004) utilizaram a RM para avaliar a relação entre as desordens internas da ATM com o tipo de inserção do MPL e revelaram que quando as fibras superiores do MPL se inserem diretamente no disco e não só na cabeça da mandíbula, o disco articular pode se deslocar anteriormente com mais facilidade. 
As imagens de RM da ATM são obtidas por cortes nos planos sagitais e coronais oblíquos, que acompanham a inclinação natural da cabeça da mandíbula bilateralmente, com a finalidade de aumentar a avaliação das suas estruturas. Estes planos oblíquos são difíceis de serem obtidos nas radiografias e tomografias, mas fáceis de serem realizados com os recursos técnicos da RM (QUEMAR; RAVALEC; AKOKA, 1993).

Imagens nos planos sagitais oblíquos permitem observar com mais detalhes o MPL, o disco articular, a cabeça da mandíbula e a fossa da mandíbula em uma mesma imagem, possibilitando a observação completa de todo o conjunto e da relação destas estruturas entre si (MUSGRAVE et al., 1991; SCHELLHAS, 1989).

O reconhecimento das alterações musculares, especificamente as alterações nas cabeças superior e inferior do MPL, pode ajudar na realização do diagnóstico mais preciso da DTM, também na compreensão melhor dos sintomas clínicos, levando o profissional ao planejamento do tratamento mais eficiente.

O objetivo neste trabalho foi avaliar a relevância da RM no estudo do MPL em pacientes com e sem DTM. 


\section{REVISÃO DA LITERATURA}

\subsection{Anatomia do Músculo Pterigóideo Lateral}

O conhecimento sobre anatomia da Articulação Temporomandibular (ATM) é necessário para o diagnóstico e o tratamento das Desordens Temporomandibulares, principalmente porque os componentes da ATM estão diretamente envolvidos nas desordens intra-articulares (BERTILSSON; STROM, 1995).

A ATM é formada pelos ossos Temporal e Mandíbula. No osso Temporal encontra-se a fossa da mandíbula e o tubérculo articular e na mandíbula, encontrase a cabeça da mandíbula, principais estruturas ósseas desta articulação (SICHER; DUBRUL, 1991).

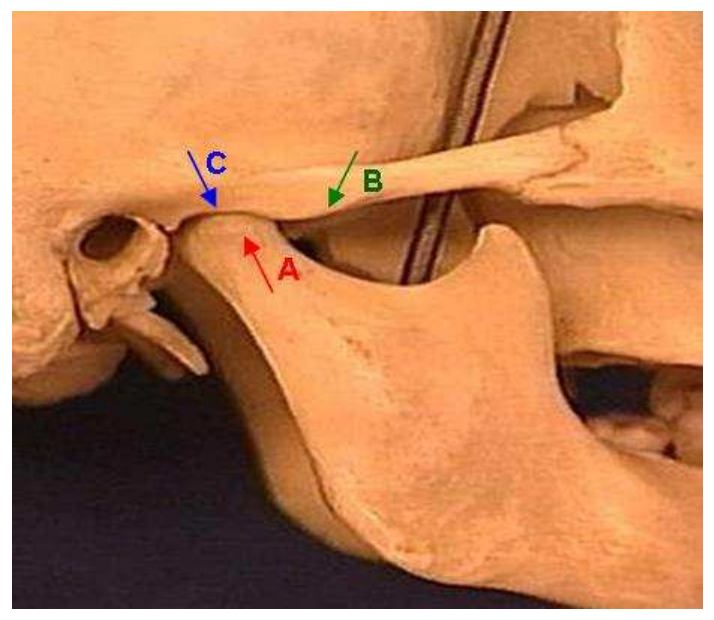

Figura 2.1 - Componentes Ósseos da ATM $(\mathrm{A} \rightarrow$ cabeça da mandíbula, $\mathrm{B} \rightarrow$ tubérculo articular, $\mathbf{C} \rightarrow$ fossa da mandíbula)

Fonte: www.auladeanatomia.com . 
O Músculo Pterigóideo Lateral (MPL) é o mais curto dos músculos da mastigação. É o único que se dispõe horizontalmente e que se relaciona diretamente com a ATM (MADEIRA, 2001).

Está situado profundamente ao ramo da mandíbula e ao músculo temporal (MCDEVITT, 1989).

O MPL divide-se em duas partes, cabeças ou bandas como são chamadas. A cabeça inferior, de forma triangular é maior e origina-se na face lateral da lamina lateral do processo pterigóide do osso esfenóide e a cabeça superior, menor, de forma quadrilátera, origina-se na superfície infratemporal da asa maior do osso esfenóide, abaixo da crista infratemporal (FIGUN; GARINO, 1994; MADEIRA, 2001; MCDEVITT, 1989).

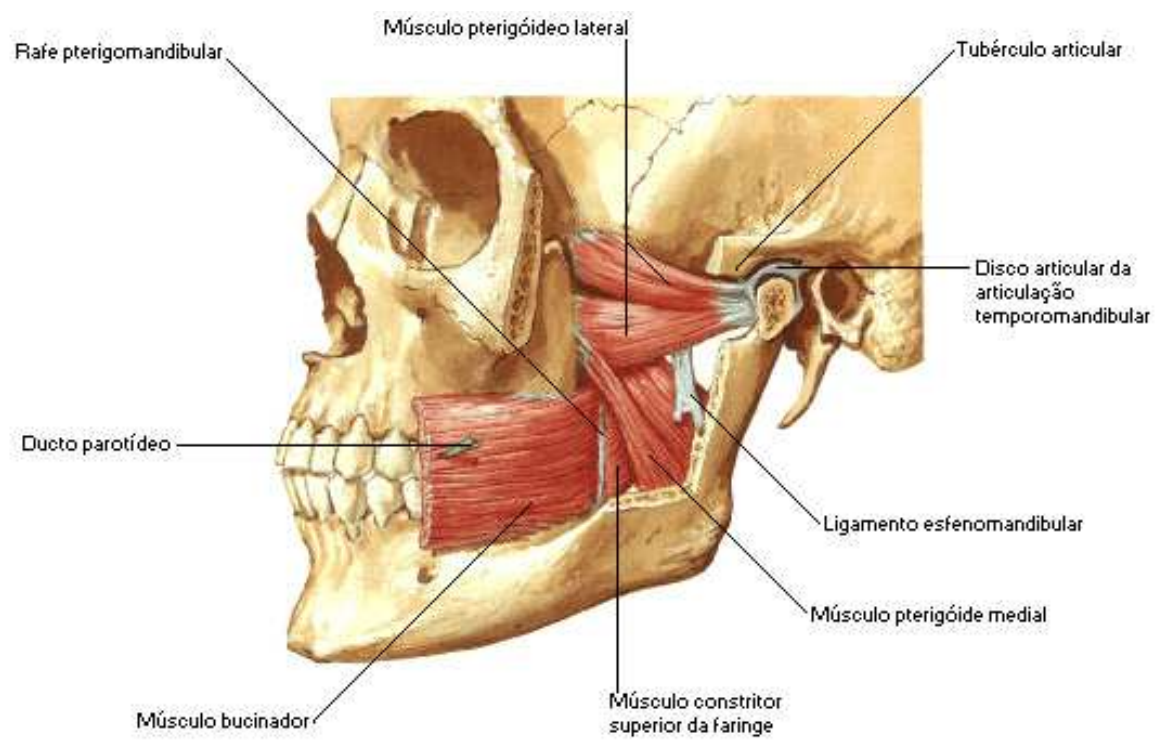

Figura 2.2 - Músculo Pterigóideo Lateral e estruturas circunvizinhas.

Fonte: www.auladeanatomia.com . 
À medida que as duas cabeças caminham para a sua inserção, suas fibras se fundem e se inserem na fóvea pterigóidea do colo da mandíbula. Uma pequena parte das fibras superiores insere-se na porção anterior da cápsula articular e no disco articular da ATM. A inserção no disco pode ocorrer em diferentes locais, levando à teoria de que o deslocamento do disco articular poderia estar relacionado a hiperatividade do MPL (MURRAY et al., 2004).

As fibras superiores têm a função especifica de dar estabilidade ao disco articular, evitando seu deslocamento posterior, guiando e estabilizando o conjunto cabeça da mandíbula/disco articular (WANG; YAN; YUAN, 2001).

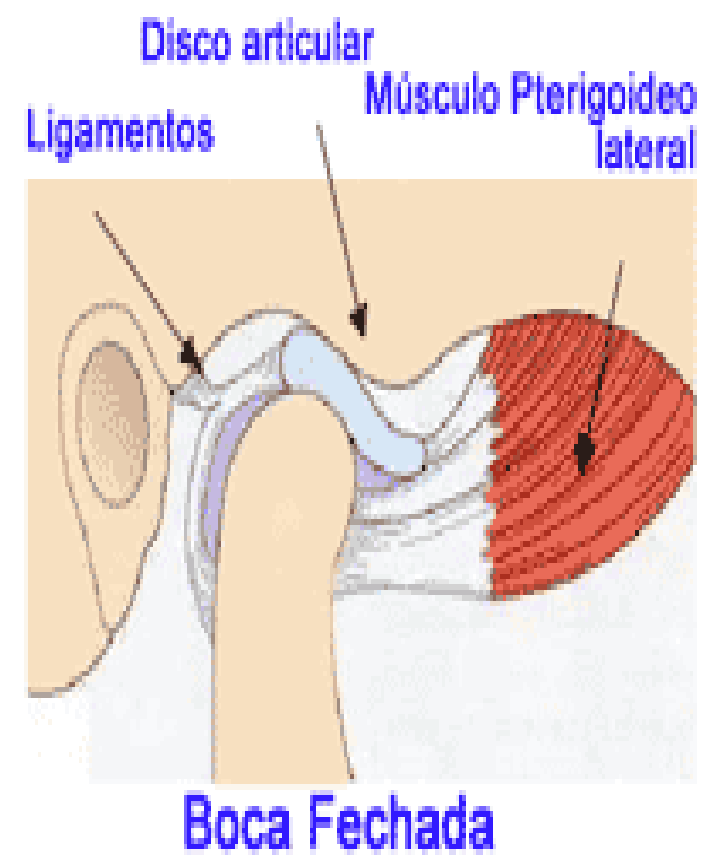

Figura 2.3 - Esquema mostrando a relação do disco articular com o Músculo Pterigóideo Lateral

Fonte: www.centrodedor.com.br/images/atm_01.jpg . 


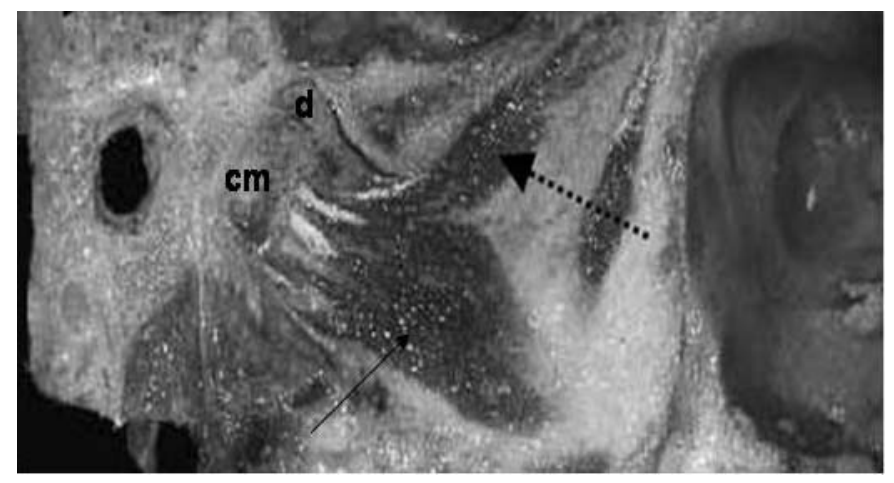

Figura 2.4 - Corte longitudinal da ATM, com destaque para a cabeça superior (seta tracejada) e cabeça inferior (seta continua).

Fonte: http://herkules.oulu.fi/isbn9514266439/isbn9514266439.pdf .

A contração simultânea bilateral dos MPL direito e esquerdo faz com que as cabeças da mandíbula deslizem para frente, no momento da protrusão (FIGUN; GARINO, 1994; MADEIRA, 2001).

Quando um dos MPL se contrai, unilateralmente, ele desloca o mento para o lado oposto, num movimento de lateralidade. Neste caso é a cabeça inferior do músculo em atividade unilateral durante o movimento contralateral (FIGUN; GARINO, 1994; MADEIRA, 2001).

A cabeça inferior do músculo está envolvida na geração e controle dos movimentos horizontais da mandíbula, como protrusão, retrusão e deglutição, mas também atua durante a abertura da mandíbula. Enquanto que a cabeça superior, além de estabilizar a ATM, atua durante o fechamento da mandíbula. As duas cabeças do músculo também atuam durante o ranger dos dentes. O MPL encontrase inativo durante o repouso da mandíbula (MURRAY et al., 2004).

Recentes estudos anatômicos sugerem que a cabeça inferior do MPL, não é palpável, por razões topográficas, como a sobreposição do Músculo Pterigóideo 
Medial nesta região, fazendo com que os achados clínicos na palpação do MPL, sejam menos reais do que se acreditava (STRATMANN et al., 2000; TURP; MINAGI, 2001).

A ATM é vascularizada pela circulação colateral de todos os vasos sanguíneos na área da articulação. A porção anterior da ATM obtém sua irrigação das artérias temporal profunda média e artéria massetérica, ramos da artéria maxilar e nas faces posterior e lateral da articulação, da artéria temporal profunda posterior, ramo da artéria temporal superficial. As faces posterior e média da ATM são irrigadas por outros ramos da artéria maxilar, as artérias timpânica anterior, auricular profunda e meníngea média (GRAY,1988).

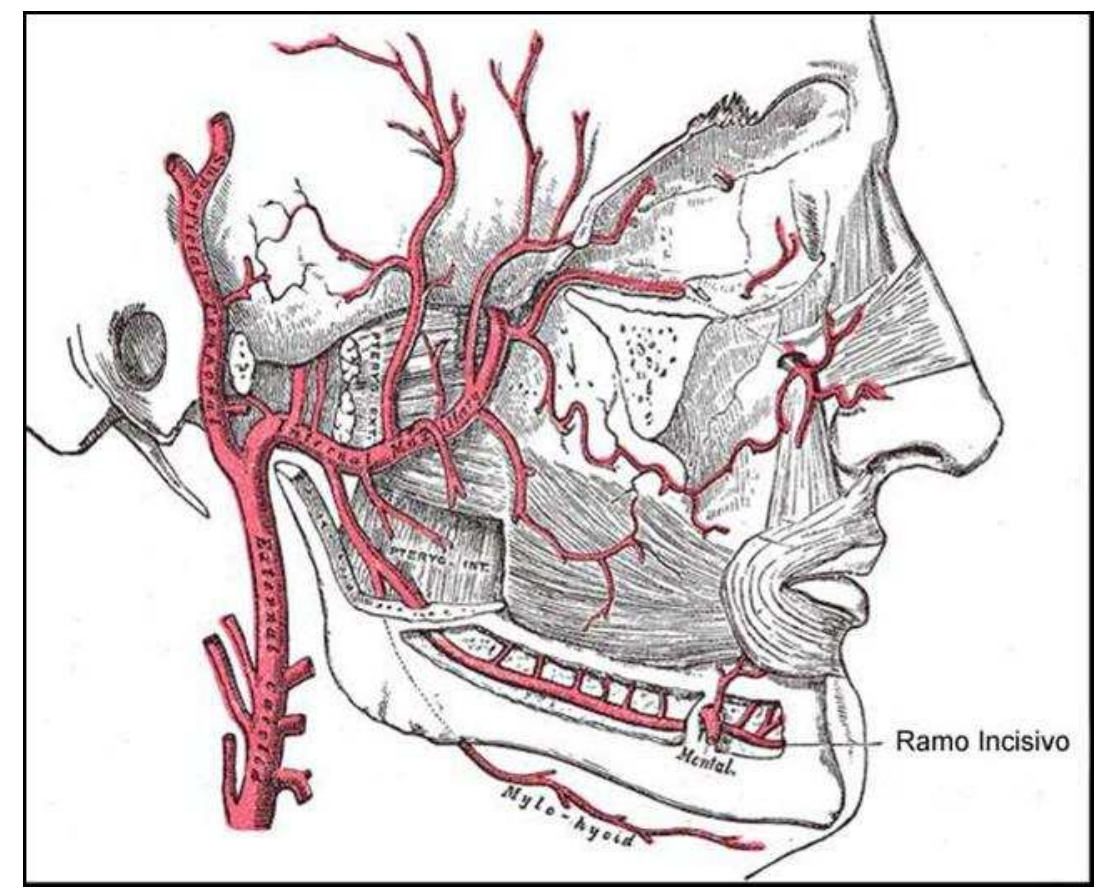

Figura 2.5 - Vascularização da ATM e do MPL Fonte: www.baterbly.com . 
As veias que drenam a ATM desembocando no plexo pterigóideo, na veia temporal superficial e na veia maxilar, correspondem às artérias que a irrigam (GRAY, 1988).

Estas mesmas áreas se encontram inervadas, inclusive a cápsula articular, o tecido subsinovial e a periferia do disco articular, porém, as áreas de pressão que são a porção central do disco articular, as superfícies articulares da cabeça da mandíbula e do osso temporal parecem não ter inervação (GRAY, 1988).

O nervo trigêmeo ( $V$ par craniano), por intermédio do nervo mandibular, emite ramos dos feixes anterior e posterior que seguem para a ATM. Estes ramos são do mesmo tronco nervoso que enerva os músculos mastigatórios, e que contém fibras motoras e sensitivas de propriocepção. A porção anterior da ATM está inervada pelo ramo anterior do nervo mandibular (ramo do trigêmeo) e ramos do nervo massetérico. A porção posterior da ATM está inervada pelos ramos do nervo aurículo-temporal da divisão posterior do ramo mandibular do nervo trigêmeo (SICHER; DUBRUL, 1991).

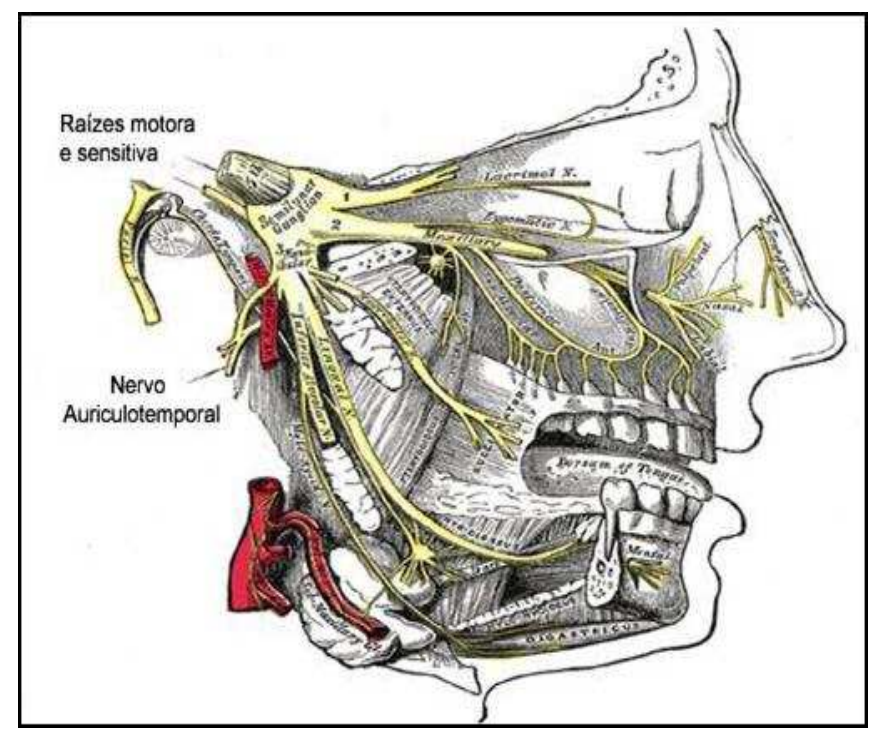

Figura 2.6 - Inervação da ATM Fonte: www.bartlebly.com . 


\subsection{Princípios Básicos da Ressonância Magnética}

A Ressonância Magnética (RM) é um método de diagnóstico por imagem utilizado amplamente nos centros de medicina avançados do mundo todo. Apresenta como principal vantagem não utilizar radiação ionizante. A imagem é formada com base em um potente campo magnético e ondas de radiofreqüência, que não causam dano ao paciente (WESTBROOK; KAUT, 2000).

O fenômeno da RM foi descoberto na década de 40, mas só nos anos 80 passou a ser utilizado como ferramenta diagnóstica na medicina (SCHERZINGER; HENDEE, 1985).

A intensidade do campo magnético utilizada em RM é da ordem de alguns milhares de Gauss (G), por isso as medidas do campo são expressas no Sistema Internacional de Unidade, em Tesla $\left(1 \mathrm{~T}=10000 \mathrm{G}=10^{4} \mathrm{G}\right)$ e podem variar de $0,2 \mathrm{~T}$ a 3,0 T, dependendo do aparelho, quando utilizados para exame diagnóstico de rotina (HELMS et al., 1984).

Os princípios de imagem por RM têm por base o movimento giratório de núcleos específicos presentes em tecidos biológicos, conhecidos como núcleos ativos em RM. Estes núcleos se caracterizam por sua tendência a alinhar seu eixo de rotação a um campo magnético externo aplicado. Isto ocorre quando o número de massa do átomo (soma dos prótons e nêutrons do núcleo atômico) é impar. O processo dessa interação átomo-campo magnético é o momento angular ou rotação (spin). Exemplos de núcleos ativos em RM são: Hidrogênio ( $n^{\circ}$ de massa 1 ), Carbono ( $n^{\circ}$ de massa 13), Nitrogênio ( $n^{\circ}$ de massa 15$)$ e Oxigênio ( $n^{\circ}$ de massa 17$)$ (WESTBROOK; KAUT, 2000). 
O núcleo de Hidrogênio $(H)$ é o núcleo ativo mais utilizado em RM clínica devido ao sinal magnético deste núcleo ser bem superior ao de outros núcleos e também ao fato do $\mathrm{H}$ ser o átomo mais abundante no corpo humano, principalmente devido à sua concentração na água. Na ausência de um campo magnético, os momentos magnéticos dos núcleos de H têm uma orientação ao acaso. Quando são submetidos a um forte campo magnético estático externo (Bo), seus momentos magnéticos se alinham a ele. Alguns dos núcleos de $\mathrm{H}$ alinham-se paralelamente ao campo magnético (mesma direção) e uma porção menor dos núcleos se alinha na direção antiparalela ao campo magnético (direção contrária). Núcleos de alta energia térmica alinham-se antiparalelamente ao campo magnético (spin-down) e núcleos de baixa energia térmica não têm energia suficiente para se oporem ao campo magnético na direção antiparalela, logo alinham-se paralelamente (spin-up) (WESTBROOK; KAUT, 2000).

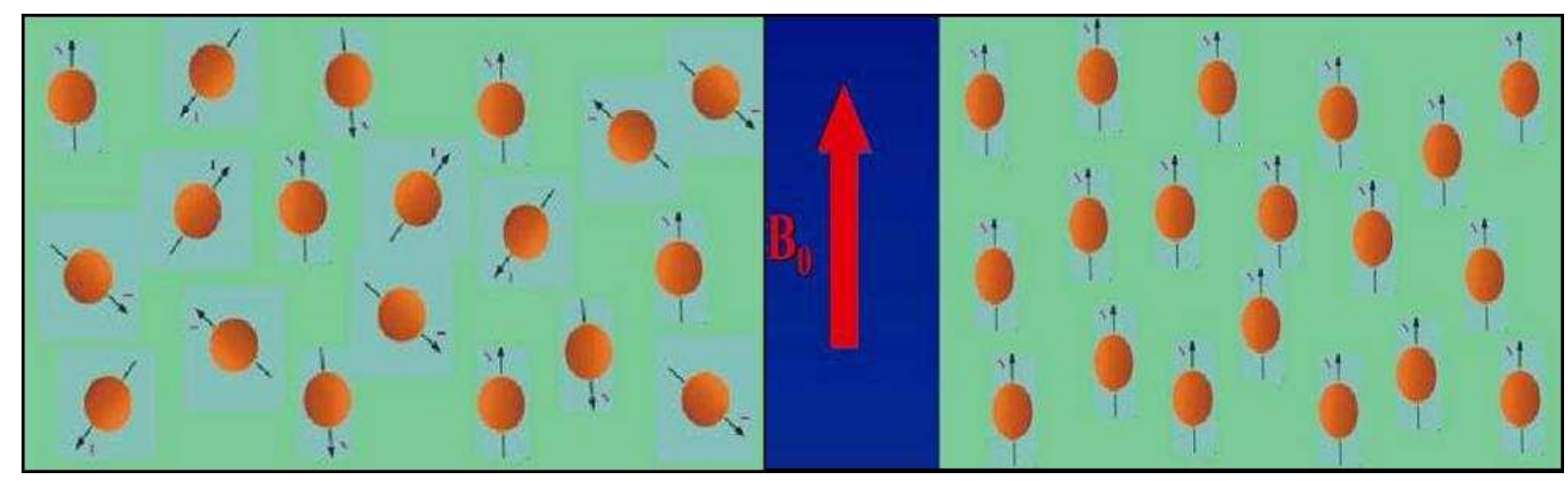

Figura 2.7 - Partículas giratórias com momento magnético orientado aleatoriamente, à esquerda e os momentos magnéticos alinhados na direção do campo (paralelos), em configuração de baixa energia, à direita.

Fonte: www.easymeasure.co.uk/principlesmri . 
À medida que aumenta a potência do campo magnético, diminui o número de núcleos com energia para opor-se a ele. Como há um número maior de momentos alinhados paralelamente, estes cancelam o número menor de momentos magnéticos alinhados antiparalelamente, produzindo seu momento magnético efetivo, denominado Vetor de Magnetização Efetiva (VME). A magnitude do VME é maior em campos magnéticos de alta potência, ocasionando um sinal melhor. Os momentos magnéticos de todos estes núcleos de hidrogênio também produzem uma rotação adicional ou oscilação quando submetidos ao Bo, denominada de trajetória de precessão e a velocidade com que o VME oscila denomina-se Freqüência de Precessão (WESTBROOK; KAUT, 2000).

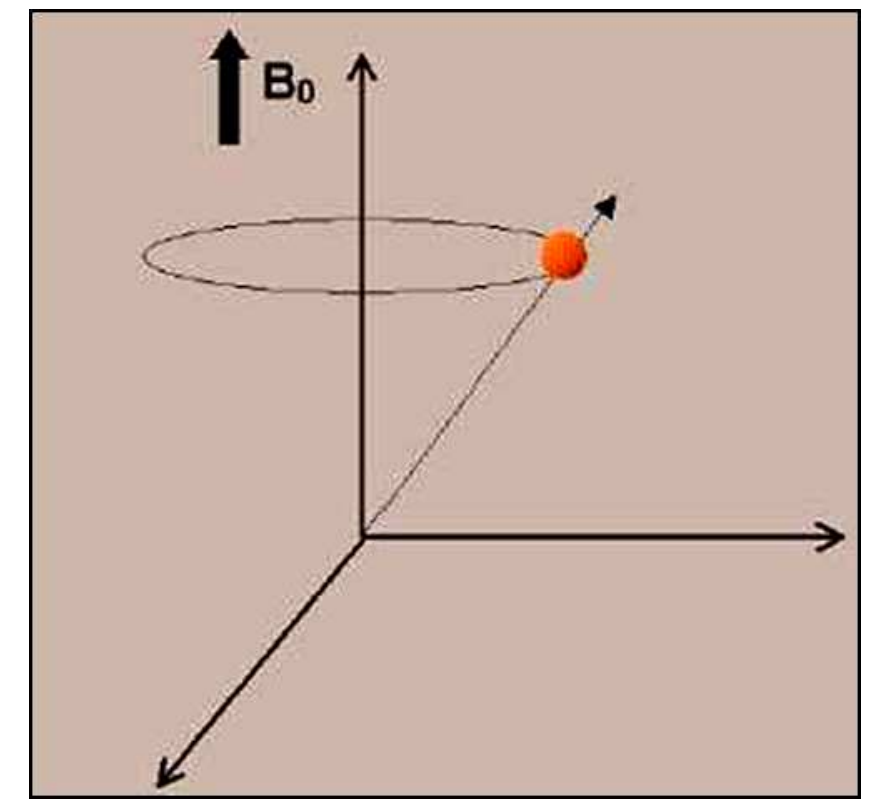

Figura 2.8 - Esquema demonstrando a Precessão do núcleo de Hidrogênio. Fonte: www.easymeasure.co.uk/principlesmri . 
A freqüência de precessão é denominada de Freqüência de Larmor, por ser determinada pela equação de Larmor. Cada elemento tem uma freqüência de Larmor de acordo com a potência do campo magnético. Por exemplo, a freqüência de Larmor do H, a um campo de 1,5 T é de $63,86 \mathrm{MHz}$; a 1,0 T é de 42,57 MHz e a 0,5 T é de 21,28 MHz. O núcleo ganha energia e entra em ressonância caso a energia aplicada a ele seja de uma freqüência exatamente igual a sua freqüência de Larmor. Esta energia corresponde à faixa de radiofreqüência (RF). A aplicação de um pulso de RF que faz com que ocorra a ressonância é denominada Excitação. Esta absorção de energia causa aumento no número de população de núcleos de $\mathrm{H}$ em rotação negativa (spin-down), pois alguns núcleos Spin-up ganham energia pela ressonância e tornam-se de alta energia (Spin-down) (HELMS et al., 1984).

Além da energia produzida pelo campo magnético temos agora também a energia proporcionada pelo pulso de RF. Ao aumentar a potência do campo é necessário mais energia (RF mais altas) para produzir ressonância. As leis de indução de Faraday afirmam que se colocar uma bobina receptora ou qualquer fio condutor na área de um campo magnético em movimento, com VME em precessão no plano transverso, é induzida uma voltagem nesta bobina receptora. Esta voltagem constitui o sinal de RM. Ao desligar o pulso de RF, o VME passa novamente a sofrer influência de Bo e a realinhar-se a ele. Para isso o VME tem que perder a energia que the foi dada pelo pulso de RF, este fenômeno é denominado Relaxação ou Relaxamento (WESTBROOK; KAUT, 2000).

A relaxação leva à recuperação da magnetização no plano longitudinal (recuperação T1) e ao declínio da magnetização no plano transverso (declínio T2). Recuperação T1 significa núcleos liberando sua energia no ambiente ou retículo circundante (relaxamento do retículo de Spin) para recuperarem sua magnetização 
longitudinal. Declínio T2 significa troca de energia entre núcleos vizinhos para perda da magnetização transversa. É a interação dos campos magnéticos de cada núcleo com seu vizinho (relaxação Spin-Spin) (WESTBROOK; KAUT, 2000).

Uma seqüência de pulsos de RF consiste em vários componentes: O Tempo de Repetição (TR) é o tempo que vai da aplicação de um pulso de RF à aplicação do pulso de RF seguinte, em milissegundos (ms). O TR determina o grau de relaxação T1. O Tempo de Eco (TE) é o tempo necessário que vai da aplicação do pulso RF ao máximo de sinal induzido no fio receptor, em ms. O TE determina o grau de declínio da magnetização transversa, controla então o grau de relaxação T2 (WESTBROOK; KAUT, 2000).

Uma das principais vantagens da RM em comparação a outras modalidades de aquisição de imagem é a excelente discriminação dos tecidos moles proporcionada por suas imagens. Um tecido tem sinal intenso caso tenha um grande componente transverso de magnetização. A amplitude do sinal recebido pela bobina é pequena quando há um pequeno componente de magnetização transversa, ocasionando uma área escura na imagem. Os dois extremos de contraste na imagem de RM são tecido adiposo e água. O tecido adiposo tem tempos T1 e T2 curtos e a água tem tempos T1 e T2 longos. As imagens ponderadas em T1 se caracterizam por tecido adiposo brilhante e água escura. As imagens ponderadas em T2 se caracterizam por água brilhante e tecido adiposo escuro. O contraste por densidade de prótons designa as diferenças na intensidade do sinal entre os tecidos, decorrentes do seu número relativo de prótons por unidade de volume. Tecidos com uma elevada densidade de prótons (tecido cerebral) têm um grande componente transverso de magnetização (sinal intenso) e os tecidos com baixa densidade de 
prótons (osso cortical) têm um pequeno componente transverso de magnetização (sinal fraco) (WESTBROOK; KAUT, 2000).

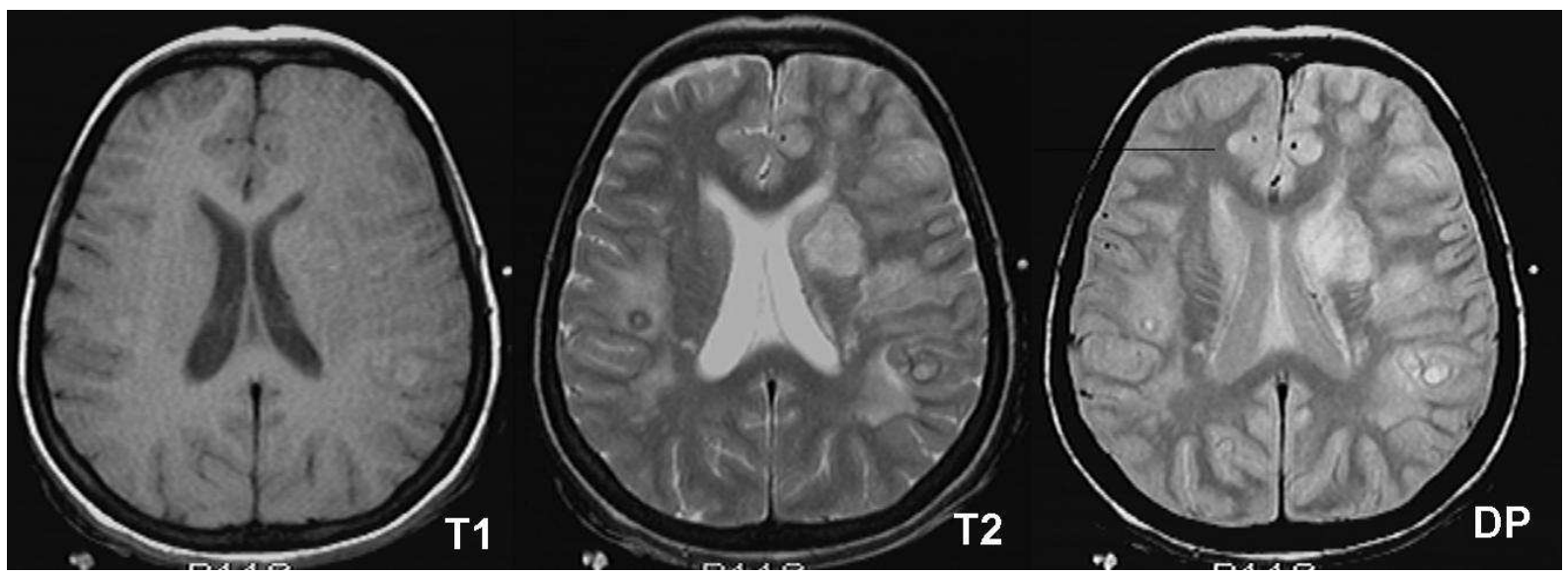

Figura 2.9 - Exemplos de imagens de RM ponderadas em T1, T2 e DP Fonte: www.cis.rit.edu/htbooks/mri .

Gradientes são alterações do campo magnético principal (Bo), geradas por bobinas localizadas no corpo do magneto. A passagem de corrente por uma bobina gradiente induz a um campo magnético gradiente em torno dele, que pode ser acrescentado ou subtraído da potência do Bo. Os Gradientes executam tarefas importantes durante uma seqüência de pulsos: seleção de cortes, localização espacial e espessura dos cortes (WESTBROOK; KAUT, 2000).

As imagens de volume têm muitas aplicações em potencial, mas são mais usadas para a aquisição de imagens das articulações, onde a anatomia muitas vezes é confusa e não está estritamente no plano. Os volumes podem ser muito úteis para o acompanhamento de ligamentos e outras estruturas que cruzam o plano da imagem, assim como também devem ser usados na busca de lesões muito 
pequenas. A espessura pode ser reduzida para menos de $1 \mathrm{~mm}$, podendo obter-se uma resolução muito boa (WESTBROOK; KAUT, 2000).

A seqüência Spin eco utiliza um pulso de excitação de $90^{\circ}$, seguido de um ou mais pulsos de restituição de fase de $180^{\circ}$ para gerar eco. Podem ser usadas em quase todos os exames. Nas imagens ponderadas em T1 servem para demonstrar a anatomia e nas ponderadas em T2, as alterações patológicas. Gradiente eco usa ângulos de inclinação variáveis, assim o tempo de exame pode ser reduzido. Usa-se um gradiente e não um pulso de RF para restituição de fase. Podem ser usadas para aquisição de imagens ponderadas em T1, T2 e Densidade de Prótons e possibilitam uma diminuição do tempo do exame (WESTBROOK; KAUT, 2000).

Todas as imagens de RM têm artefatos em algum grau. É necessário que as causas desses artefatos sejam conhecidas e estes possam ser compensados na medida do possível, apesar de que alguns artefatos são irreversíveis e só podem ser reduzidos, já outros podem ser eliminados totalmente. Um artefato conhecido como fantasma é produzido por qualquer estrutura que se mova durante a aquisição dos dados, como por exemplo, a parede torácica durante a respiração, o movimento pulsátil dos vasos, a deglutição e o movimento ocular. Os núcleos em fluxo, como os núcleos do sangue, apresentam características de contraste diferentes dos núcleos estacionários. O movimento dos núcleos em fluxo leva a artefatos designados como artefatos de movimento de fluxo (ou fantasmas de fase). Todo movimento do paciente causa artefatos, pode ser involuntário ou voluntário e degrada a imagem. Em casos extremos pode ser necessária a sedação do paciente (WESTBROOK; KAUT, 2000).

As quatro principais considerações que determinam a qualidade da imagem são: Razão Sinal-Ruído (RSR), Razão Contraste-Ruído (RCR), Resolução Espacial 
e Tempo de Exame. O ruído é gerado pela presença do paciente no magneto e pelo ruído elétrico de fundo do sistema. O sinal aumenta ou diminui em relação ao ruído. A resolução espacial é controlada pelo tamanho do voxel, voxels pequenos levam a uma boa resolução espacial, pois podem diferenciar as estruturas pequenas. $O$ tempo de exame é o tempo necessário para completar-se a aquisição de dados. Os tempos de exame são importantes para a manutenção da qualidade das imagens, pois tempos de exame longos dão mais chance ao paciente de se mover. Para se obter tempo de exame mais curto, deve se usar o mais curto TR possível e a matriz mais grosseira possível (WESTBROOK; KAUT, 2000).

As bobinas transmissoras de RF usadas são geralmente cilíndricas e dividemse em bobina corporal, localizada no corpo do próprio magneto e bobina de cabeça, que fica acoplada a uma bobina receptora. As bobinas receptoras têm que estar posicionadas corretamente para detectar adequadamente o sinal de RM. A bobina de volume (ou gaiola) tanto pode transmitir RF como receber o sinal de RM e é denominada Transceptora. Ela pode ser usada para aquisição de imagens da cabeça, das extremidades ou de todo o corpo (QUEMAR et al.,1998).

As bobinas de superfície são usadas para melhorar a RSR, isto ocorre porque esta bobina está mais próxima da anatomia emissora do sinal e são recebidos ruídos apenas das vizinhanças da bobina e não de todo o corpo. Geralmente estas bobinas são pequenas, de forma especial e só recebem o sinal do volume sensível da bobina, cuja área estende-se à circunferência da bobina e com profundidade no paciente igual ao raio da mesma. As bobinas de sinergia (phased-array) são largamente usadas porque consistem em bobinas e receptores múltiplos cujos sinais individuais são combinados para criar-se uma imagem com melhor RSR e maior 
cobertura. Podem ser da coluna, pélvica, da mama e da ATM (WESTBROOK; KAUT, 2000).

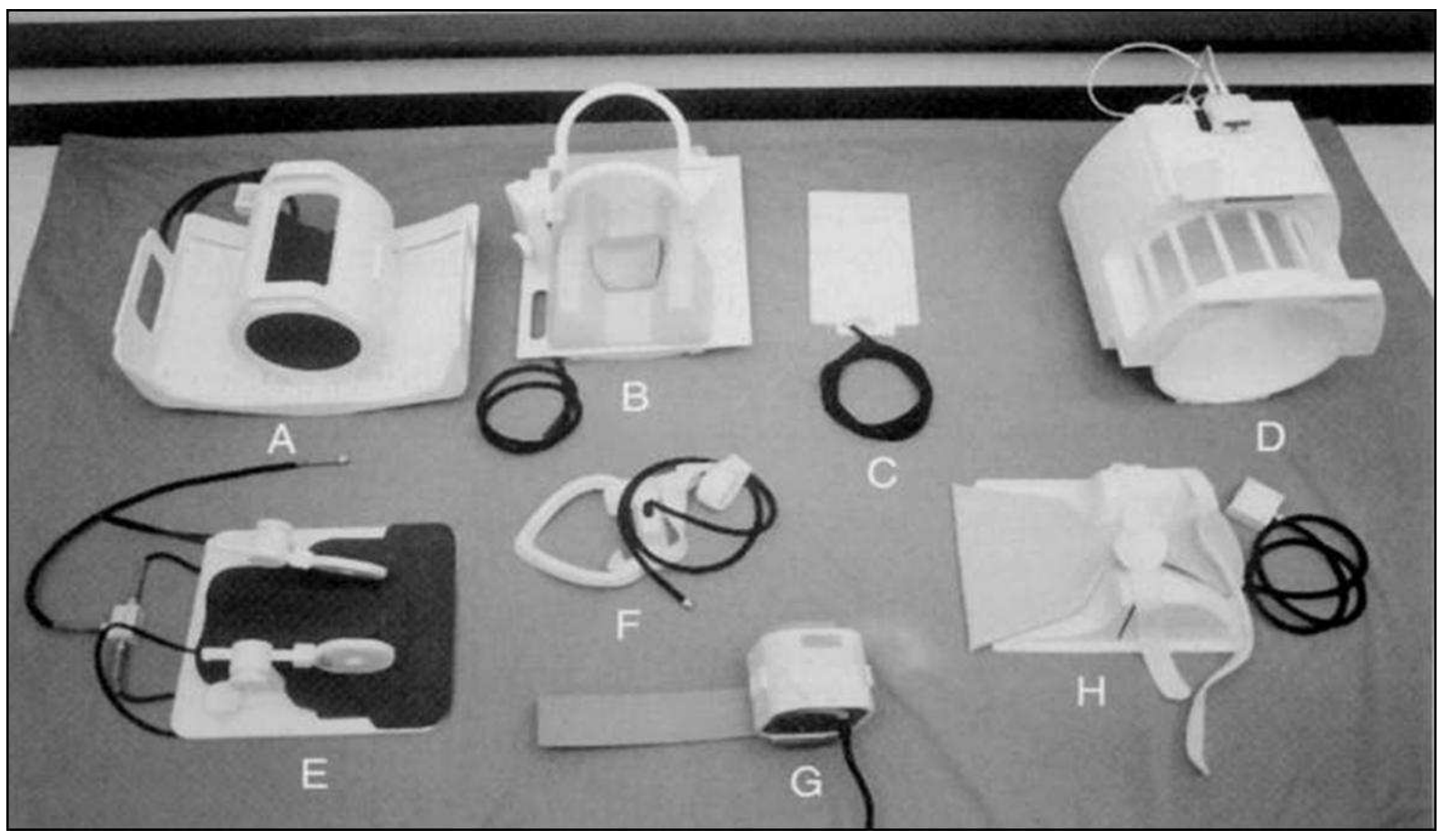

Figura 2.10 - Diferentes tipos de bobinas utilizadas em exames de RM: A- Bobina para membro, BBobina de volume para pescoço, C- Bobina de superfície plana (bobina de lâmina licenciada), D- Bobina para cabeça, E- Bobina de superfície (ATM bilateral), F- Bobina para ombro, G- Bobina para punho, $\mathbf{H}$ - Bobina para coluna.

Fonte: cfhr.epm.br/images/jpg/aulaRM/bobinas.jpg .

O sinal de RF recebido pelo fio é amplificado e passa então a um processador. Os dados são então transmitidos a outro processador de imagens, para que cada pixel possa ter uma cor em escala de cinza na imagem. A aquisição dos dados e observação das imagens se dá por um console do operador, fora da sala de exame, que também proporciona acesso a toda uma gama de técnicas de manipulação de imagens, como a análise de várias imagens ao mesmo tempo, a 
avaliação de imagens num circuito cine e a reformatação de imagens de volume 3D (WESTBROOK; KAUT, 2000).

As imagens de RM são armazenadas a partir do console de imagens num filme revestido de uma emulsão, semelhante ao usado na Tomografia Computadorizada. $\mathrm{O}$ armazenamento dos dados das imagens pode ser por meio de arquivo em fita magnética, fita cassete, CD ou disco óptico. As imagens são armazenadas de tal modo que seja possível recuperar os casos para manipulação e aquisição de imagens adicionais no futuro para comparação com outros exames do mesmo paciente (WESTBROOK; KAUT, 2000).

Pacientes com marca-passos cardíacos, clips ferromagnéticos, neuroestimuladores, implantes ferromagnéticos são contra-indicados para o exame de RM devido à possibilidade desses elementos se moverem de sua posição normal quando submetidos ao campo magnético. Também pode ocorrer o fenômeno da indução de correntes, particularmente no caso dos marca-passos, que possuem longos cabos e funcionam como eletrodos. Fortes correntes de Faraday podem ocorrer nestes eletrodos a cada pulso de RF que funcionam como cargas elétricas aplicadas diretamente ao coração, podendo provocar arritmias ou mesmo parada cardíaca (SCHELLOCK, 2002).

Clips cirúrgicos de qualquer natureza que não sejam ferromagnéticos, DIUs (de cobre), próteses de aço, implantes de titanium, amálgamas dentários, aparelhos ortodônticos fixos e válvulas cardíacas não contra-indicam exames de RM, pois não têm componente ferroso em suas estruturas, embora alguns artefatos localizados possam aparecer e prejudicar a imagem (SCHELLOCK, 2002).

Embora até agora não se tenha detectado nenhum efeito deletério sobre as grávidas e os fetos, recomenda-se que realizem o exame apenas após o terceiro 
mês de gravidez. Apenas uma pequena parcela dos pacientes apresenta claustrofobia. Atualmente já existem aparelhos de RM abertos que tornam o exame mais confortável (SCHELLOCK, 2002).

Deve-se tomar atenção para que nenhuma pessoa entre na sala do exame com ferramentas ferromagnéticas, aspiradores de pó, cilindros de oxigênio que não sejam de alumínio, cartões magnéticos (que se desmagnetizam), relógios, celulares e chaves (SCHELLOCK, 2002).

\subsubsection{Ressonância Magnética da ATM}

As imagens da ATM podem ser obtidas em aparelhos de RM com magnetos variando de 0,2 a 3,0 T, mas sabe-se que aparelhos de alto campo (1,0 T ou 1,5 T) permitem obter imagens de alta qualidade, com tempos de exame curtos, aquisição de cortes finos, menor incidência de artefatos de movimento, melhor RSR e resolução espacial superior (WESTBROOK; KAUT, 2000).

Podem ser utilizadas bobinas de cabeça (head coil), bobinas de superfície e mais recentemente microbobinas. As bobinas de cabeça permitem o exame simultâneo das duas articulações (direita e esquerda), com ótima resolução espacial e favorável RSR. As bobinas de superfície, que medem $12 \mathrm{~cm}$ de diâmetro, são colocadas mais próximas da região de interesse, emitindo sinal mais eficiente e consequentemente imagens mais detalhadas. As bobinas de superfície duplas permitem a aquisição simultânea das duas articulações, com pequena duração do tempo de exame e estudos comparativos dos lados direito e esquerdo fidedignos. As 
microbobinas, novidade no mercado, também são bobinas de superfície, com diâmetro de $47 \mathrm{~mm}$, que prometem melhor qualidade das imagens, mas com o inconveniente de só se obterem as imagens de uma articulação de cada vez, aumentando o tempo total de duração do exame (IWAMA et al., 2006; WESTBROOK; KAUT, 2000;).

As sequências de imagens ponderadas em T1 são utilizadas rotineiramente por oferecerem excelente detalhe anatômico. As imagens ponderadas por densidade de prótons apresentam boa resolução espacial da imagem do disco articular. Já as imagens ponderadas em T2 oferecem pobre detalhe anatômico e são indicadas para se avaliar efusão articular e edema medular (KATZBERG; WESTESSON, 1993).

Inicialmente, realizam-se imagens no plano axial para a localização das cabeças da mandíbula e sobre elas delimita-se um box, denominado FOV (field of view), para programação dos cortes sagitais a serem realizados. Em seguida os cortes coronais, como complemento (TASAKI; WESTESSON, 1993).

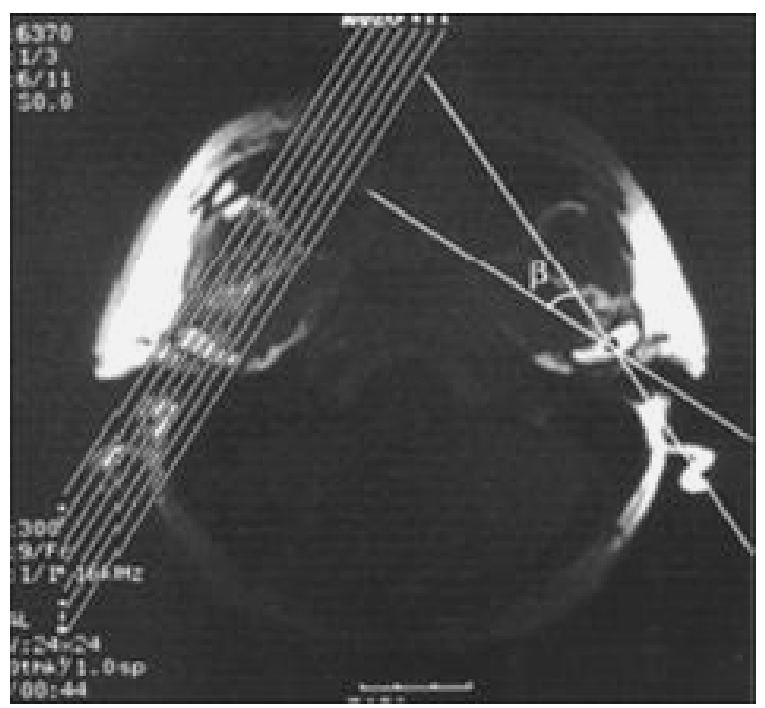

Figura 2.11 - Imagem de RM no plano Axial localizadora da ATM. 
As imagens de RM da ATM são obtidas em cortes nos planos sagitais e coronais oblíquos, que acompanham a inclinação natural da cabeça da mandíbula de cada indivíduo, bilateralmente. Este recurso permite um melhor delineamento das estruturas como a cabeça da mandíbula e o disco articular (MUSGRAVE et al., 1991).

Normalmente, utilizam-se também seqüências Spin eco (SE) e Gradiente eco (GE), ponderadas em T1. As seqüências SE são melhores para determinar a forma e o tamanho do disco e a seqüências GE, são superiores para a identificação dos músculos e da cortical óssea (TASAKI; WESTESSON, 1993).

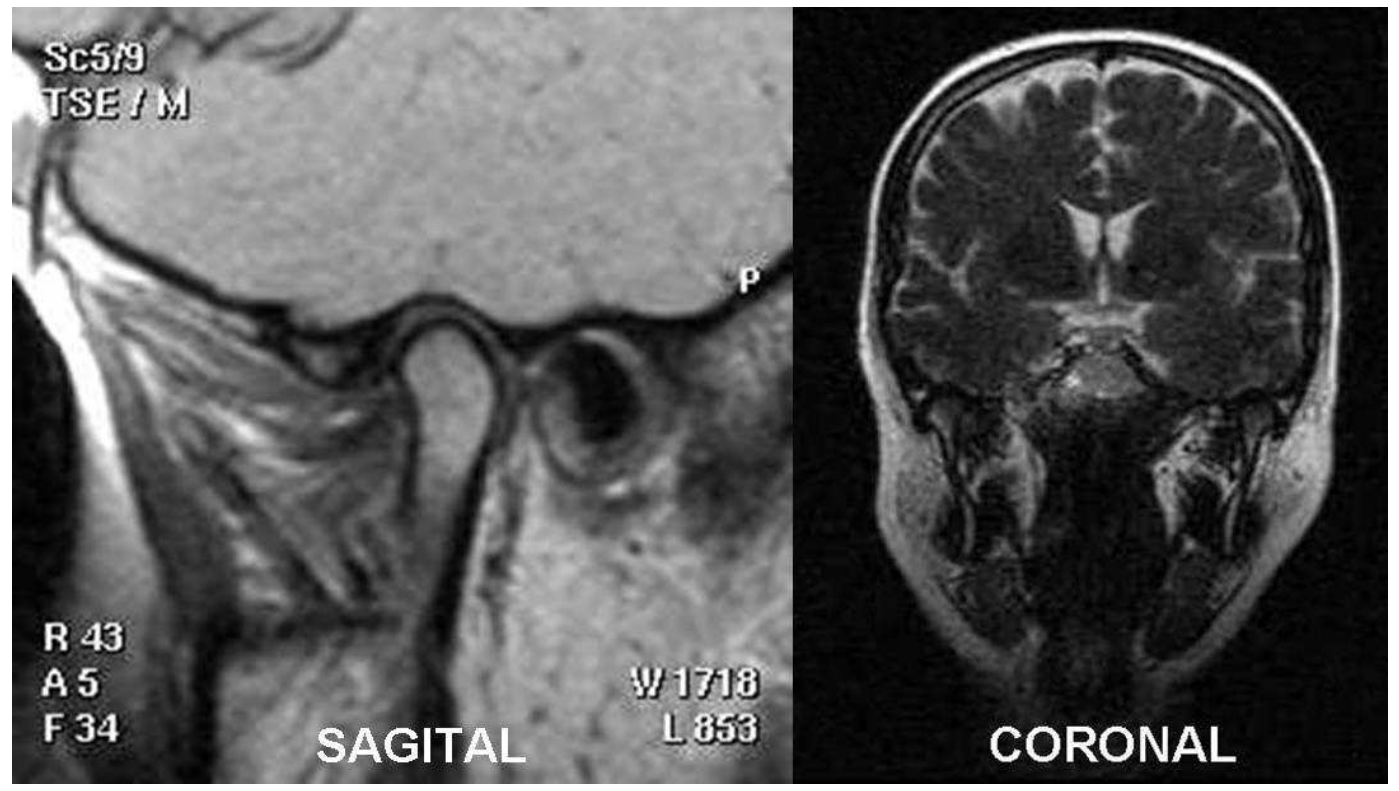

Figura 2.12 - Cortes Sagital e Coronal da ATM na RM.

Imagens coronais revelam o deslocamento lateral e medial do disco articular que não são evidentes nos cortes sagitais, assim como os limites da cápsula articular e o ligamento temporomandibular que dá sustentação lateral à articulação. 
O disco articular nas imagens ponderadas em T1 aparece em hiposinal. Em condições normais ele apresenta forma de "gravata borboleta". Divide-se em banda anterior, intermediária e posterior. A banda intermediária é muito delgada (1 a 2mm) e as bandas anterior e posterior mais espessas (4 a $5 \mathrm{~mm}$ ), sendo que a posterior é ligeiramente mais espessa que a anterior. Em situação de normalidade, o disco articular localiza-se entre o ponto mais superior da cabeça da mandíbula e o ponto mais inferior do tubérculo articular, em posição de boca fechada. Na abertura máxima da boca, o disco articular e a cabeça da mandíbula posicionam-se inferiormente ao tubérculo articular (HEFFEZ; MAFEE; ROSENBERG, 1995).

O tecido retrodiscal (zona bilaminar) é uma estrutura fina, possuindo intensidade de sinal homogênea intermediária, na posição de boca fechada. Já com a boca aberta, este tecido expande-se na direção anterior, inferiormente a cabeça da mandíbula e pode apresentar intensidade de sinal heterogênea, devido ao fluxo de sangue para dentro desta região durante a abertura da boca, em imagens ponderadas em T1 (KATZBERG: WESTESSON, 1993).

O osso cortical da cabeça da mandíbula, da cavidade da mandíbula e do tubérculo articular apresenta hiposinal. O trabeculado ósseo aparece com intensidade de sinal intermediária (acinzentado) e a medula óssea, rica em material orgânico, hipersinal (brilhante), nas imagens ponderadas em T1 (HEFFEZ; MAFEE; ROSENBERG, 1995).

A fibrocartilagem que recobre o osso cortical aparece com sinal de intensidade intermediária, separando o sinal de baixa intensidade do córtex do osso temporal, daquele do disco articular (também hiposinal). Já a fibrocartilagem que recobre a cabeça da mandíbula é menos perceptível. Com o aumento na qualidade das imagens de RM, a cápsula articular freqüentemente é bem observada nas 
imagens coronais. Aparece como uma linha escura, plana e fina, localizada lateralmente à cabeça da mandíbula (KATZBERG: WESTESSON, 1993).

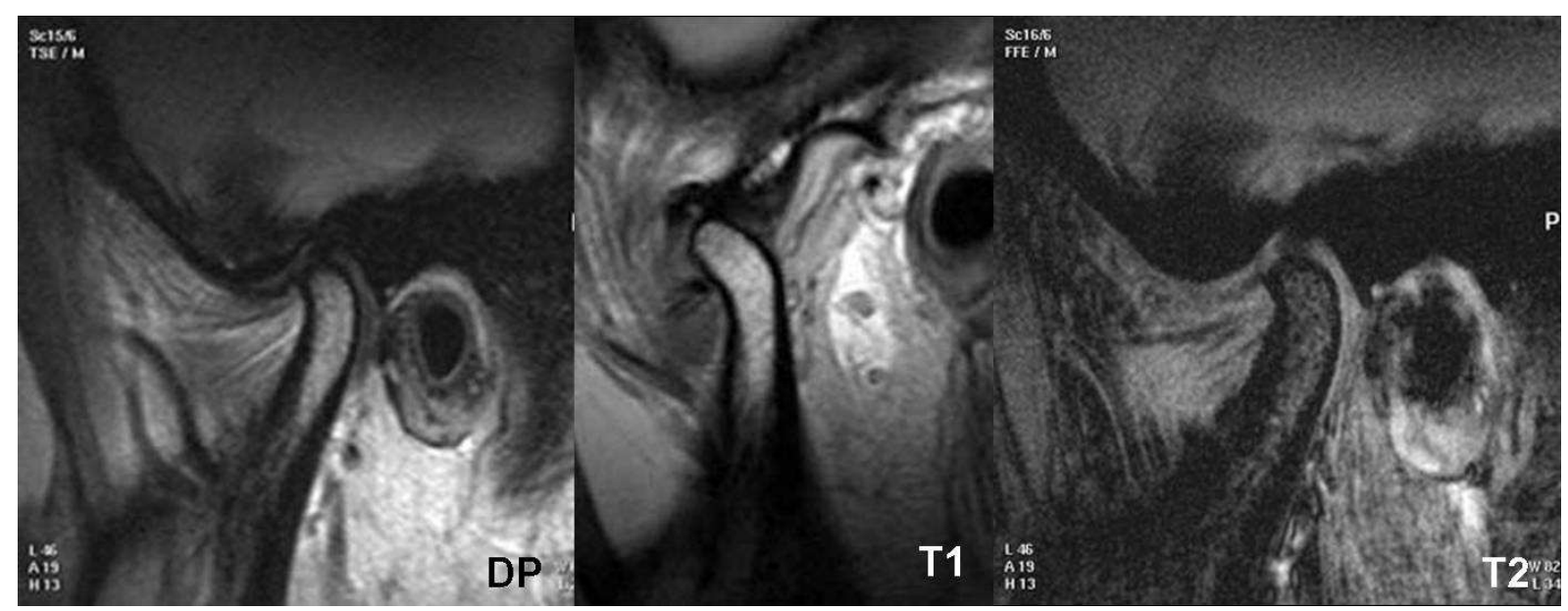

Figura 2.13 - Cortes Sagitais, imagens ponderadas em DP, T1 e T2. Visão geral da ATM e do MPL.. DP e T2 - boca fechada e T1 - boca aberta.

A inserção do feixe superior do MPL é frequentemente demonstrada nas imagens sagitais, como uma estrutura com hiposinal que se insere na porção anteromedial do disco, da cápsula e da cabeça da mandíbula. Os dois feixes do MPL aparecem normalmente separados por uma área adiposa, triangular, de sinal intenso (KATZBERG; WESTESSON, 1993).

A RM dinâmica da ATM (ou Movie) tem sido utilizada para se avaliar seus aspectos funcionais. As imagens são reconstruídas a partir de uma série de aquisições estáticas com aberturas de boca variáveis, desde fechada até abertura máxima, passando por repouso e abertura intermediária. Essas imagens constituemse, na realidade, em um modo Pseudo-cine e são importantes na observação da relação entre as estruturas durante a abertura da boca, como a posição da cabeça 
da mandíbula em relação ao disco articular e destas com o tubérculo articular (EBERHARD; BANTELON; STEGER, 2000).

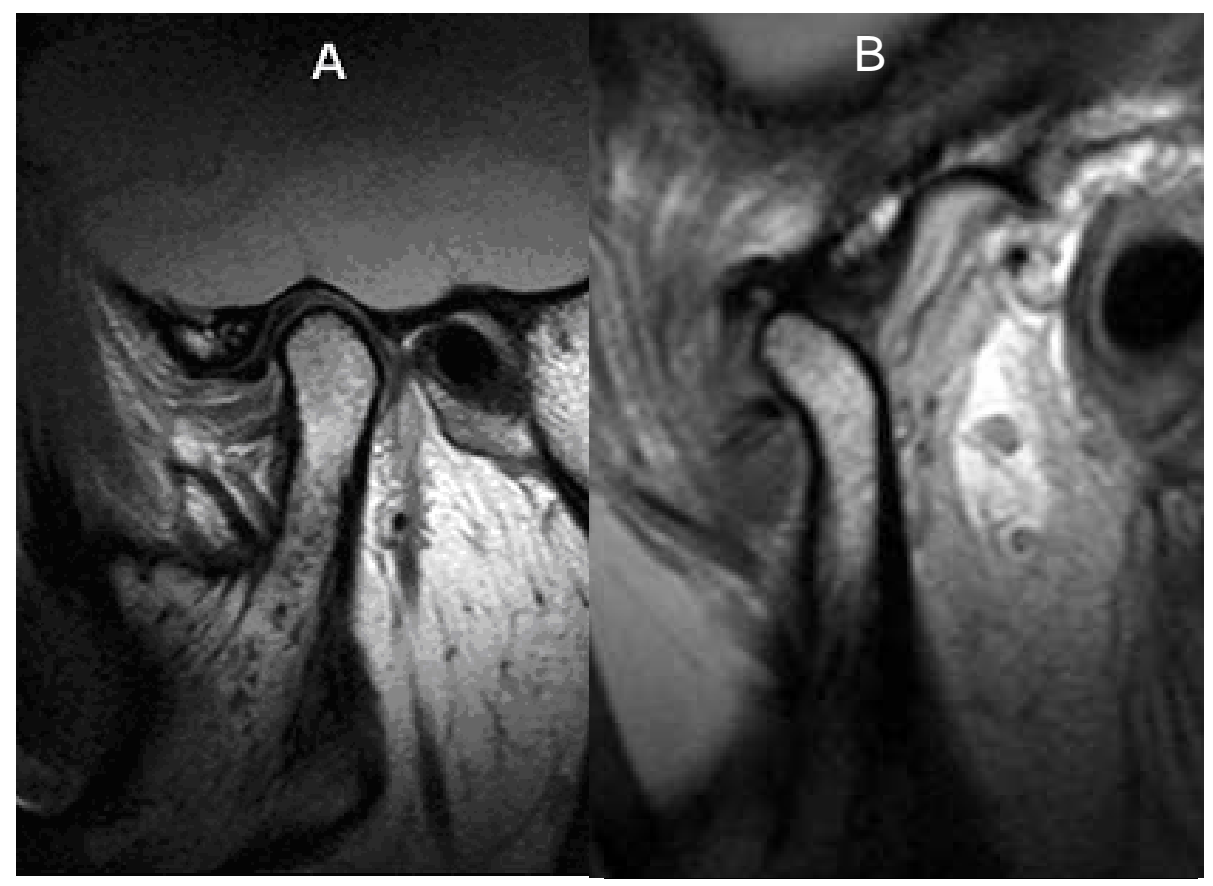

Figura 2.14 - ATM normal, boca fechada (A) e boca aberta (B).

\subsection{Aplicação da Ressonância Magnética na avaliação do Músculo Pterigóideo Lateral}

Os primeiros trabalhos relatando a utilização da RM no estudo da ATM surgiram no final da década de 1980, por Helms et al. (1984); Katzberg et al. (1986) e Schellhas et al. (1986).

Schellhas (1989) relatou que a RM é um método de diagnóstico por imagem eficaz para se detectar alterações nos músculos da mastigação. 
Greene e Laskin (1988) e Solberg (1986) concordaram que dor muscular é um dos principais aspectos da DTM.

De acordo com Westesson (1993), a RM pode ser de grande ajuda na avaliação das alterações da estrutura articular e dos músculos mastigatórios, na DTM.

Quemar, Ravalec e Akoka (1993) estudaram a morfologia do MPL e da cabeça da mandíbula por meio de imagens de RM, em pessoas que não apresentavam DTM. A definição das imagens permitiu observar tanto as variações anatômicas da cabeça da mandíbula, como também a união músculo-articular, principalmente em relação à cabeça superior do MPL.

Ainda no mesmo ano, Hong (1993) ressaltou a importância da participação do MPL na abertura e fechamento da boca e como é fácil este músculo ser lesionado no caso de traumas agudos ou crônicos, principais causas da DTM. Ao mesmo tempo em que avaliou a dificuldade em se estudar o MPL, devido à sua localização profunda. Utilizando a RM em pacientes de boca aberta e fechada, concluiu que a cabeça superior deste músculo, insere-se principalmente na fossa pterigóide da cabeça da mandíbula e que a direção das fibras musculares não é totalmente horizontal, mas com alguma inclinação e que as duas cabeças do músculo encontram-se relaxadas na posição de boca fechada e estão contraídas na posição de abertura máxima da mandíbula, sincronicamente.

Um estudo detalhado da relação entre os músculos da mastigação, a cápsula e o disco articular, realizado por Schmolke (1994), demonstrou que o MPL influencia diretamente na posição do disco durante os movimentos mandibulares.

Gan, Ma e Wang (1994) estudaram a disfunção da ATM, pela RM, em pacientes com boca aberta e fechada; e relataram que a porção superior do MPL 
mostra-se mais encurtada e estreitada na posição de boca aberta do que na de boca fechada, o que sugere que este músculo está em estado de contração na abertura da boca. No caso de pacientes com DTM, edema e expansão do MPL foram observados pela RM, em $80 \%$ dos casos.

Liu et al. (2000) observaram que poucos trabalhos discutiram a associação das alterações morfológicas dos componentes da ATM e mais especificamente do MPL, com a sintomatologia clínica da DTM. Por meio da RM puderam verificar que as disfunções internas da ATM estão mais intimamente relacionadas com a relação espacial dos componentes da ATM, do que com a morfologia individual destes componentes, como as estruturas ósseas, o disco articular e o MPL.

Com relação à sintomatologia dos pacientes com DTM, Manfredi, Silva e Vendite (2001) relataram que o sinal mais freqüente dos distúrbios extra-capsulares ou miogênicos é a dor facial difusa. Historicamente, o trabalho muscular excessivo foi considerado como causador de fadiga, que então levava à dor. Os sinais produzidos, quando o músculo masseter é o maior envolvido, são descritos como dor na mandíbula. Quando há maior envolvimento do músculo temporal há a queixa de cefaléia. Os sinais de otalgia e dor retrobulbar (atrás da órbita) indicam uma maior sensibilidade no músculo pterigóideo lateral.

Yang et al. (2001) utilizaram a RM para estudar pacientes com hipermobilidade (hiper-excursão) da mandíbula e a associação desta disfunção com o MPL. O resultado deste estudo indicou que alterações patológicas do MPL não são raras em pacientes com hipermobilidade da mandíbula e são mais freqüentemente observadas na cabeça superior do que na cabeça inferior deste músculo. 
Os mesmos, Yang et al. (2002), novamente investigaram alterações no MPL, por meio de RM, em pacientes com deslocamento anterior do disco articular, sem redução e compararam com a sintomatologia clínica e outras alterações da ATM observadas na RM, como hiper e hipomobilidade; e osteoartrite.

Taskaya-Yýlmaz e Ogutcen-Toller (2002) observaram que quanto maior a deformidade do disco articular detectada pela RM, mais substancial são os sintomas e sinais clínicos dos pacientes com DTM. Sensibilidade à palpação do MPL foi associada a deslocamento anterior do disco articular com ou sem redução e concluíram que a RM pode ser usada para planejamento cirúrgico e também para os casos de difícil diagnóstico destas desordens temporomandibulares. Os mesmos autores avaliaram a relação entre a DTM e as inserções variáveis do MPL pela RM (TASKAYA-YÝLMAZ et al., 2004).

Goto et al. (2002) obtiveram imagens de RM em pacientes adultos jovens, antes e depois da abertura da boca e sugeriram que alterações volumétricas dos músculos mastigatórios ocorrem entre a abertura e o fechamento da boca e que há uma diferença na mudança de volume entre os músculos, isto é, apenas alterações leves foram observadas nos músculos masseter e pterigóideo medial, entretanto, o MPL diminui significantemente o seu volume durante a abertura da boca.

Finden, Enochs e Rao (2007) observaram por meio da RM, que em pacientes com deslocamento do disco articular com e sem redução, a intensidade de sinal apresentada na cabeça superior do MPL foi variável. 


\section{PROPOSIÇÃO}

O propósito neste estudo foi avaliar o Músculo Pterigóideo Lateral em pacientes com e sem Desordens Temporomandibulares por meio de Ressonância Magnética da ATM. 


\section{MATERIAL E MÉTODOS}

Esta pesquisa teve inicio após o projeto de pesquisa ser avaliado e aprovado pela Comissão de Ética em Pesquisa do Hospital São Luiz Projeto n ${ }^{0}$ 102/2005 CAAE: 0020.0.220.017-05 (ANEXO A) e tornado ciente pelo Comitê de Ética em Pesquisa da FOUSP (ANEXO B), mencionando estar de acordo com os princípios éticos, segundo as diretrizes e normas regulamentadoras de pesquisa, envolvendo seres humanos, conforme resolução N ${ }^{\circ} 196 / 96$ do Conselho Nacional de Saúde.

\subsection{Material}

Realizamos um estudo prospectivo e pareado em pacientes com suspeita de Disfunção Temporomandibular (DTM), provenientes de clínicas privadas, encaminhados ao serviço de Ressonância Magnética do Hospital São Luiz, em São Paulo, para exames com finalidade diagnóstica, no período de abril de 2006 a julho de 2008.

O grupo estudado foi constituído de 50 indivíduos (100 ATM), sendo 38 do gênero feminino (76\%) e 12 do gênero masculino (24\%), com idades variando entre 18 e 63 anos, com média de idade de 33,8 anos.

O grupo foi dividido em dois (2) subgrupos: grupo sintomático e grupo controle. 
O grupo sintomático foi composto por 35 pacientes (70 ATM) com queixa clínica e suspeita diagnóstica de DTM e o grupo controle foi constituído por 15 voluntários (30 ATM) assintomáticos ou que não apresentavam sinais e sintomas clínicos de DTM.

\subsubsection{Critérios de Inclusão}

Foram considerados critérios de inclusão, sinais clínicos de DTM, tais como: dor miofacial, limitação na abertura de boca e sons articulares (click), para o grupo de pacientes sintomáticos e ausência de sinais e sintomas de DTM para o grupo controle.

\subsubsection{Critérios de Exclusão}

Foram considerados critérios de exclusão:

- pacientes menores de 18 anos

- pacientes totalmente desdentados

- pacientes claustrofóbicos

- pacientes que necessitem de sedação para a realização do exame

- pacientes com trismo

- pacientes submetidos a cirurgia bucomaxilofacial recentemente 
- pacientes com prótese metálica na mandíbula

- pacientes com trauma bucomaxilofacial

- pacientes com marcapasso

- pacientes com clips cerebral

- pacientes com válvula cardíaca metálica

- pacientes com implantes cocleares

\subsection{Métodos}

Os pacientes foram consultados sobre a sua concordância em ceder as informações de seus exames para uso na pesquisa, após serem esclarecidos sobre todos os procedimentos e riscos (ANEXO C). Se os pacientes não apresentaram objeções, o Termo de Consentimento Livre e Esclarecido (APÊNDICE A) foi lido e assinado por todos, individualmente.

\subsubsection{Exame Clínico}

O correto diagnóstico, baseado em anamnese, exame físico e exames complementares são de fundamental importância para um planejamento correto do tratamento. A avaliação muscular é muito importante no exame clínico de pacientes com dor e suspeita de DTM (CONTI; MIRANDA; ORNELAS, 2000). 
A anamnese e os exames clínicos de todos os pacientes, grupo sintomático e assintomático, foram realizados por um mesmo profissional, de acordo com 0 Research Diagnostic Criteria for Temporomandibular Disorders (RDC/TMD), proposto em 1992 por um grupo de pesquisadores e clínicos, para coletar dados e tornar possível comparações entre os achados de diferentes examinadores clínicos (DWORKIN; LERESCHE, 1992; LIMCHAICHANA et al.,2007).

A anamnese consistiu de um questionário completo e padronizado para todos os pacientes.

O exame clínico incluía a palpação da articulação (região pré-auricular), dos músculos extra-orais (temporal e masseter), a observação de sons articulares e dos movimentos da mandíbula, como abertura, protrusão, lateralidade direita e esquerda. Durante os movimentos mandibulares foi observado se o paciente apresentava dor, som articular ou alguma limitação de movimento. Também foram avaliadas a simetria facial e o alinhamento das arcadas. Durante a abertura máxima da boca, avaliou-se a medida milimétrica da abertura da boca entre os dentes incisivos centrais superiores e inferiores. Todos esses dados foram assinalados em um questionário que continha também a anamnese do paciente, de acordo com Apêndice B.

Os sons articulares avaliados foram estalo (click) ou crepitação. Por estalo entende-se como sendo um som simples, distinto emitido pela ATM durante abertura ou fechamento da mandíbula. E crepitação é definida como múltiplos sons de rangido emitidos pela articulação durante abertura ou fechamento da mandíbula (TRUELOVE et al.,1992).

Para a medida da abertura máxima da boca dos pacientes, foi utilizado o dispositivo Burnett, o mesmo aparelho que depois foi usado durante a realização do 
exame de RM, em abertura máxima, como descreveremos mais adiante, na Técnica do Exame (BURNETT; DAVIS; READ, 1987).

Para o exame do Músculo Pterigóideo Lateral (MPL), foi utilizado o Teste Funcional Muscular Anterior (teste do palito); os pacientes foram orientados a morder um palito (do tipo otorrinológico), entre os incisivos centrais em protrusão, por um minuto e após esse tempo foi avaliado se os pacientes apresentaram dor, conforme teste utilizado pelo Instituto da Cabeça da UNIFESP (DWORKIN; LERESCHE; 1992).

4.2.2 Protocolo de exame de RM para ATM e MPL

Após o posicionamento do paciente em decúbito dorsal e da bobina específica (head coil), foram realizadas as seguintes seqüências:

- Sequência localizadora nos planos axial e coronal, ponderada em FFE (Gradiente Eco) para identificação das ATM para programação das demais sequências (Tabela 4.1).

- Sequência ponderada em DP, no plano sagital oblíquo (perpendicular ao eixo da cabeça da mandíbula) com boca fechada (Tabela 4.1).

- Sequência ponderada em T2 no plano sagital oblíquo com boca fechada (Tabela 4.1).

- Sequência ponderada em T2, aquisição volumétrica com 1,20mm de espessura no plano sagital oblíquo (Tabela 4.1). 
- Sequência ponderada em T1 no plano coronal oblíquo (paralelo ao eixo da cabeça da mandíbula) (Tabela 4.1).

- Sequência ponderada em T1 no plano sagital oblíquo com boca aberta (utilização de mordedor específico Burnett (Burnett Bidirectional TMJ device) (Tabela 4.1).

- Sequência dinâmica: Movie com cortes de $1 \mathrm{~mm}$ em três posições de boca: oclusão, repouso e abertura máxima.

O tempo total para realização dos exames de RM da ATM bilateral em cada paciente foi de aproximadamente 30 minutos (Tabela 4.1).

Tabela 4.1 - Principais parâmetros das seqüências de RM utilizadas na avaliação dos pacientes

\begin{tabular}{|c|c|c|c|c|c|c|c|c|}
\hline & $\begin{array}{l}\text { Loc } \\
1\end{array}$ & $\begin{array}{l}\text { Loc } \\
2\end{array}$ & Sag PD & Sag T2 & Sag Vol & Cor T1 & $\begin{array}{l}\text { Sag T1 } \\
\text { B.Aberta }\end{array}$ & $\begin{array}{l}\text { Movie } \\
1 \mathrm{~mm}\end{array}$ \\
\hline $\begin{array}{l}\text { Seqüência de } \\
\text { pulso }\end{array}$ & $\mathrm{FFE}^{*}$ & $\mathrm{FFE}^{*}$ & SE & TSE & $\mathrm{FFE}^{*}$ & TSE & TSE & FFE $^{*}$ \\
\hline Bobina & Head & Head & Head & Head & Head & Head & Head & Head \\
\hline Plano de corte & Axial & Coronal & Sagital & Sagital & Sagital & Coronal & Sagital & Sagital \\
\hline TR (mseg) & 128 & 56 & 1000 & 2913 & 48 & 460 & 652 & 50 \\
\hline TE (mseg) & 7 & 7 & 15 & 120 & 14 & 14 & 13 & 14 \\
\hline TI (mseg) & - & - & - & - & - & - & - & - \\
\hline Matriz & $256 \times 256$ & $256 \times 256$ & $256 \times 512$ & $256 \times 512$ & $256 \times 512$ & $256 \times 512$ & $256 \times 512$ & $256 \times 512$ \\
\hline $\begin{array}{l}\text { Espessura de } \\
\text { corte }(\mathrm{mm})\end{array}$ & 4.0 & 6.0 & 3.0 & 3.0 & 1.20 & 3.0 & 3.0 & 1.5 \\
\hline $\begin{array}{l}\text { Espaçamento } \\
\text { entre cortes (mm) }\end{array}$ & 0.4 & 1.0 & 0.3 & 0.3 & - & 0.3 & 0.3 & - \\
\hline Número de cortes & 9 & 4 & 6 & 6 & 20 & 6 & 6 & 10 \\
\hline $\begin{array}{l}\text { Número } \\
\text { aquisições }\end{array}$ & 1 & 1 & 2 & 2 & 2 & 2 & 2 & $0.2^{\star \star}$ \\
\hline $\begin{array}{l}\text { Tempo } \\
\text { aquisição } \\
\text { (minutos) }\end{array}$ & $00: 16$ & $00: 07$ & $3: 26$ & $2: 40$ & $2: 37$ & $3: 15$ & $2: 15$ & $2: 37$ \\
\hline $\begin{array}{l}\text { Supressão de } \\
\text { gordura (SPIR) }\end{array}$ & Não & Não & Não & Não & Não & Não & Não & Não \\
\hline $\begin{array}{l}\text { Ângulo } \\
\text { Inclinação }\end{array}$ & 50 & 50 & 90 & 90 & 15 & 90 & 90 & 15 \\
\hline
\end{tabular}




\subsubsection{Equipamentos}

As imagens foram obtidas por meio de aparelho de Ressonância Magnética, super condutivo, modelo GIROSCAN NT10 de fabricação da Philips Medical Systems ${ }^{\circledR}$ (Eindhoven - DA - Nederland), operando em campo magnético de 1 Tesla (1T), com gradientes de $15 \mathrm{mT} / \mathrm{seg}$, do serviço de Diagnóstico por Imagem do Hospital São Luiz (São Paulo - SP - Brasil).

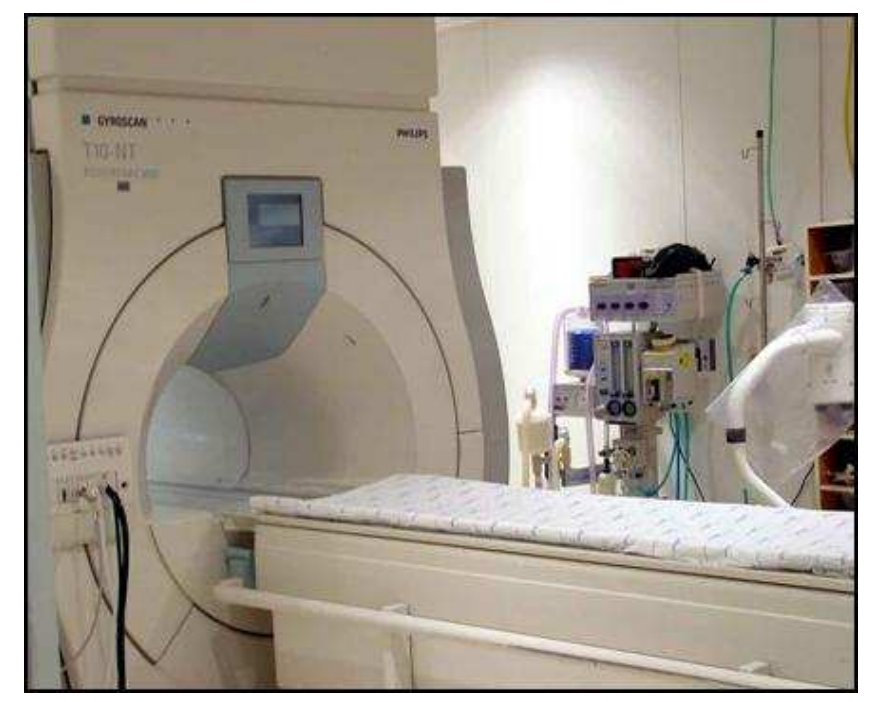

Figura 4.1 - Aparelho de Ressonância Magnética Philips Medical Systems®

Todos os pacientes foram submetidos ao exame de RM bilateral das ATM. Para o posicionamento do paciente na mesa de exame do aparelho de RM, não é necessário remover as roupas, porém, foi solicitado aos pacientes que retirassem todos os objetos que pudessem interferir no processo de imagem, principalmente aqueles contendo metal, como brincos, broches, colares, relógios de pulso, canetas esferográficas e chaves. Os pacientes também foram orientados a retirar próteses 
dentárias removíveis e aparelhos ortodônticos móveis que poderiam interferir na qualidade da imagem.

A bobina de RM utilizada para transmissão e recepção de sinais foi a de cabeça (head coil).

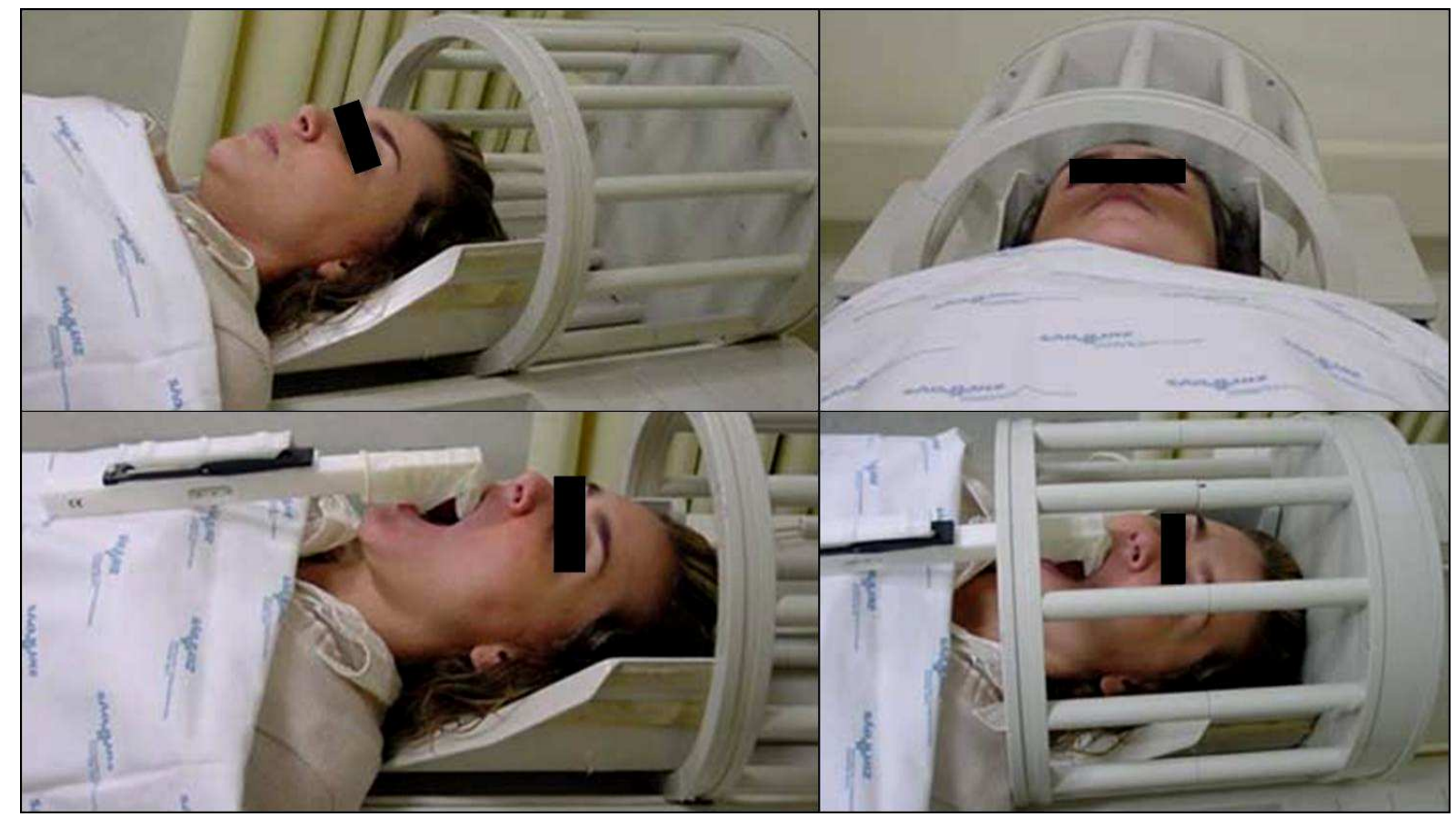

Figura 4.2 - Posicionamento do paciente, do mordedor na boca do paciente e da bobina para realização do exame de RM da ATM

Para as seqüências com abertura máxima da boca, utilizou-se um mordedor apropriado desenvolvido por Burnett (Burnett Bidirectional TMJ device), comercializado pela Empresa Medrad Inc.® (Indianola - PA - USA) e gentilmente cedido pela Philips Medical Systems ${ }^{\circledR}$ (Eindhoven - DA - Nederland), para o uso na nossa pesquisa. Este dispositivo tem como qualidades ser de material não ferromagnético, permitindo grande abertura milimétrica (até $55 \mathrm{~mm}$ ) da boca e som audível de click a cada milímetro aumentado, colocado entre os dentes anteriores do 
paciente, no momento da aquisição das imagens sagitais em abertura máxima (BURNETT; DAVIS; READ, 1987).

Para a proteção dos pacientes todos os mordedores foram cobertos por uma capa de silicone esterilizada e descartável.

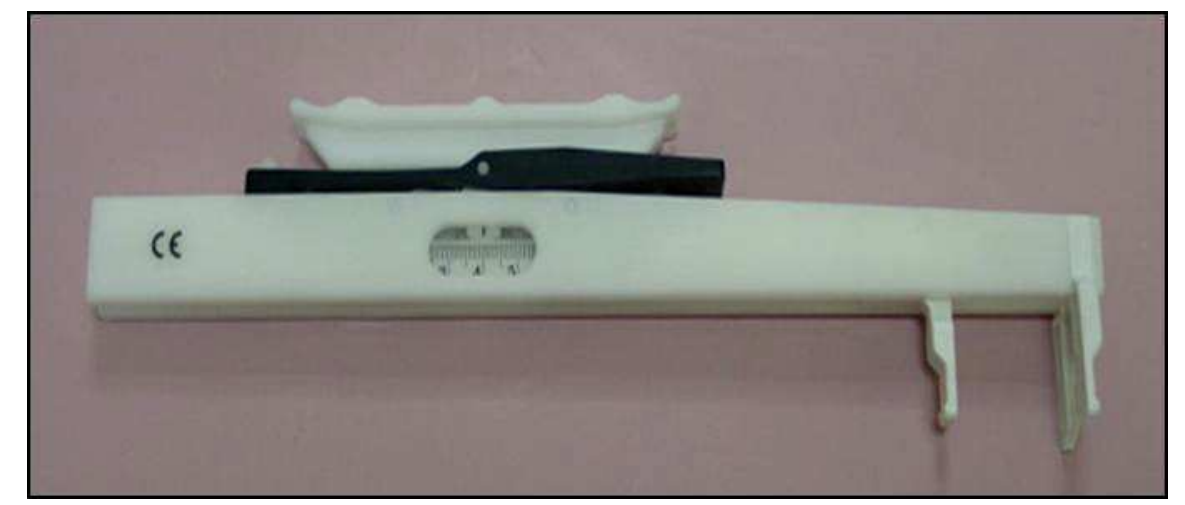

Figura 4.3 - Mordedor de Burnett da Empresa Medrad Inc.® para realização das tomadas em abertura máxima de boca

\subsubsection{Análise das imagens}

A interpretação das imagens foi efetuada por 2 (dois) examinadores independentes, com experiência em RM da ATM. Foram avaliadas as imagens dos MPL, suas anatomias, inserções e alterações. Medidas dos músculos foram realizadas em uma Workstation. As medidas do músculo do lado afetado por DTM foram comparadas com aquelas do músculo contralateral e também comparadas com as medidas obtidas dos MPL dos indivíduos sem sintomatologia de DTM.

A avaliação dos MPL foi realizada apenas nas imagens onde as duas cabeças do músculo apareciam claramente e observadas em pelo menos dois cortes de cada seqüência de RM. 
O músculo foi considerado com hipertrofia quando apresentou o tamanho aumentado e sinal homogêneo nas seqüências de Ressonância Magnética, nos cortes sagitais e coronais, manifestando-se como uma alteração convexa nas bordas do músculo na sua porção medial. Já o MPL com atrofia foi considerado como sendo o que apresentou tecido gorduroso de alta intensidade de sinal, aparecendo em amplas áreas do músculo, sem alteração no seu tamanho, nas imagens ponderadas em DP e T2. Por outro lado, contratura do MPL apresentou-se como fibroses no músculo aparecendo como áreas de baixa intensidade de sinal nas imagens ponderadas em DP e T2 (SCHELHAS, 1989).

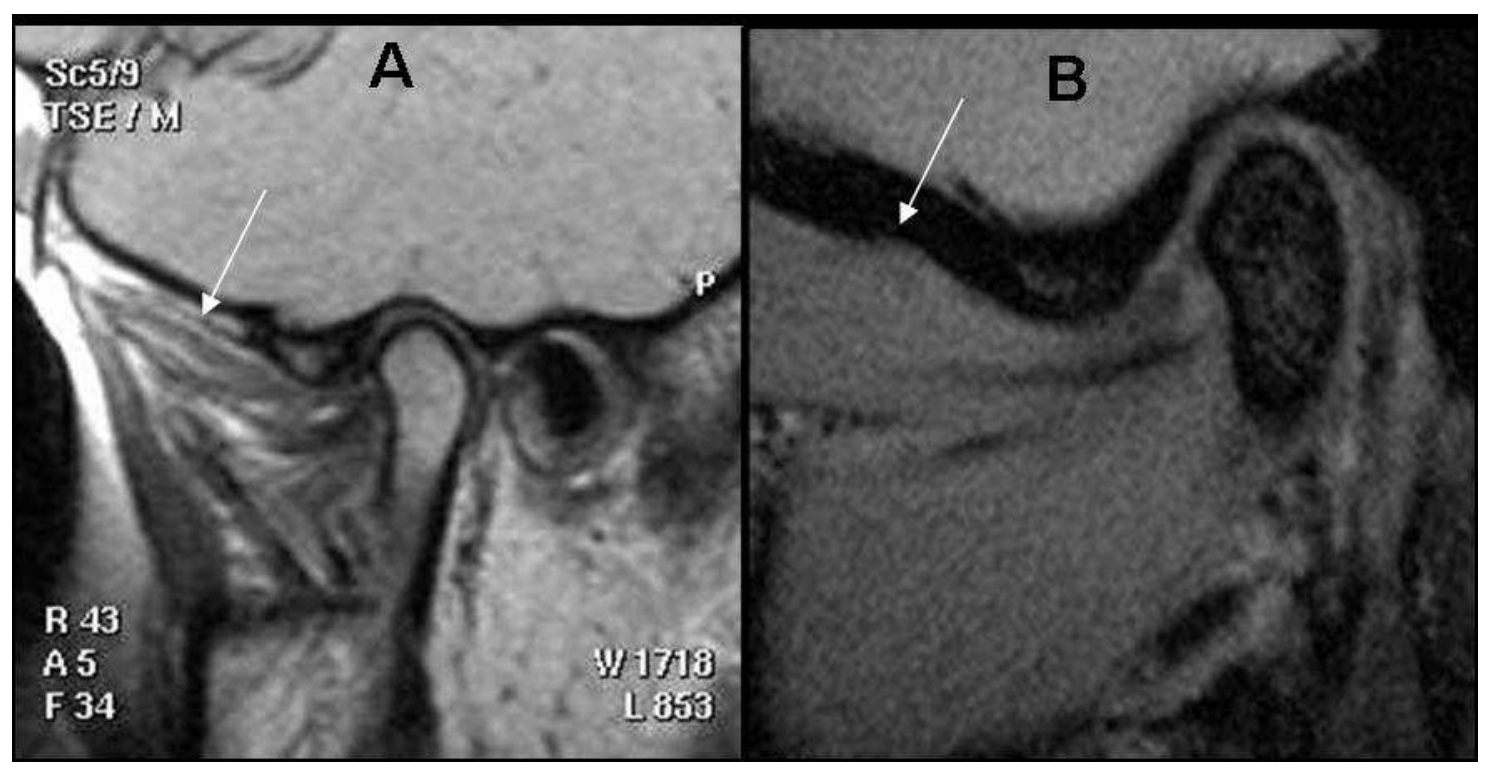

Figura 4.4 - Imagens sagitais de RM da ATM. Alterações no MPL: A - Atrofia e B - Hipertrofia 


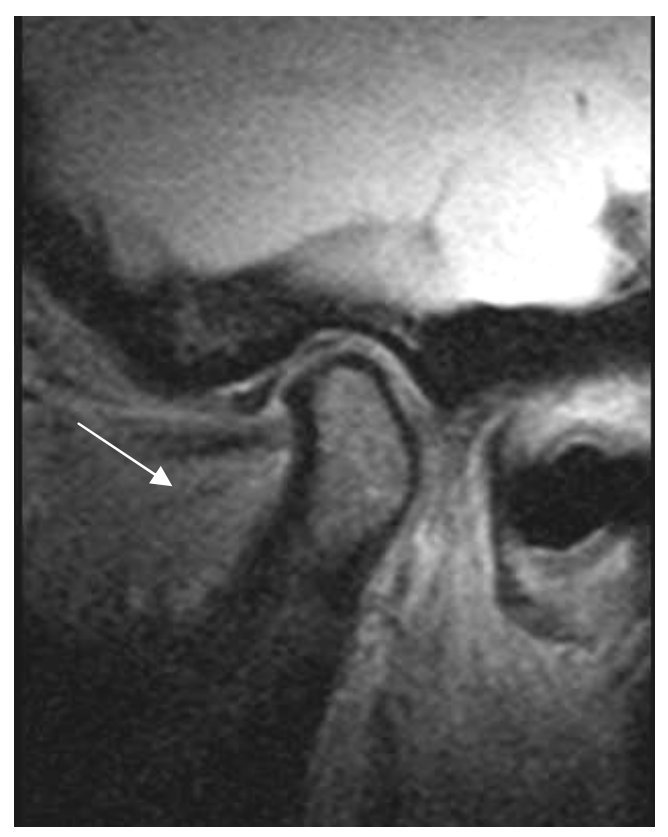

Figura 4.5 - Contratura do MPL, cabeça inferior

A posição do disco articular também foi observada para se determinar se o paciente com DTM possuía deslocamento do disco articular e se o mesmo se apresentou com ou sem redução. De acordo com Katzberg et al.(1996), disco normal é aquele no qual a sua banda posterior, na junção com a zona bilaminar se localiza na posição superior ou de 12 horas em relação à porção mais superior da cabeça da mandíbula. O tipo mais comum de deslocamento do disco articular é o deslocamento anterior, quando esta junção da banda posterior com a zona bilaminar encontra-se anteriormente localizada em relação à posição de 12 horas. Se o disco deslocado anteriormente retorna ao topo da cabeça da mandíbula na abertura máxima da boca, diz-se que o deslocamento anterior é com redução (DDAR), mas se ao invés disso, o disco permanece na posição anterior durante a abertura de boca máxima, significa que o deslocamento do disco é sem redução (DDAsR). 


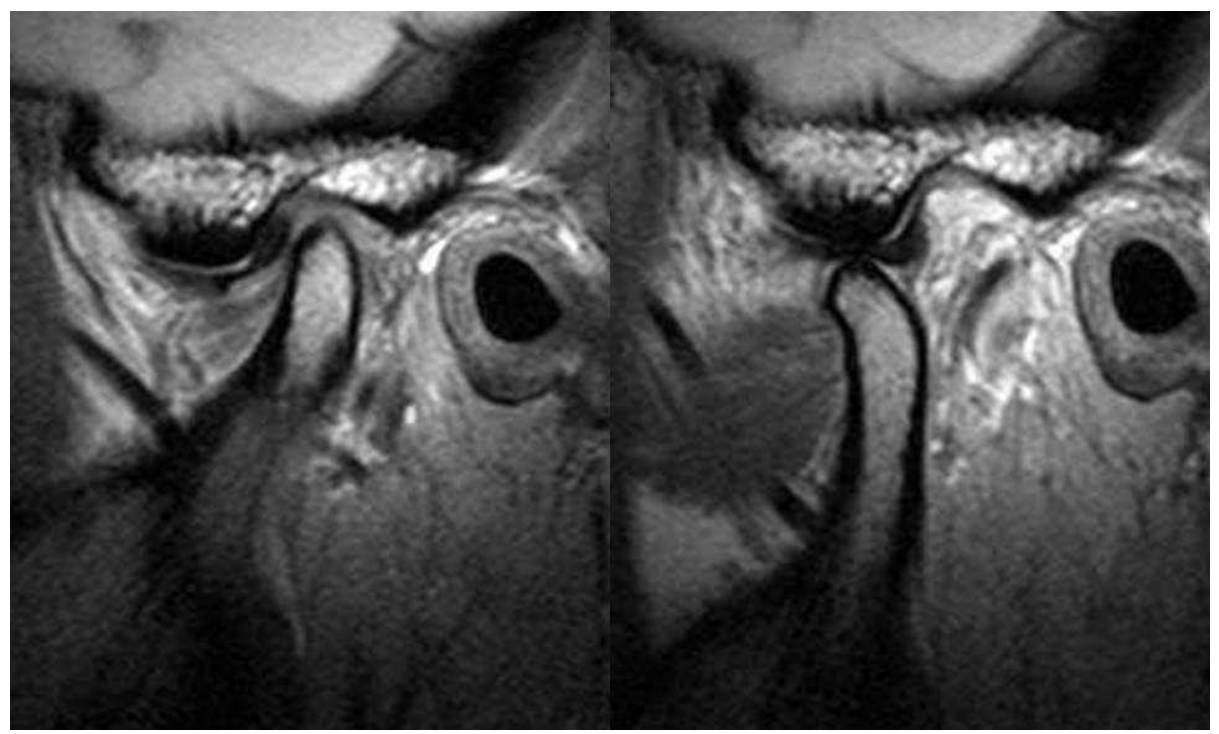

Figura 4.6 - Deslocamento anterior do disco articular com redução (DDAR)

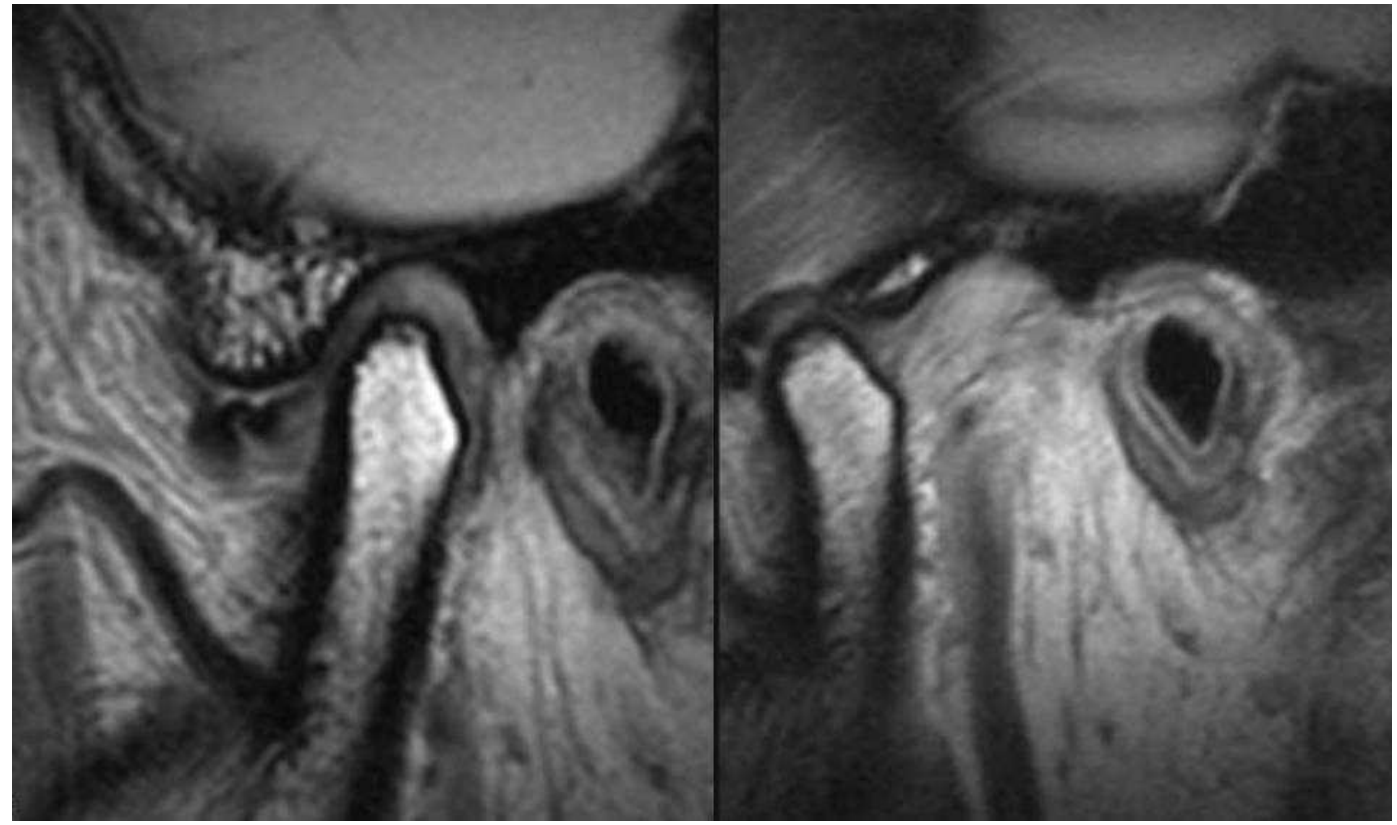

Figura 4.7 - Deslocamento anterior do disco articular sem redução (DDAsR) 
Alterações ósseas foram definidas como aplainamento, presença de osteófitos, esclerose ou erosão na cabeça da mandíbula, segundo Westesson (1993).

A mobilidade da cabeça da mandíbula foi classificada em normal, hipomobilidade e hipermobilidade. Para esta avaliação, é traçada uma linha imaginária horizontal tangencial ao topo da cavidade articular e uma linha vertical passando pelo topo do tubérculo articular, nas imagens sagitais oblíquas em RM. As duas linhas se encontram em um determinado ponto formando um ângulo, onde $0^{\circ}$ é o topo da cavidade articular e $90^{\circ}$ é no topo do tubérculo articular. O diagnóstico da mobilidade da cabeça da mandíbula foi considerada medindo-se a localização da cabeça da mandíbula na máxima abertura da boca nas imagens (BENITO; CASARES; BENITO, 1998).

Consideramos como hipomobilidade ou limitação da cabeça da mandíbula, quando esta se localizava entre $0^{\circ}$ e $90^{\circ}(<909$, neste caso a cabeça da mandíbula não chega a alcançar o topo do tubérculo articular. Mobilidade normal foi determinada quando a cabeça da mandíbula estava localizada entre $90^{\circ}$ e $120^{\circ} \mathrm{em}$ relação ao tubérculo articular. E hipermobilidade, quando a cabeça da mandíbula transladou excessivamente além do topo do tubérculo articular (> 1209 (BENITO; CASARES; BENITO, 1998).

Consideramos como abertura máxima da boca, o limite máximo de abertura mandibular em adultos, determinado por Agerberg (1974), variando entre 40mm e $60 \mathrm{~mm}$, valores esses que podem alterar de acordo com idade, gênero e tamanho do individuo. Amplitudes de abertura máxima mandibular, observadas inferiores a 40mm, foram consideradas como limitação na abertura da boca. 


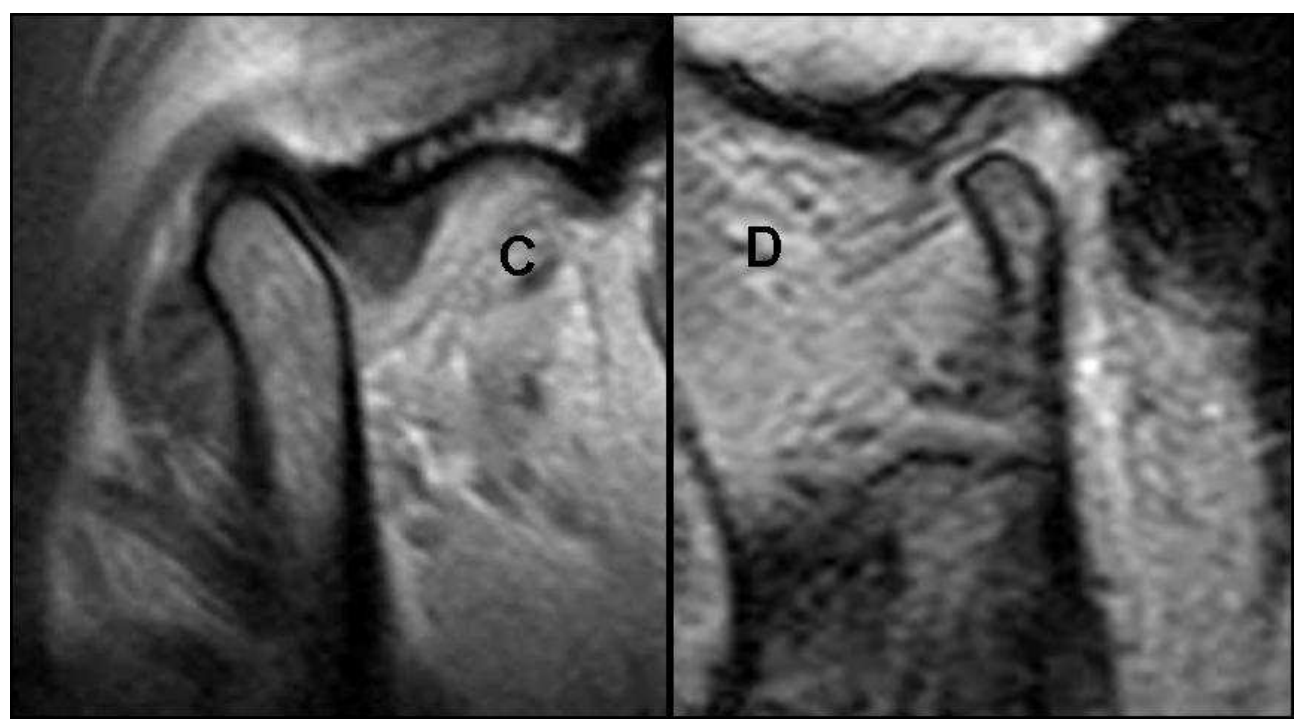

Figura 4.8 - Imagens sagitais de RM da ATM mostrando tipos de mobilidade da cabeça da mandíbula Hipermobilidade (C) e Hipomobilidade (D)

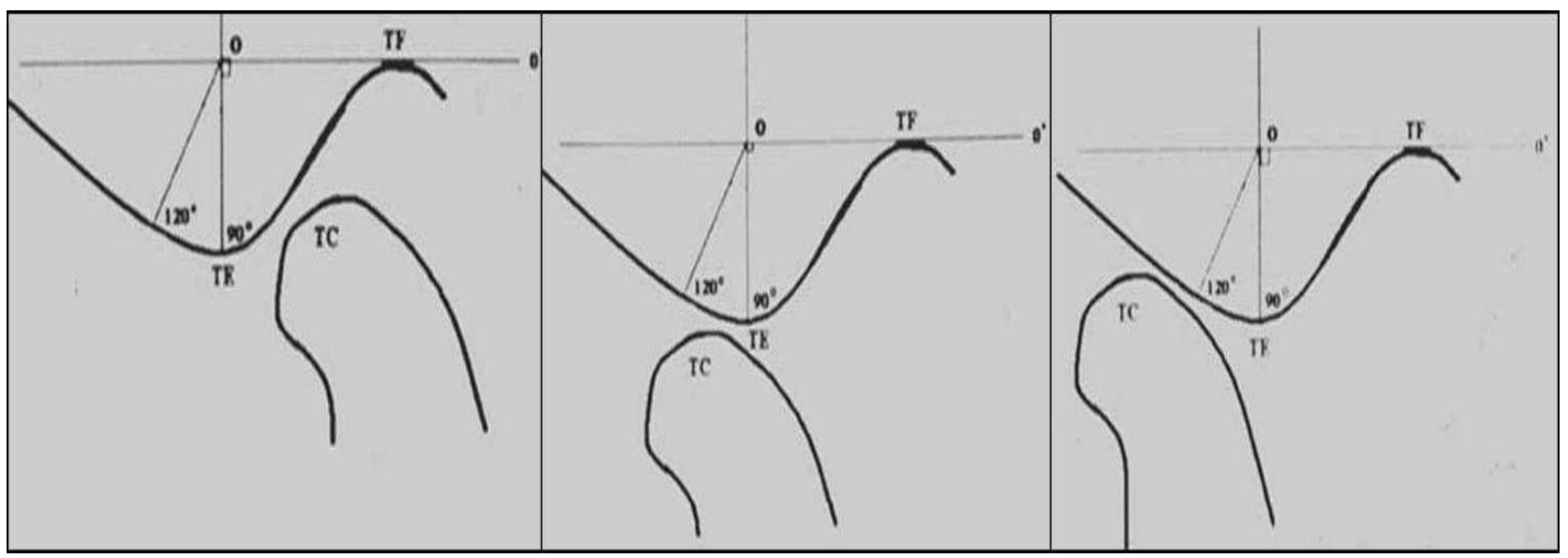

Figura 4.9 - Esquema demonstrando a Hipermobilidade da cabeça da mandíbula 


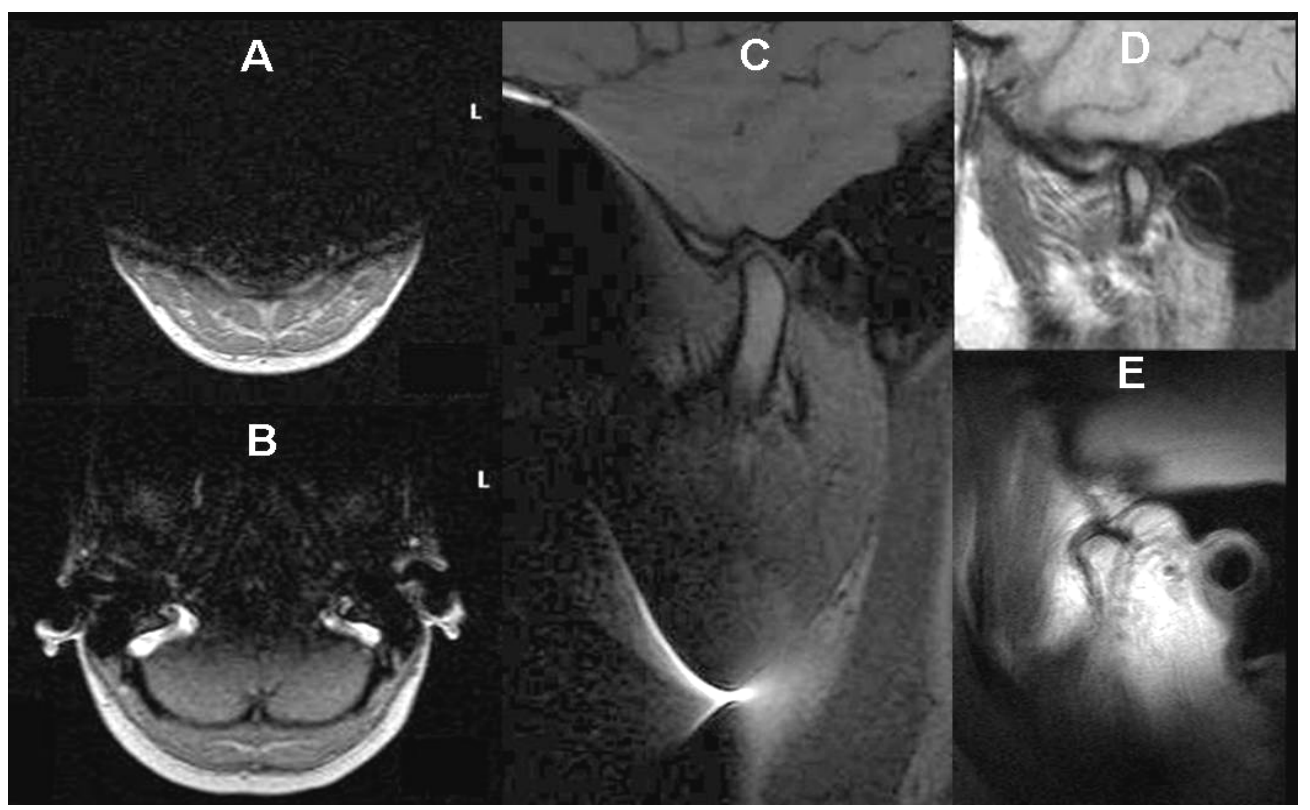

Figura 4.10 - Artefatos mais comuns observados nas imagens de ATM: causada pelo aparelho ortodôntico (A, B e C) e de Movimento (D e E)

\subsubsection{Análise Estatística}

As variáveis de natureza qualitativa foram analisadas pelo cálculo de freqüências absolutas e relativas, além da construção de gráficos de barras (BUSSAB; MORETTIN, 2006).

As análises inferenciais empregadas com o intuito de confirmar ou refutar evidências encontradas na análise descritiva foram:

- Análise de Variância com Medidas Repetidas;

- Análise de Variância Simples;

- Teste de Qui-quadrado de Pearson e teste Exato de Fisher (ou sua extensão);

- Teste t-Student para amostras independentes.

Em todas as conclusões obtidas pelas análises inferenciais foi utilizado o nível de significância $(\alpha)$ igual a $5 \%(p \leq 0,05)$. 


\section{RESULTADOS}

A análise estatística de todas as informações coletadas nesta pesquisa foi inicialmente feita de forma descritiva. Para as variáveis de natureza quantitativa foram calculadas algumas medidas-resumo, como média, desvio-padrão, entre outras, e confeccionados gráficos do tipo boxplot (BUSSAB; MORETTIN, 2006). Algumas informações sobre a construção e interpretação do boxplot podem ser obtidas no Apêndice C. As variáveis de natureza qualitativa foram analisadas pelo cálculo de freqüências absolutas e relativas, além da construção de gráficos de barras (BUSSAB; MORETTIN, 2006).

As análises inferenciais empregadas com o intuito de confirmar ou refutar evidências encontradas na análise descritiva foram:

- Análise de Variância com Medidas Repetidas na comparação entre:

- os grupos com e sem Disfunção Temporomandibular (DTM) com respeito às medidas do Músculo Pterigóideo Lateral (MPL) nos cortes axial, T1 sagital com boca fechada e T2 sagital com boca aberta, considerando os lados direito e esquerdo (NETER et al., 1996);

o os grupos com e sem Disfunção Temporomandibular (DTM) e presença de Estalo, com respeito às medidas do Músculo Pterigóideo Lateral (MPL) nos cortes axial, T1 sagital com boca fechada e T2 sagital com boca aberta, considerando os lados direito e esquerdo (NETER et al., 1996);

o os grupos com e sem Disfunção Temporomandibular (DTM) e presença de Dor, com respeito às medidas do Músculo Pterigóideo Lateral (MPL) nos cortes axial, T1 sagital com boca fechada e T2 
sagital com boca aberta, considerando os lados direito e esquerdo (NETER et al., 1996);

- Análise de Variância Simples na comparação das medidas do MPL nos cortes axial, T1 sagital com boca fechada e T2 sagital com boca aberta, entre os diferentes tipos de Deslocamento do Disco Articular (DDA), Mobilidade da Cabeça da Mandíbula e Morfologia do MPL;

- Teste de Qui-quadrado de Pearson e teste Exato de Fisher (ou sua extensão) no estudo da associação entre as informações do Gênero, tipo de DDA, Mobilidade da Cabeça da Mandíbula, Morfologia do MPL e Abertura da boca, em ambos os grupos com e sem DTM; além da associação entre a Morfologia do MPL com respeito ao DDA e Mobilidade da Cabeça da Mandíbula (AGRESTI, 1990);

- Teste t-Student para amostras independentes na comparação dos valores médios da idade e abertura da boca entre os grupos com e sem DTM (BUSSAB; MORETTIN, 2006).

Em todas as conclusões obtidas pelas análises inferenciais foi utilizado o nível de significância $(\alpha)$ igual a $5 \%(p \leq 0,05)$.

Os dados foram digitados em planilhas do Excel 2000 for Windows para o adequado armazenamento das informações. As análises estatísticas foram realizadas com o software Statistical Package for Social Sciences (SPSS) versão 11.0 for Windows. 
Tabela 5.1 - Distribuição dos pacientes, segundo Gênero e Grupo

\begin{tabular}{|l|l|l|l|} 
Gênero & Com DTM $(n=35)$ & Sem DTM $(n=15)$ & Total $(n=50)$ \\
\hline Feminino & 29 & 9 & 38 \\
\hline \multirow{2}{*}{ Masculino } & $82,9 \%$ & $60,0 \%$ & $76,0 \%$ \\
\cline { 2 - 4 } & 6 & 6 & 12 \\
\hline \multirow{2}{*}{ Total } & $17,1 \%$ & $40,0 \%$ & $24,0 \%$ \\
\hline & 35 & 15 & 50 \\
\hline & $100,0 \%$ & $100,0 \%$ & $100,0 \%$
\end{tabular}

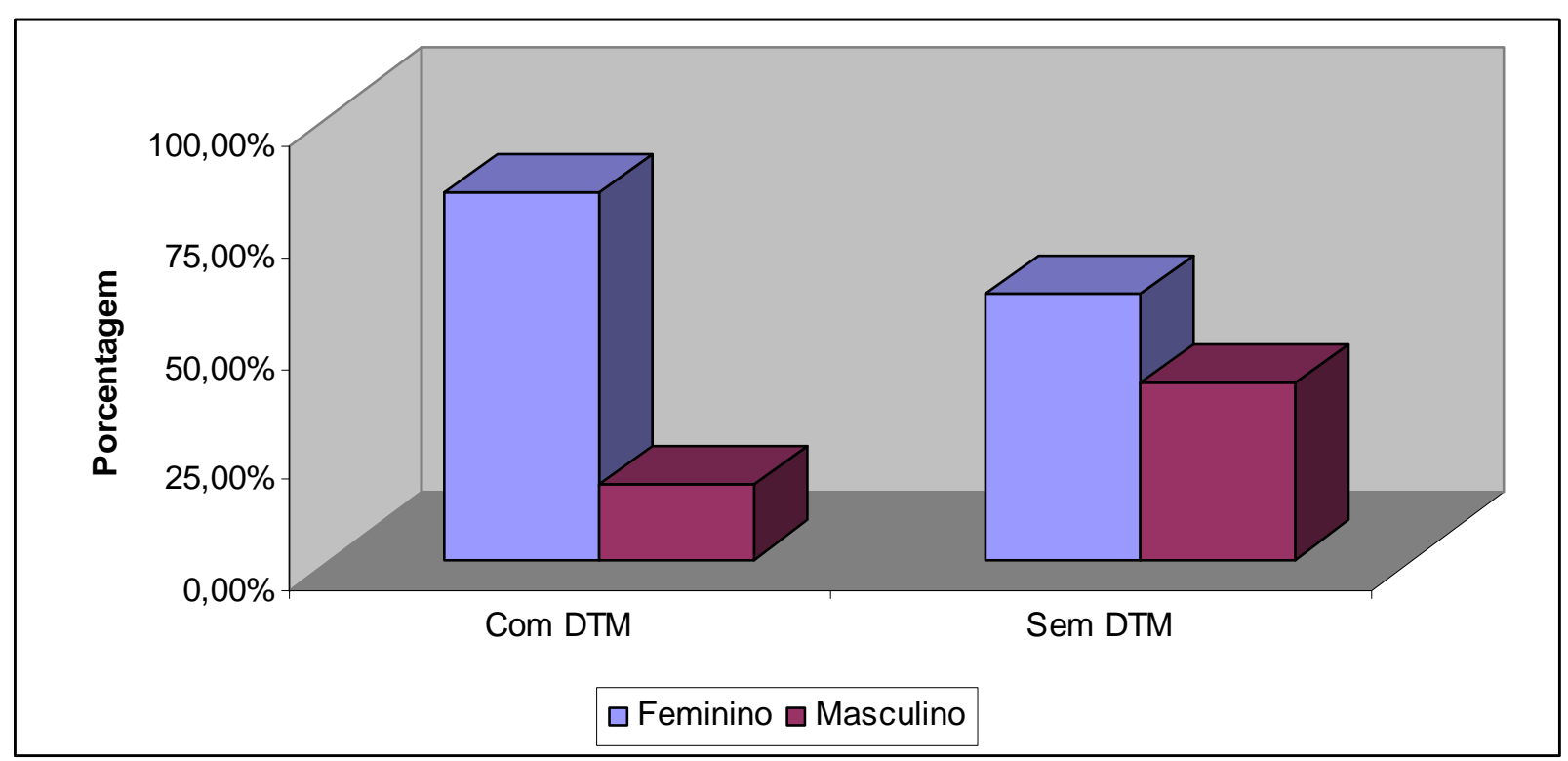

Gráfico 5.1 - Distribuição dos pacientes, segundo Gênero e Grupo

Tabela 5.2 - Medidas-resumo da Idade (anos) dos pacientes, segundo Grupo

\begin{tabular}{|l|l|l|l|}
\hline Medidas-resumo & Com DTM $(n=35)$ & Sem DTM $(n=15)$ & Total $(n=50)$ \\
\hline Média & 35,0 & 31,1 & 33,8 \\
\hline Mediana & 30,0 & 32,0 & 30,5 \\
\hline Mínimo & 18,0 & 20,0 & 18,0 \\
\hline Máximo & 63,0 & 49,0 & 63,0 \\
\hline Desvio-padrão & 13,0 & 8,1 & 11,8
\end{tabular}




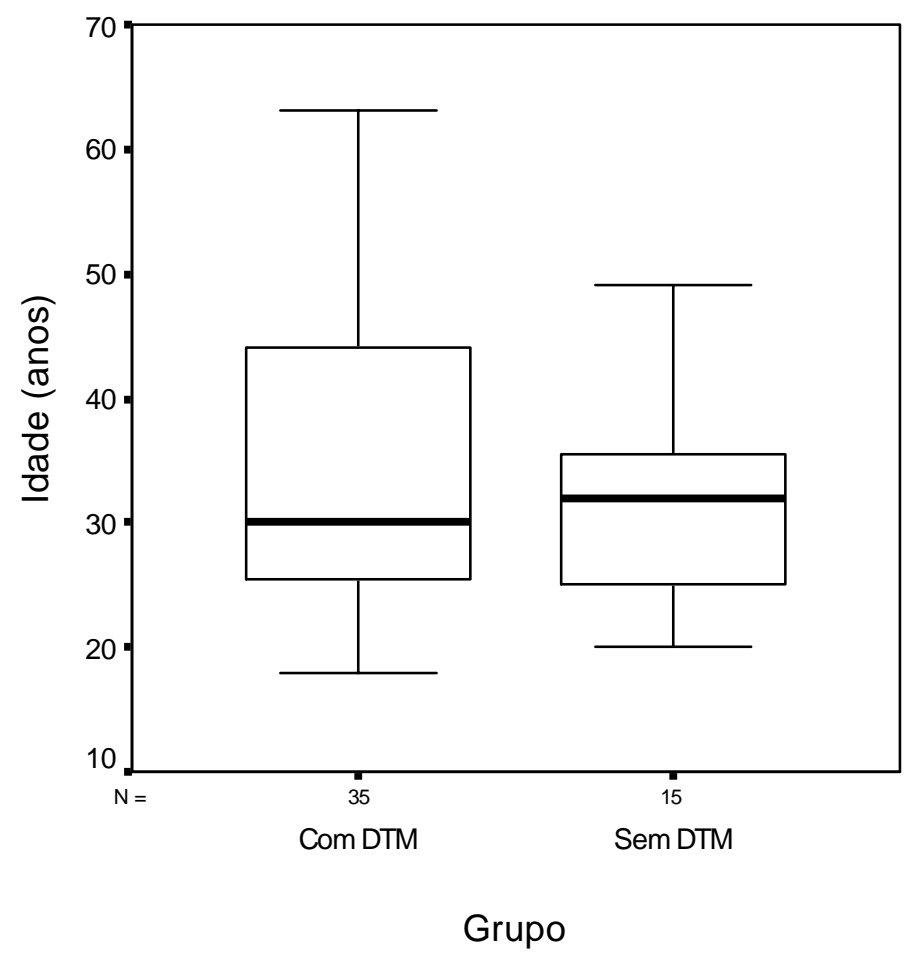

Gráfico 5.2 - Boxplot da Idade (anos) dos pacientes, segundo Grupo

Os pacientes também foram investigados quanto à localização da Queixa, além da Sintomatologia, observamos também o resultado do Teste Funcional Muscular Anterior (Teste do MPL) e as medidas da Abertura da Boca. Essas informações podem ser obtidas nas tabelas 5.3 a 5.8 e nos gráfico 5.3 a 5.14 . 
Tabela 5.3 - Distribuição da ocorrência de Queixa dos pacientes, segundo Grupo

\begin{tabular}{|c|c|c|c|}
\hline & \multicolumn{2}{|l|}{ Grupo } & \multirow[t]{2}{*}{ Total } \\
\hline Queixa & Com DTM $(n=35)$ & Sem DTM $(n=15)$ & \\
\hline \multirow[t]{2}{*}{ bilateral } & 10 & - & 10 \\
\hline & $28,6 \%$ & - & $20,0 \%$ \\
\hline \multirow[t]{2}{*}{ lado direito } & 7 & - & 7 \\
\hline & $20,0 \%$ & - & $14,0 \%$ \\
\hline \multirow[t]{2}{*}{ lado esquerdo } & 10 & - & 10 \\
\hline & $28,6 \%$ & - & $20,0 \%$ \\
\hline \multirow[t]{2}{*}{ sem queixa } & 8 & 15 & 23 \\
\hline & $22,9 \%$ & $100,0 \%$ & $46,0 \%$ \\
\hline \multirow[t]{2}{*}{ Total } & 35 & 15 & 50 \\
\hline & $100,0 \%$ & $100,0 \%$ & $100,0 \%$ \\
\hline
\end{tabular}

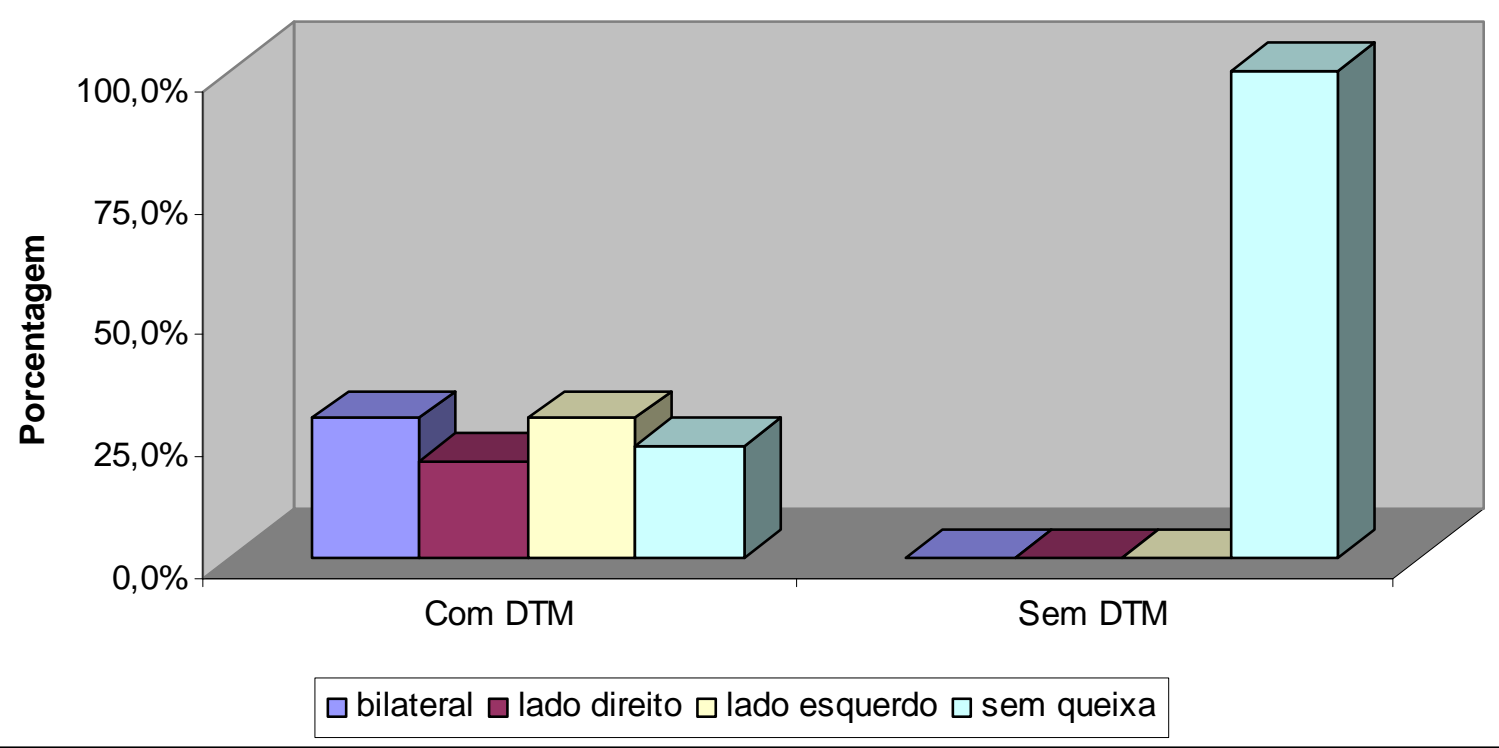

Gráfico 5.3 - Distribuição da ocorrência de Queixa dos pacientes, segundo Grupo 
Tabela 5.4 - Distribuição da Sintomatologia entre os pacientes, segundo Grupo

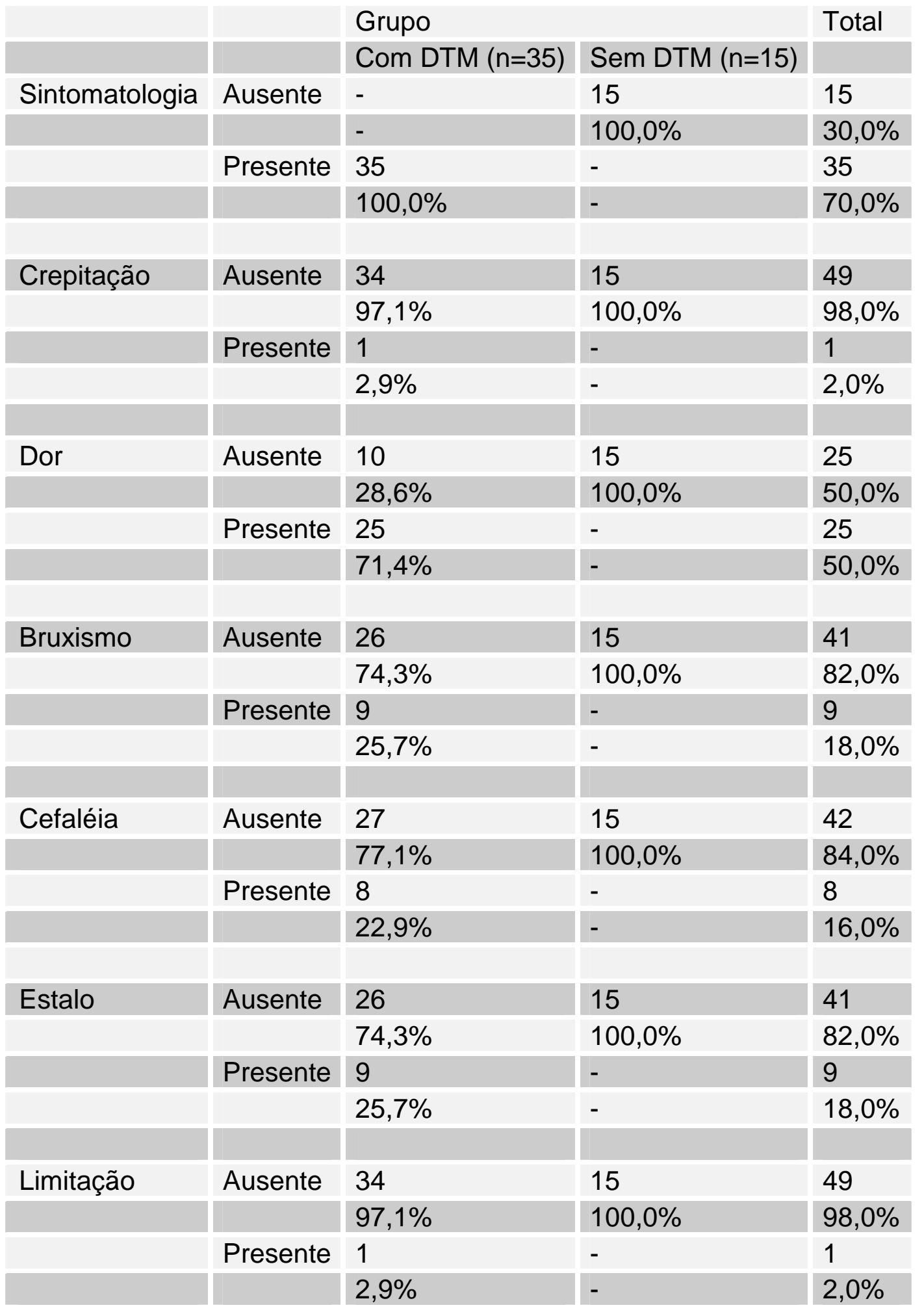




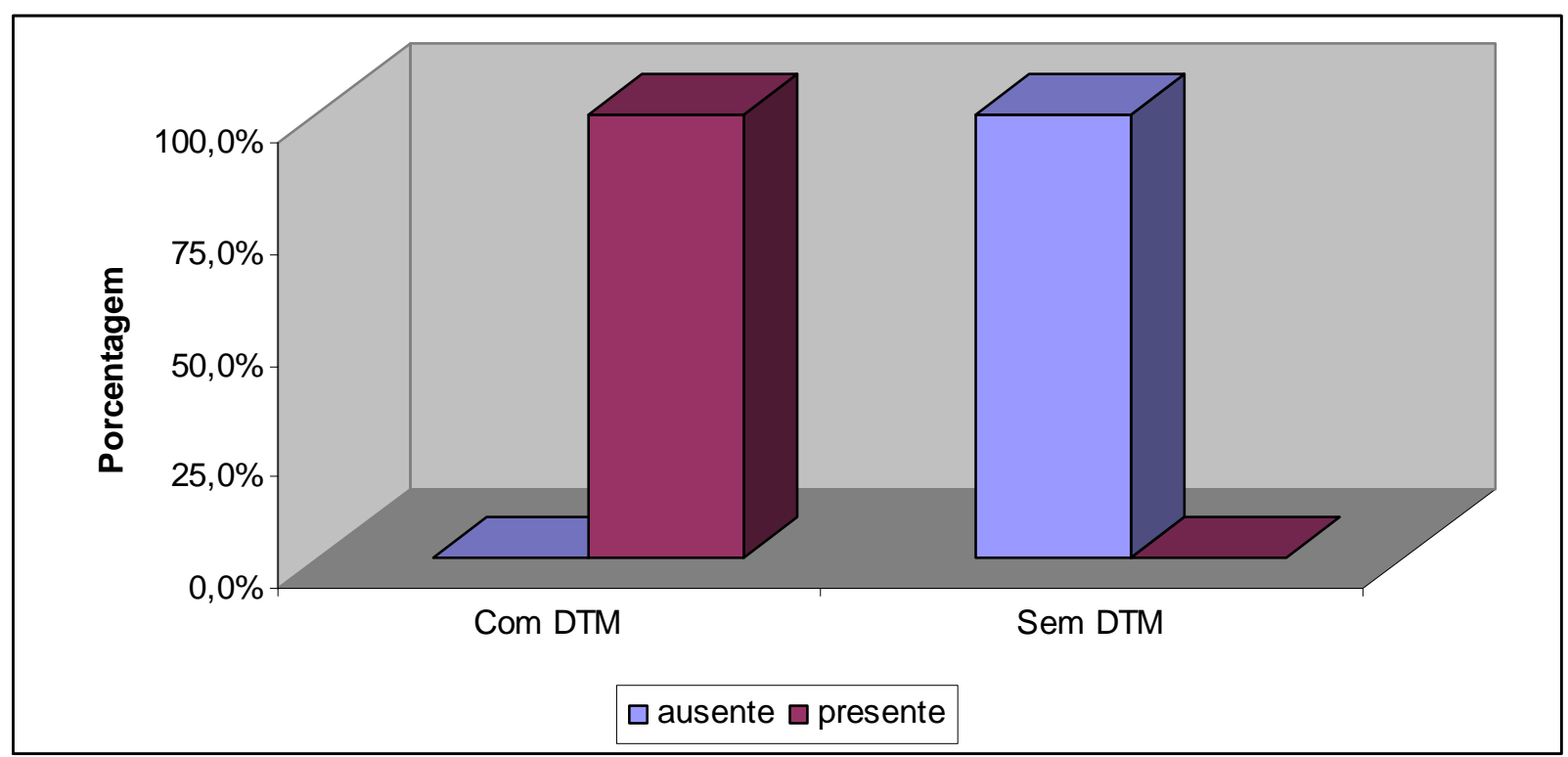

Gráfico 5.4 - Distribuição da Sintomatologia entre os pacientes, segundo Grupo

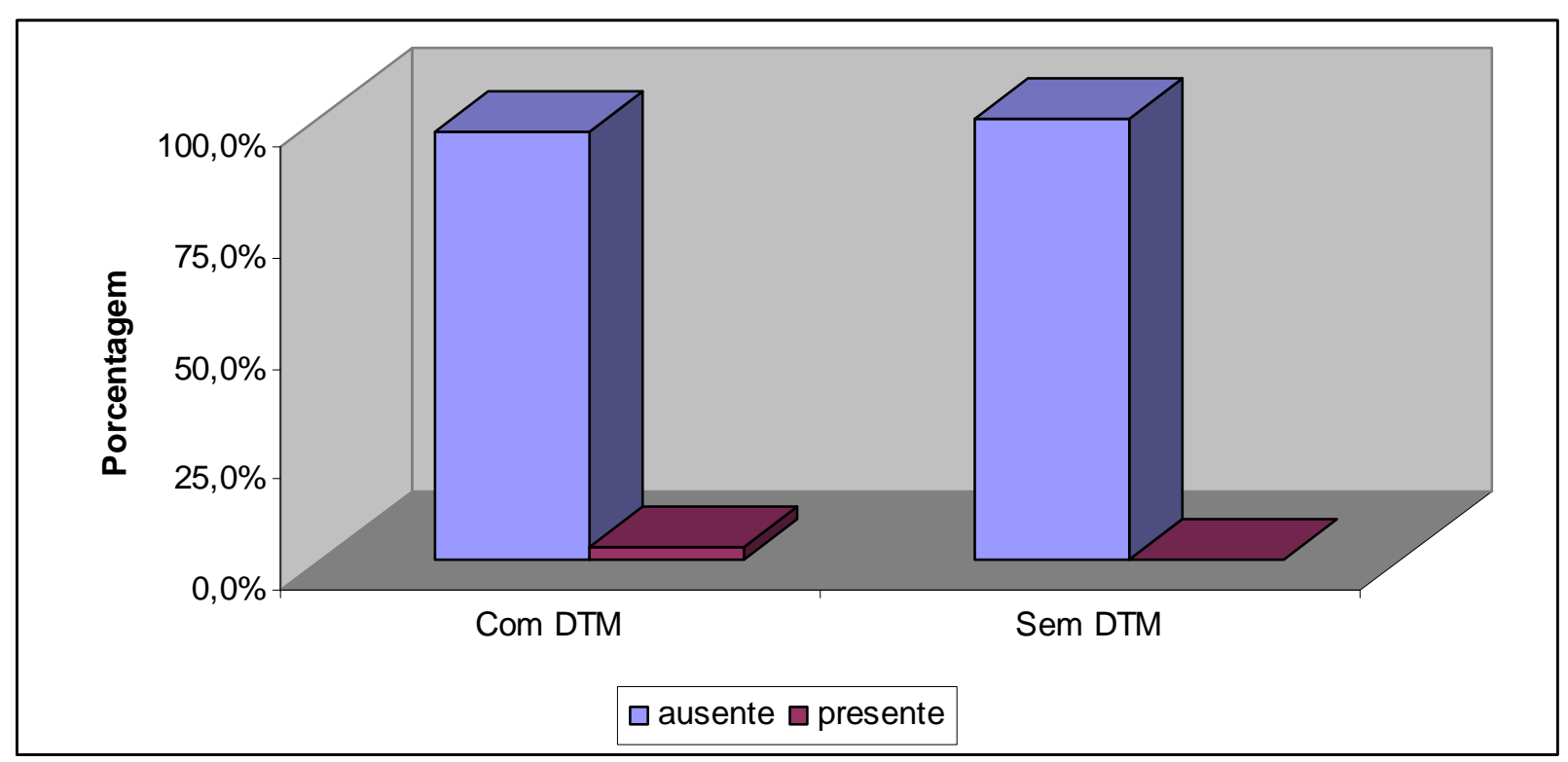

Gráfico 5.5 - Distribuição da ocorrência de Crepitação entre os pacientes, segundo Grupo 


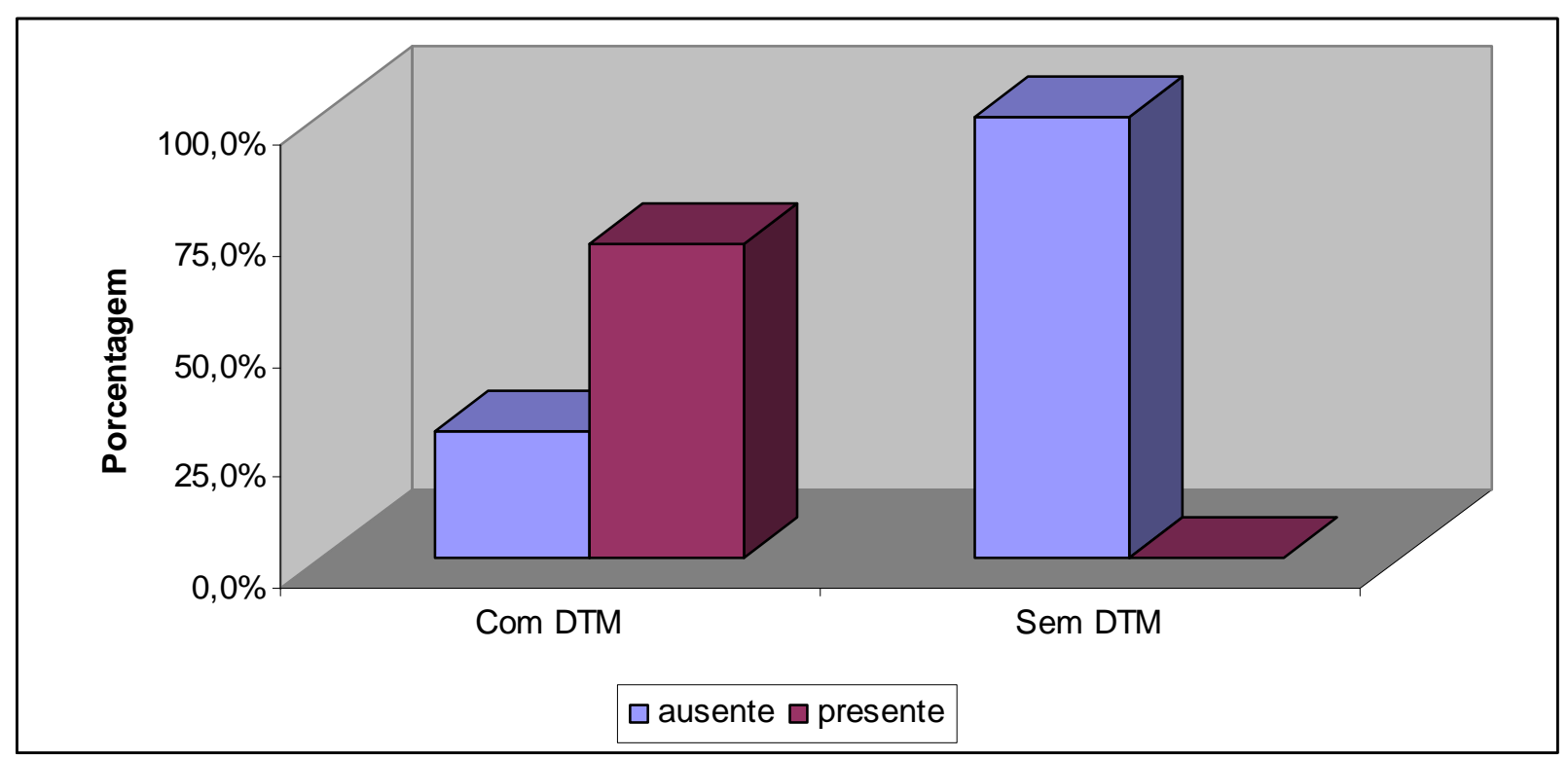

Gráfico 5.6 - Distribuição da ocorrência de Dor entre os pacientes, segundo Grupo

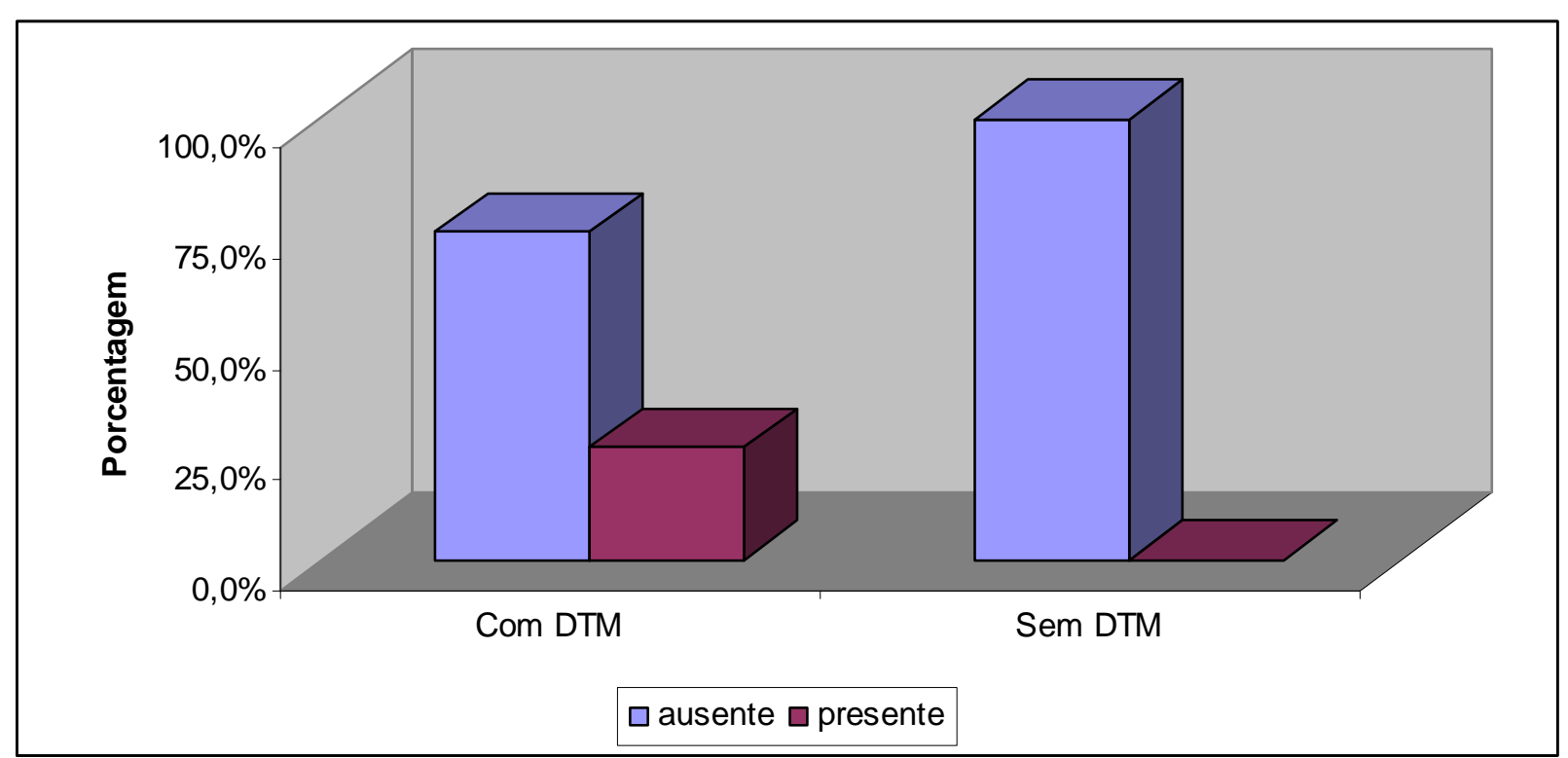

Gráfico 5.7 - Distribuição da ocorrência de Bruxismo entre os pacientes, segundo Grupo 


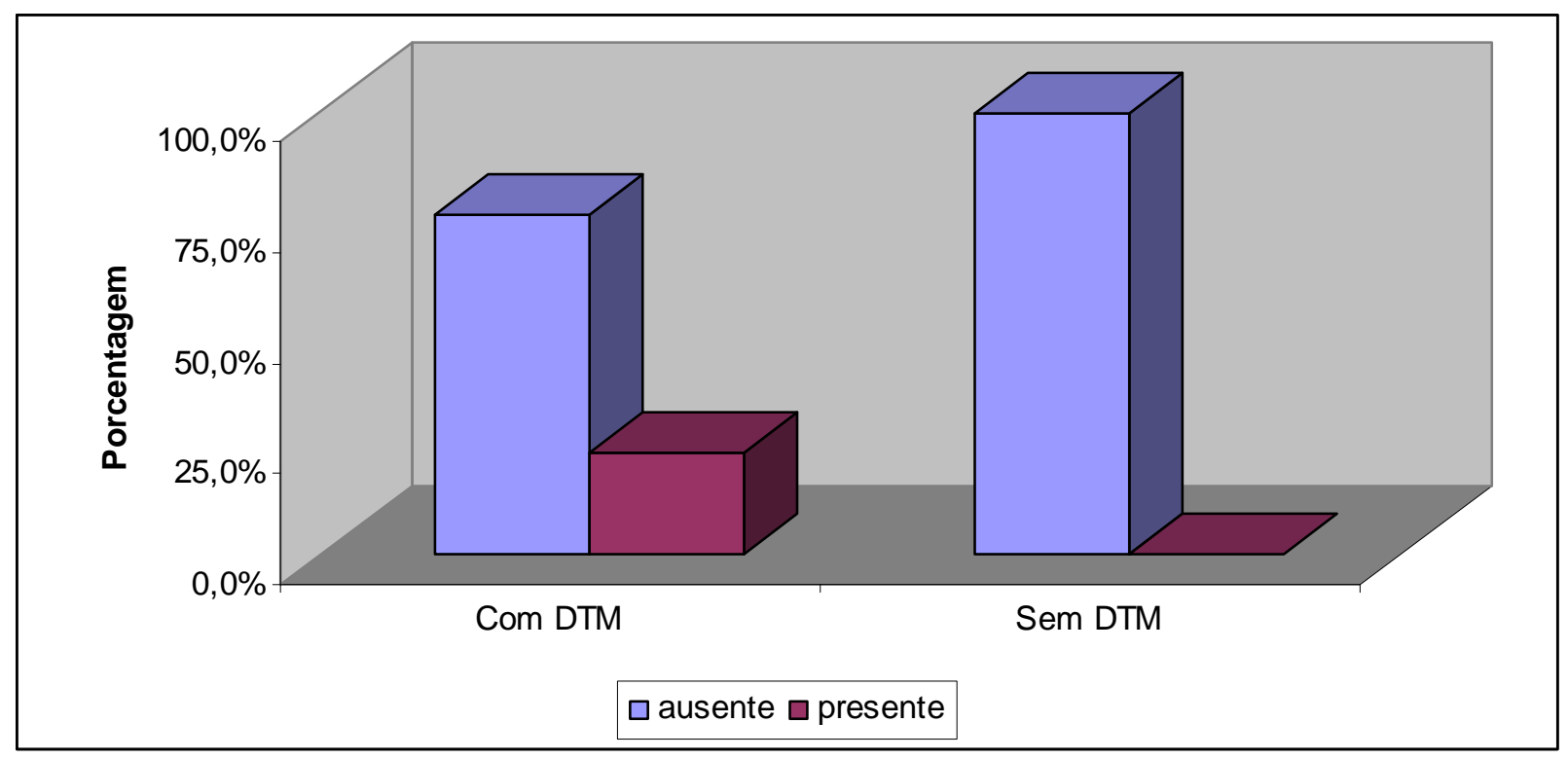

Gráfico 5.8 - Distribuição da ocorrência de Cefaléia entre os pacientes, segundo Grupo

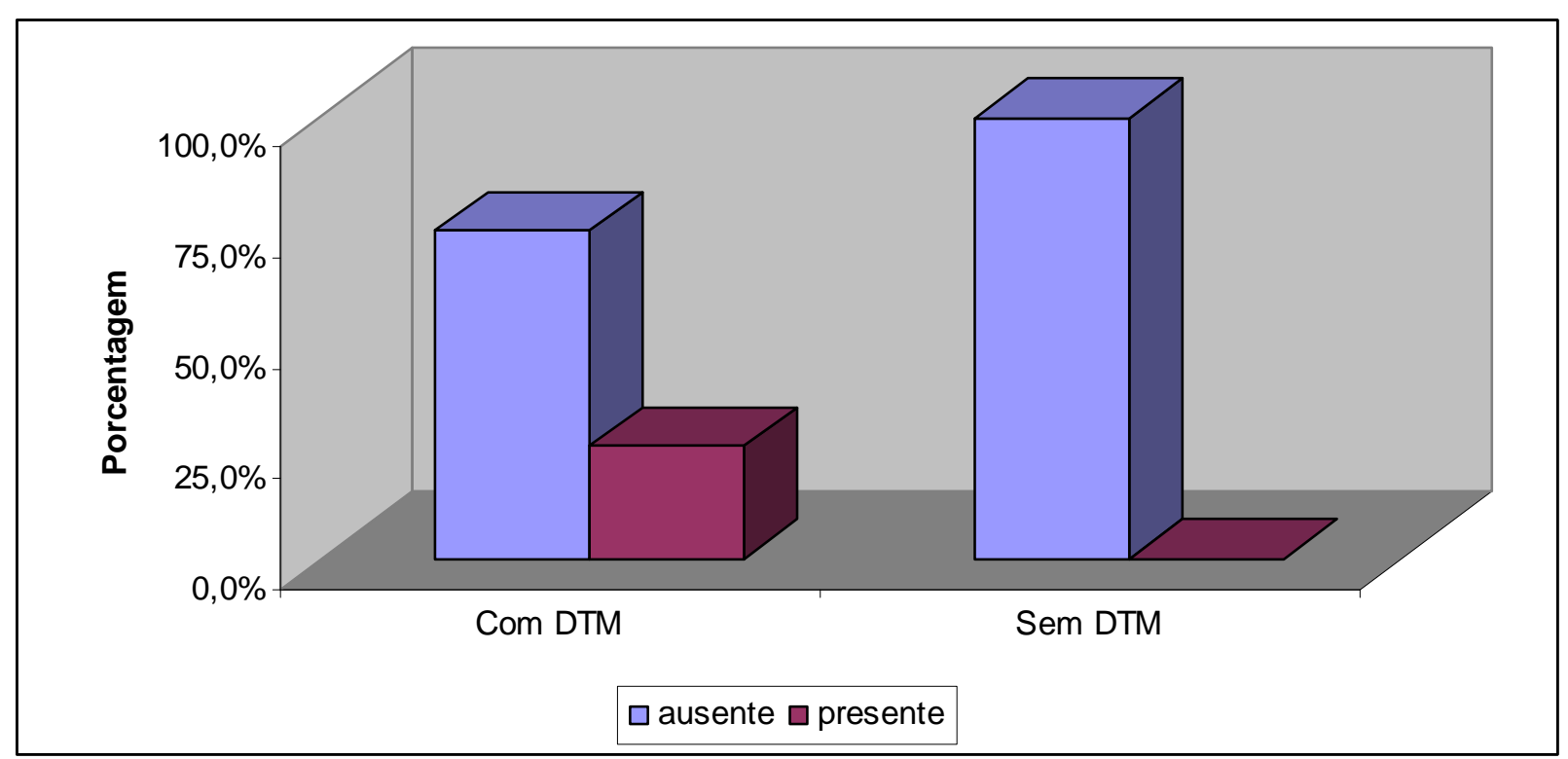

Gráfico 5.9 - Distribuição da ocorrência de Estalo entre os pacientes, segundo Grupo 


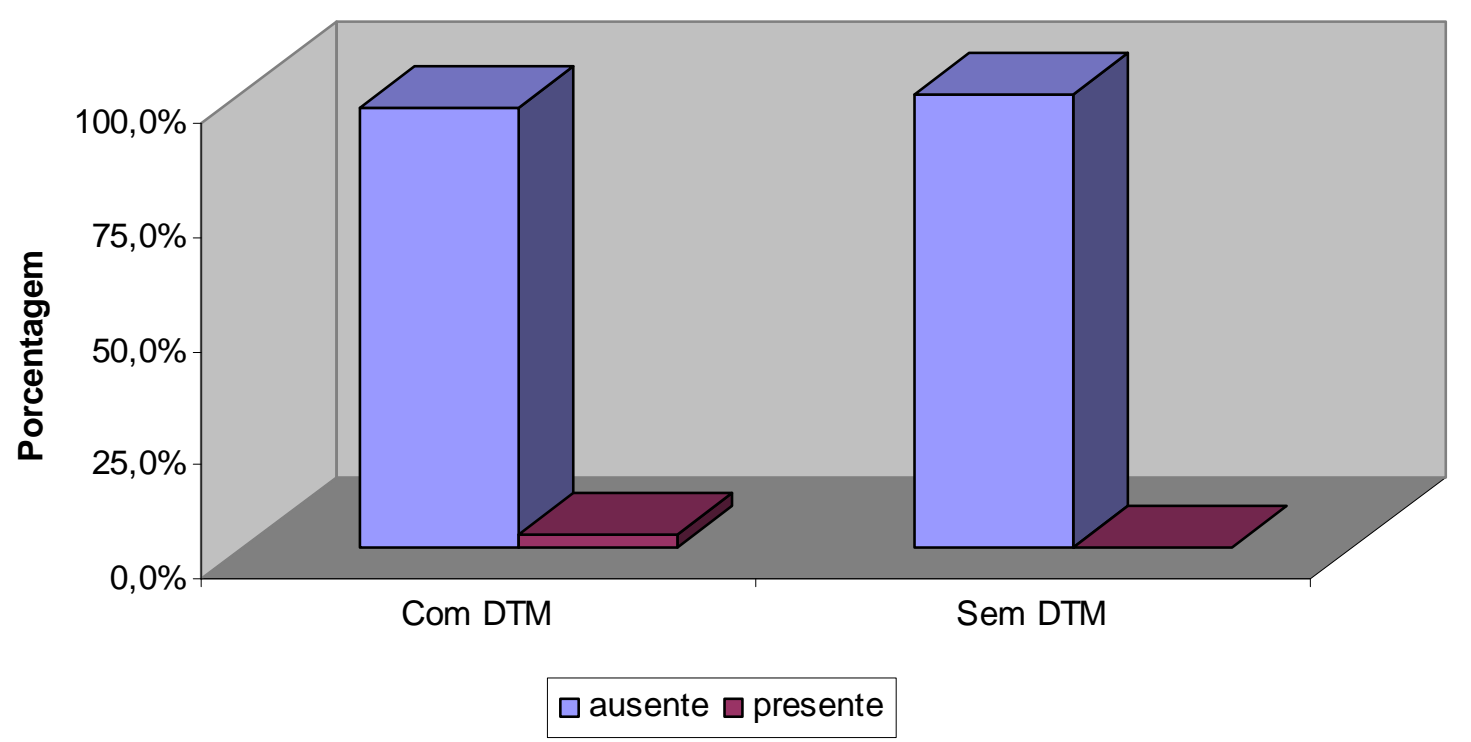

Gráfico 5.10 - Distribuição da ocorrência de Limitação da Abertura da Boca ao exame clínico, entre os pacientes, segundo Grupo

Tabela 5.5 - Distribuição da localização do Estalo entre os pacientes, segundo Grupo

\begin{tabular}{|l|l|l|l|}
\hline & Grupo & Total \\
\hline Estalo & Com DTM & Sem DTM & Com DTM \\
\hline bilateral & 11 & - & 11 \\
\hline & $31,4 \%$ & - & $22,0 \%$ \\
\hline lado direito & 6 & - & 6 \\
\hline & $17,1 \%$ & - & $12,0 \%$ \\
\hline lado esquerdo & 11 & - & 11 \\
\hline & $31,4 \%$ & - & $22,0 \%$ \\
\hline sem estalo & 7 & 15 & 22 \\
\hline & $20,0 \%$ & $100,0 \%$ & $44,0 \%$ \\
\hline Total & 35 & 15 & 50 \\
\hline & $100,0 \%$ & $100,0 \%$ & $100,0 \%$ \\
\hline
\end{tabular}




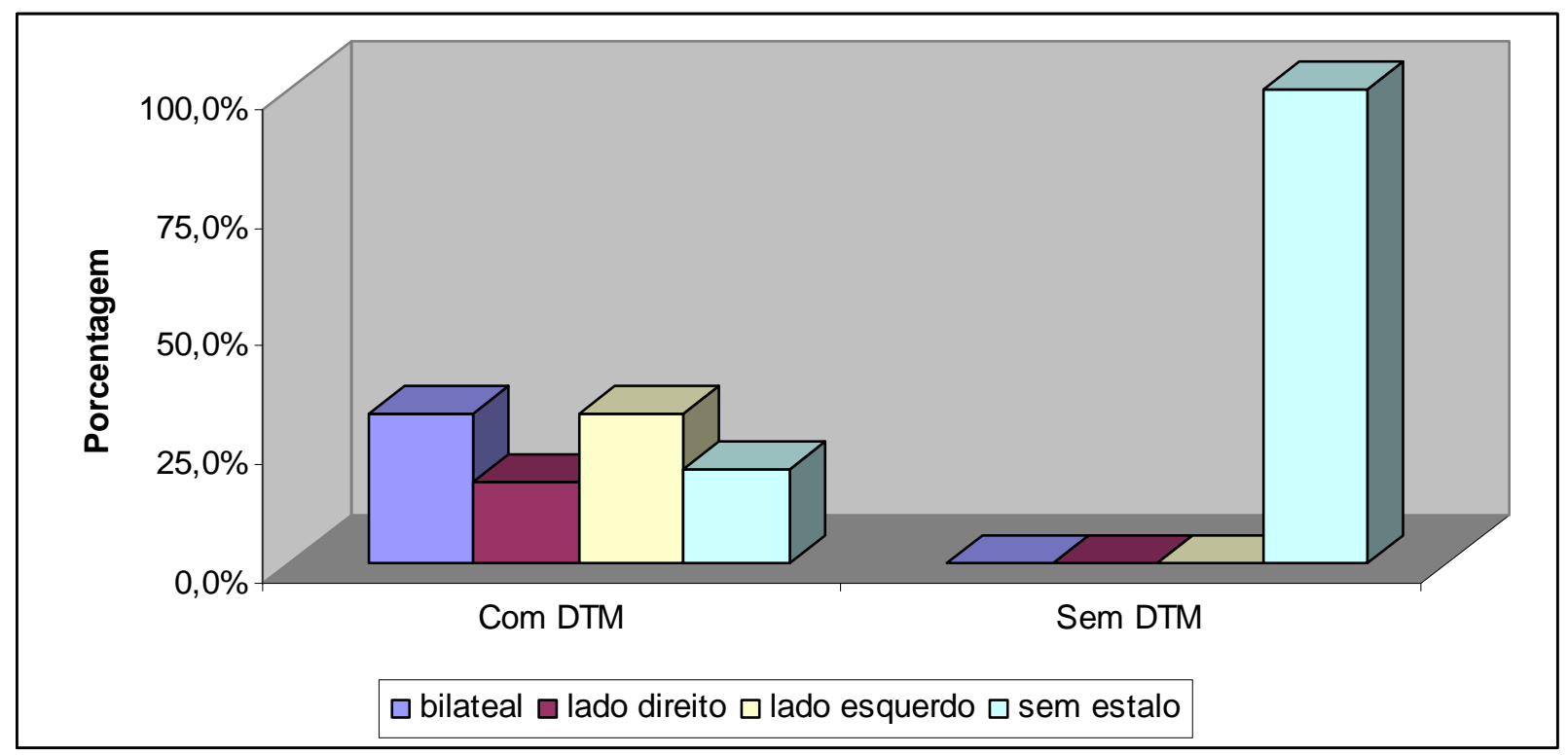

Gráfico 5.11 - Distribuição da localização do Estalo entre os pacientes, segundo Grupo

A ocorrência de Queixa $(p<0,001)$ e sintomatologia $(p<0,001)$ no grupo com DTM é estatisticamente maior quando comparado ao grupo sem DTM.

Tabela 5.6 - Distribuição do resultado do Teste do MPL dos pacientes, segundo Grupo

\begin{tabular}{|c|c|c|c|}
\hline & \multicolumn{2}{|l|}{ Grupo } & \multirow[t]{2}{*}{ Total } \\
\hline Teste do MPL & Com DTM & Sem DTM & \\
\hline \multirow[t]{2}{*}{ negativo } & 25 & 15 & 40 \\
\hline & $71,4 \%$ & $100,0 \%$ & $80,0 \%$ \\
\hline \multirow[t]{2}{*}{ positivo } & 10 & - & 10 \\
\hline & $28,6 \%$ & - & $20,0 \%$ \\
\hline \multirow[t]{2}{*}{ Total } & 35 & 15 & 50 \\
\hline & $100,0 \%$ & $100,0 \%$ & $100,0 \%$ \\
\hline
\end{tabular}




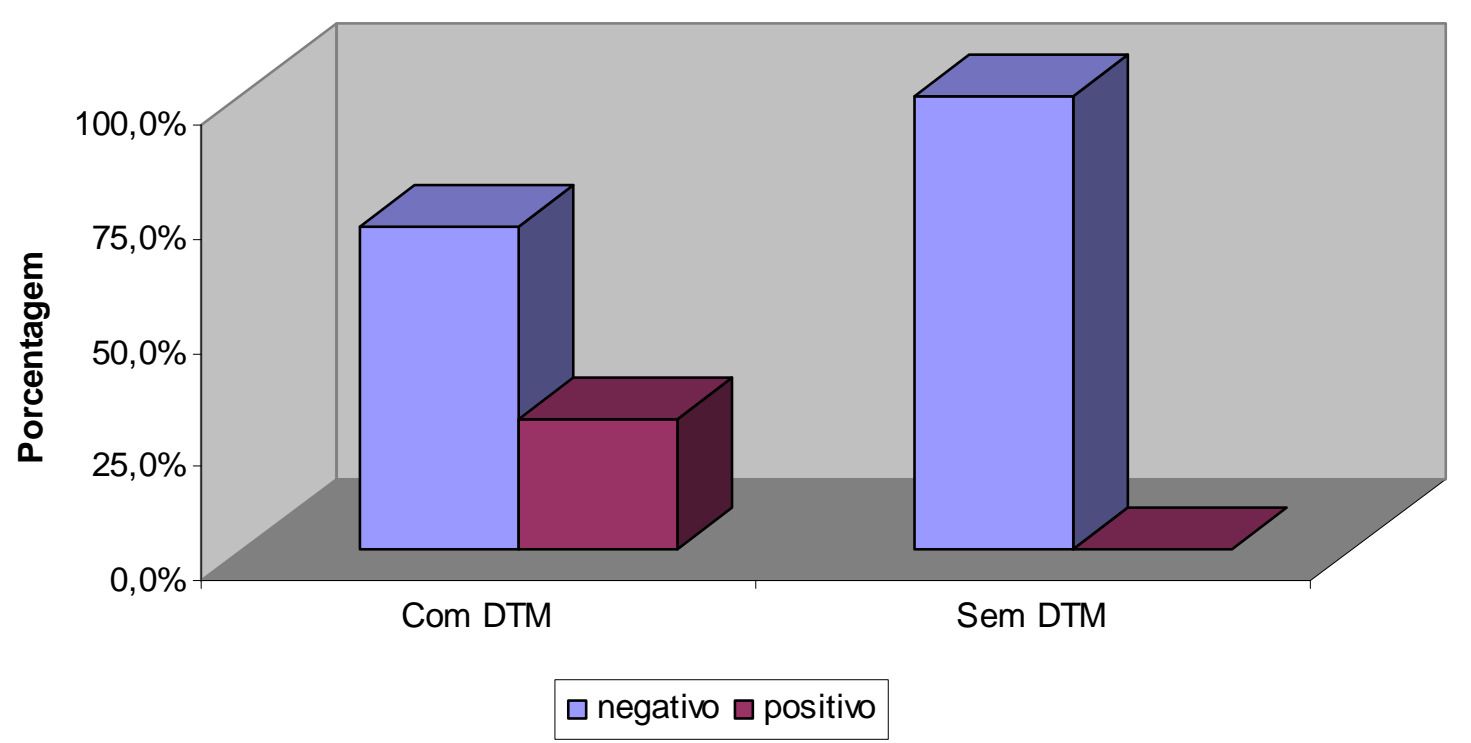

Gráfico 5.12 - Distribuição do resultado do Teste do MPL dos pacientes, segundo Grupo

O resultado é estatisticamente significante; o grupo com DTM apresentou uma ocorrência maior de resultados positivos para o Teste do MPL do que o grupo sem DTM $(p=0,022)$.

Algumas medidas-resumo da Abertura Máxima da Boca, segundo grupo com e sem DTM, estão apresentadas na tabela 5.7 e no gráfico 5.13 .

Tabela 5.7 - Medidas-resumo da Abertura da Boca $(\mathrm{mm})$ dos pacientes, segundo Grupo

\begin{tabular}{|l|l|l|l|}
\hline Medidas-resumo & Com DTM $(n=35)$ & Sem DTM $(n=15)$ & Total $(n=50)$ \\
\hline Média & 38,1 & 39,4 & 38,5 \\
\hline Mediana & 38,0 & 38,0 & 38,0 \\
\hline Mínimo & 25,0 & 35,0 & 25,0 \\
\hline Máximo & 52,0 & 47,0 & 52,0 \\
\hline Desvio-padrão & 5,8 & 3,9 & 5,3 \\
\hline
\end{tabular}




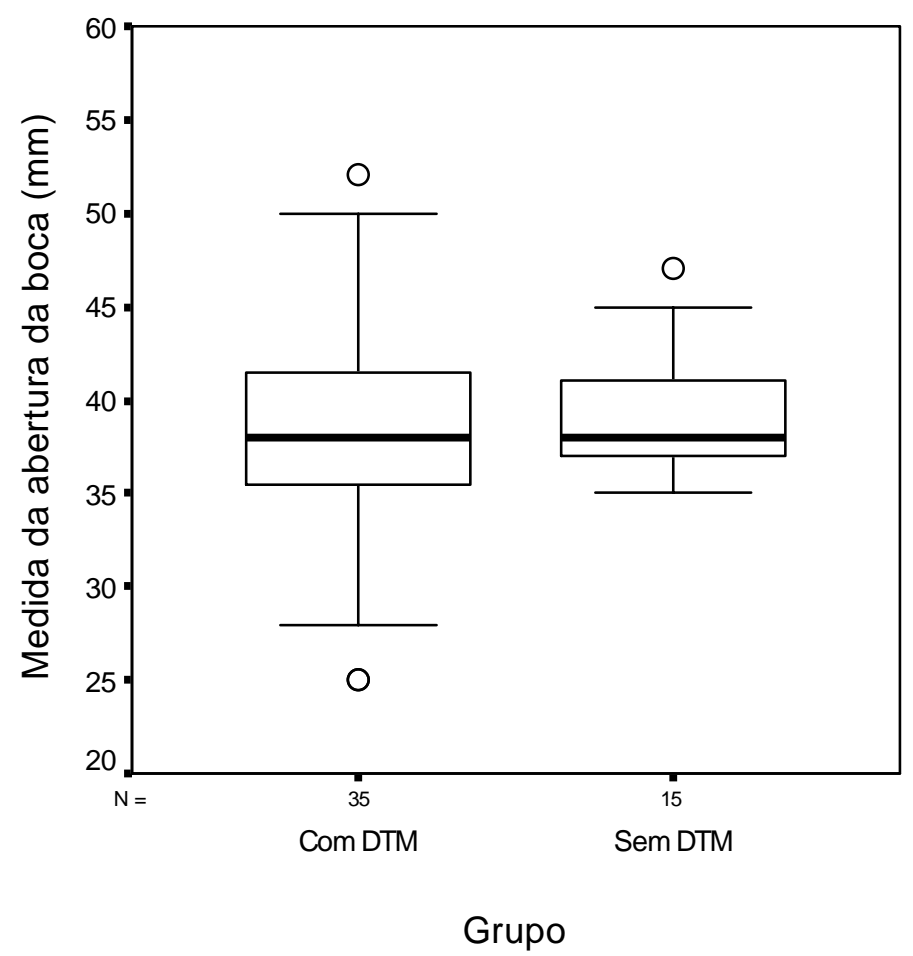

Gráfico 5.13 - Boxplot da Abertura da Boca dos pacientes, segundo Grupo

Tabela 5.8 - Distribuição da Medida da Abertura Máxima da Boca dos pacientes, segundo Grupo

\begin{tabular}{|l|l|l|l|}
\hline Medida da abertura da boca $(\mathrm{mm})$ & Grupo & \multicolumn{1}{l}{ Total } \\
\hline Anormal & 21 & 8 & 29 \\
\hline Normal & $60,0 \%$ & $53,3 \%$ & $58,0 \%$ \\
\hline Total & 14 & 7 & 21 \\
\hline & $40,0 \%$ & $46,7 \%$ & $42,0 \%$ \\
\hline & 35 & 15 & 50 \\
\hline
\end{tabular}




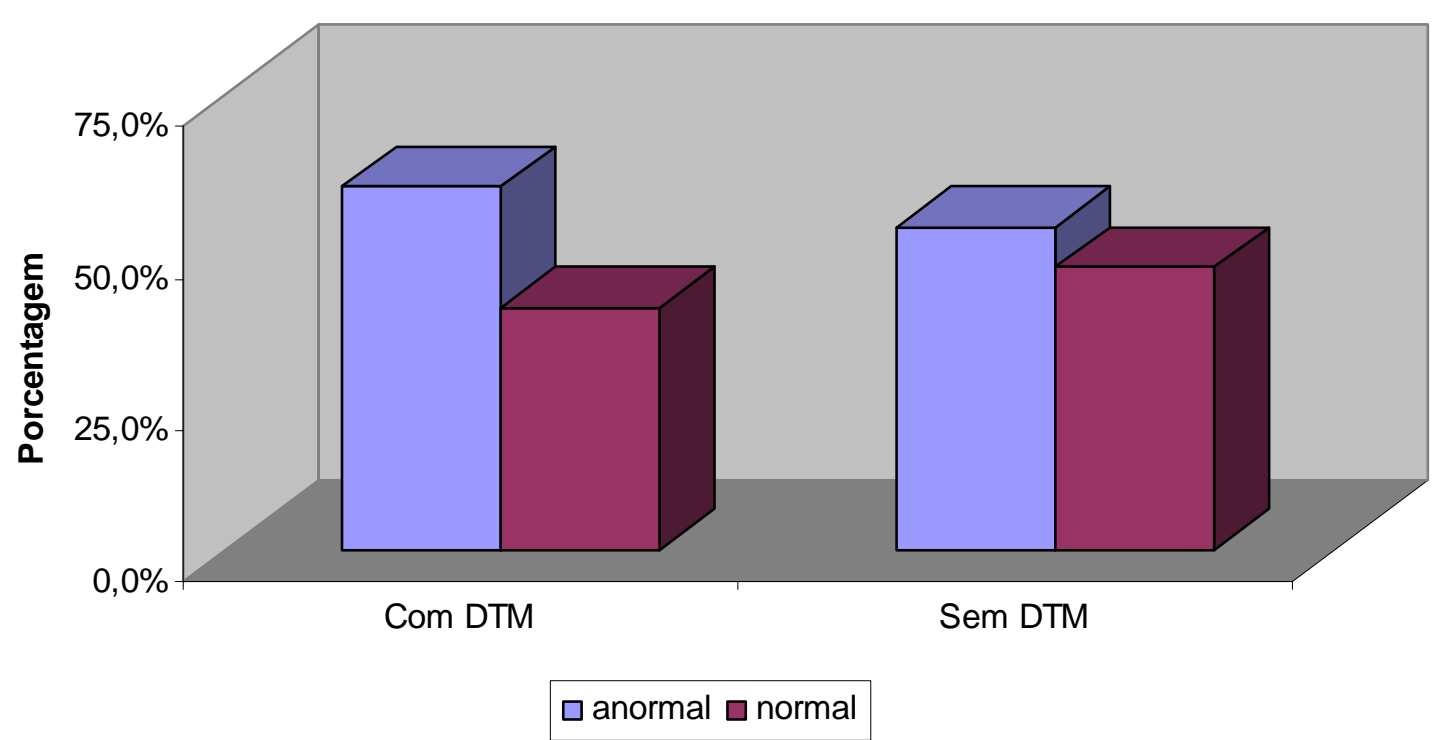

Gráfico 5.14 - Distribuição da Medida da Abertura da Boca dos pacientes, segundo Grupo 
As informações das medidas do Músculo Pterigóideo Lateral (MPL) nos cortes axial, T1 sagital com boca fechada e T2 sagital com boca aberta, para os grupos, estão resumidas nas tabelas 5.9 a 5.11 e nos gráficos 5.15 a 5.17 .

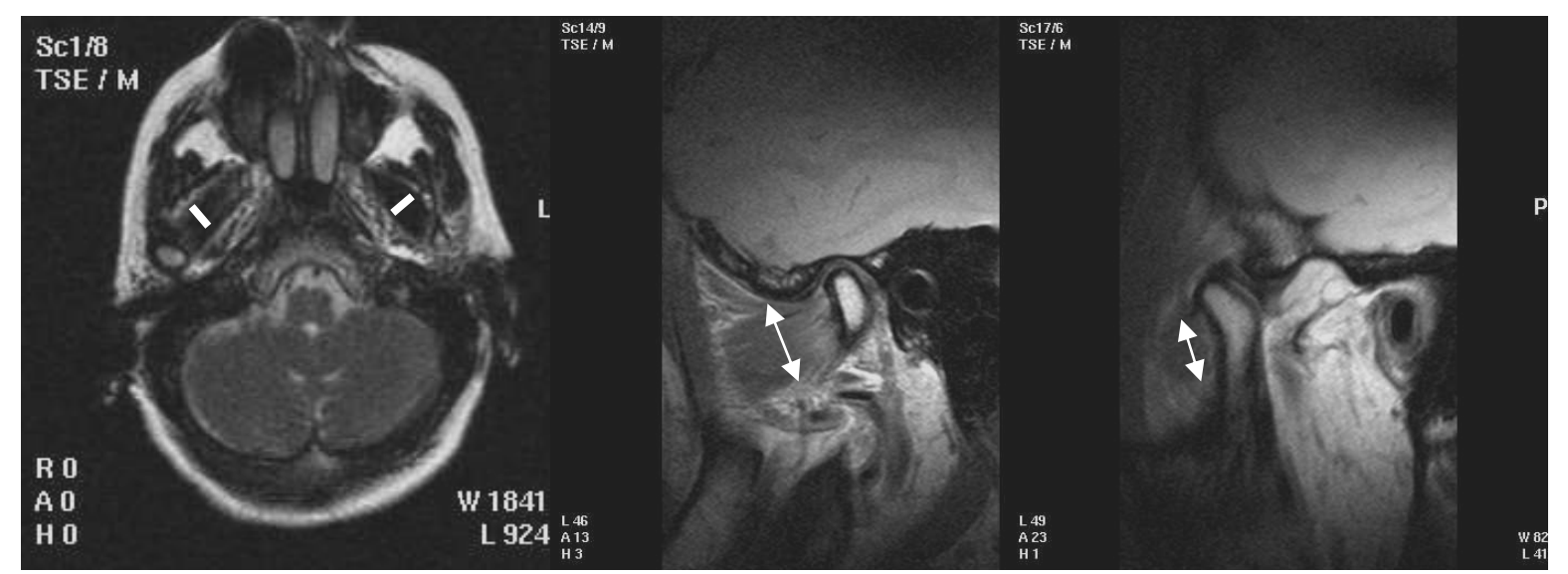

Figura 5.1 - Imagens de RM do MPL nos cortes axial, sagital T1 boca fechada e sagital T2 boca aberta

Tabela 5.9 - Medidas-resumo da medida AXIAL do MPL (mm), segundo Grupo e Lado

\begin{tabular}{|l|l|l|l|}
\hline Grupo & Medidas-resumo & Lado direito & Lado esquerdo \\
\hline Com DTM $(\mathrm{n}=35)$ & Média & 16,1 & 15,6 \\
\hline & Mediana & 15,8 & 15,3 \\
\hline & Mínimo & 9,3 & 9,5 \\
\hline & Máximo & 24,8 & 22,7 \\
\hline \multirow{2}{*}{ Sem DTM $(\mathrm{n}=15)$} & Desvio-padrão & 3,3 & 3,1 \\
\hline & Média & 14,0 & 15,0 \\
\hline & Mediana & 13,9 & 15,6 \\
\hline & Mínimo & 11,3 & 7,9 \\
\hline & Máximo & 18,0 & 19,0 \\
\hline \multirow{2}{*}{ Total $(\mathrm{n}=50)$} & Desvio-padrão & 2,1 & 3,0 \\
\hline & Média & 15,4 & 15,5 \\
\hline & Mediana & 15,2 & 15,4 \\
\hline & Mínimo & 9,3 & 7,9 \\
\hline & Máximo & 24,8 & 22,7 \\
\hline & Desvio-padrão & 3,1 & 3,1 \\
\hline
\end{tabular}




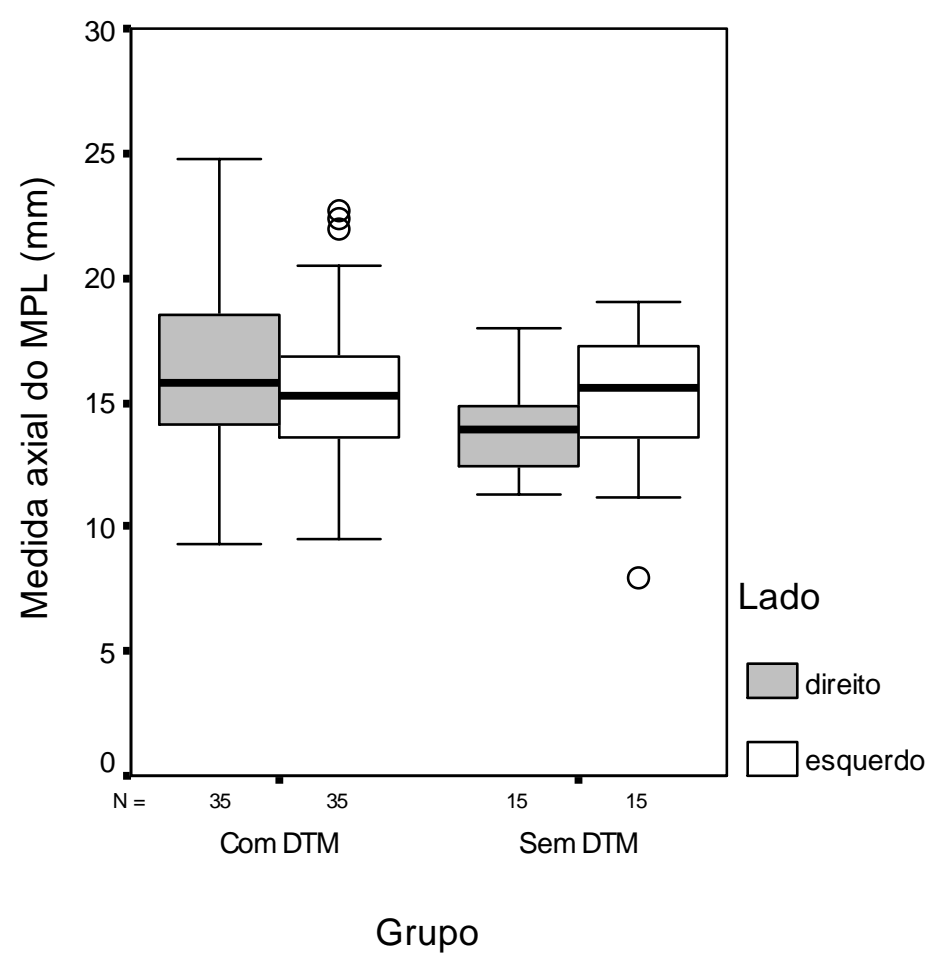

Gráfico 5.15 - Boxplot da medida AXIAL do MPL (mm), segundo Grupo e Lado

Tabela 5.10 - Medidas-resumo da medida T1 sagital com boca fechada do MPL (mm), segundo Grupo e Lado

\begin{tabular}{|l|l|l|l|}
\hline Grupo & Medidas-resumo & Lado direito & Lado esquerdo \\
\hline Com DTM $(\mathrm{n}=35)$ & Média & 17,6 & 18,8 \\
\cline { 2 - 4 } & Mediana & 15,6 & 17,1 \\
\hline & Mínimo & 7,6 & 9,9 \\
\hline & Máximo & 31,9 & 31,8 \\
\hline \multirow{2}{*}{ Sem DTM $(\mathrm{n}=15)$} & Desvio-padrão & 5,7 & 5,6 \\
& Média & 15,5 & 15,3 \\
\hline & Mediana & 16,7 & 14,6 \\
\hline & Mínimo & 5,8 & 6,1 \\
\hline & Máximo & 25,7 & 26,0 \\
\hline \multirow{2}{*}{ Total $(\mathrm{n}=50)$} & Desvio-padrão & 6,1 & 6,3 \\
\hline & Média & 17,0 & 17,7 \\
\hline & Mediana & 15,9 & 16,6 \\
\hline & Mínimo & 5,8 & 6,1 \\
\hline & Máximo & 31,9 & 31,8 \\
\hline & Desvio-padrão & 5,9 & 6,0 \\
\hline
\end{tabular}




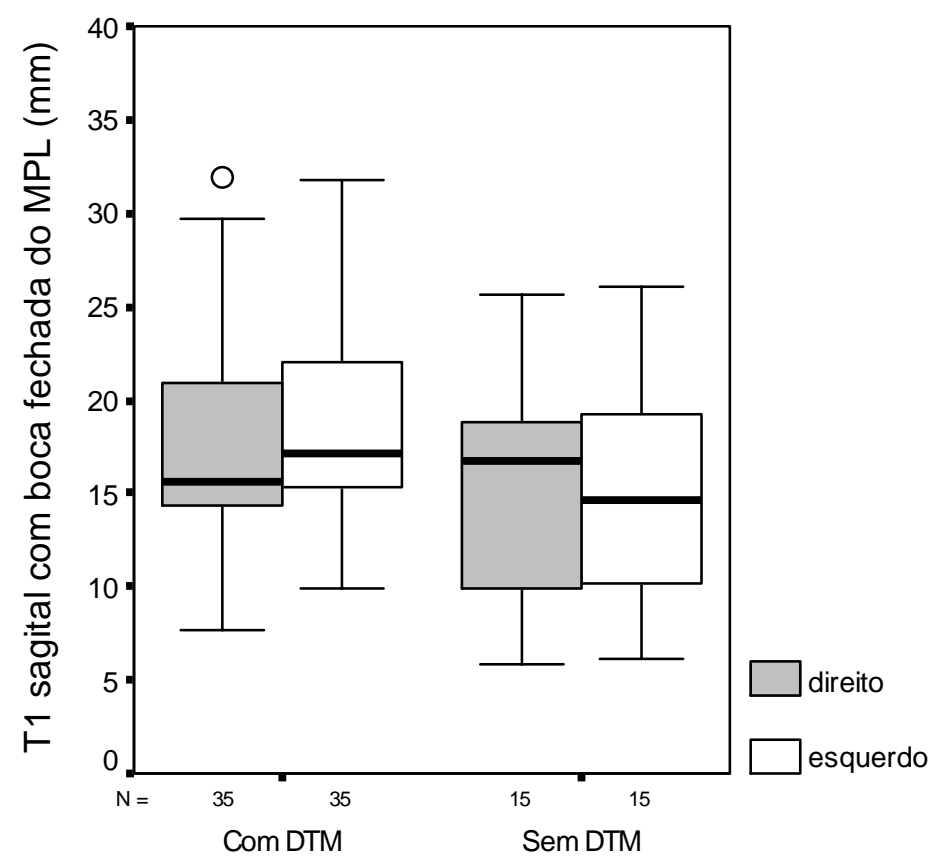

Grupo

Gráfico 5.16 - Boxplot da medida T1 sagital com boca fechada do MPL (mm), segundo Grupo e Lado

Tabela 5.11 - Medidas-resumo da medida T2 sagital com boca aberta do MPL (mm), segundo Grupo e Lado

\begin{tabular}{|l|l|l|l|}
\hline Grupo & Medidas-resumo & Lado direito & Lado esquerdo \\
\hline Com DTM $(\mathrm{n}=35)$ & Média & 12,9 & 13,0 \\
& Mediana & 12,9 & 13,1 \\
\hline & Mínimo & 3,5 & 5,0 \\
\hline & Máximo & 19,3 & 19,5 \\
\hline & Desvio-padrão & 3,1 & 3,4 \\
\hline Sem DTM $(\mathrm{n}=15)$ & Média & 11,1 & 11,3 \\
\hline & Mediana & 8,9 & 9,1 \\
\hline & Mínimo & 6,0 & 6,4 \\
\hline & Máximo & 24,0 & 25,0 \\
\hline & Desvio-padrão & 5,0 & 5,2 \\
\hline Total $(\mathrm{n}=50)$ & Média & 12,4 & 12,5 \\
\hline & Mediana & 12,4 & 11,8 \\
\hline & Mínimo & 3,5 & 5,0 \\
\hline & Máximo & 24,0 & 25,0 \\
\hline & Desvio-padrão & 3,8 & 4,1 \\
\hline
\end{tabular}




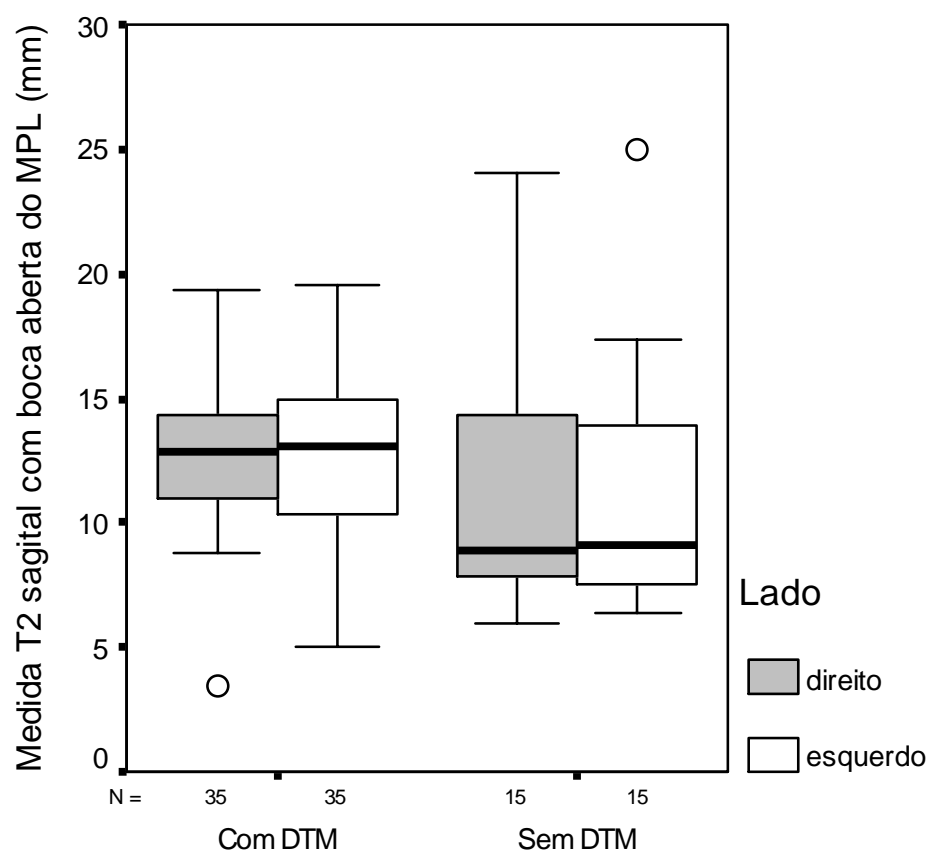

Grupo

Gráfico 5.17 - Boxplot da medida T2 sagital com boca aberta do MPL (mm), segundo Grupo e Lado 
As informações do DDA (deslocamento anterior do disco articular) e Mobilidade da Cabeça da Mandíbula, bem como a Morfologia do MPL, estão descritas nas tabelas 5.12 a 5.14 e nos gráficos 5.18 a 5.20 .

Tabela 5.12 - Distribuição do DDA dos pacientes, segundo Grupo e Lado

\begin{tabular}{|c|c|c|c|c|c|}
\hline \multicolumn{3}{|c|}{ Lado direito } & \multicolumn{3}{|c|}{ Lado esquerdo } \\
\hline Com DTM & Freqüência & Porcentagem & Com DTM & Freqüência & Porcentagem \\
\hline $\operatorname{DDAR}^{\mathrm{a}}$ & 3 & $8,6 \%$ & $\operatorname{DDAR}^{\mathrm{a}}$ & 5 & $14,3 \%$ \\
\hline $\mathrm{DDAsR}^{\mathrm{b}}$ & 3 & $8,6 \%$ & $\mathrm{DDAsR}^{\mathrm{b}}$ & 3 & $8,6 \%$ \\
\hline Normal & 29 & $82,9 \%$ & Normal & 27 & $77,1 \%$ \\
\hline Total & 35 & $100,0 \%$ & Total & 35 & $100,0 \%$ \\
\hline Sem DTM & Freqüência & Porcentagem & Sem DTM & Freqüência & Porcentagem \\
\hline $\mathrm{DDAR}^{\mathrm{a}}$ & - & - & $\mathrm{DDAR}^{\mathrm{a}}$ & - & - \\
\hline $\mathrm{DDAsR}^{\mathrm{b}}$ & - & - & $\mathrm{DDAsR}^{\mathrm{b}}$ & - & - \\
\hline Normal & 15 & $100,0 \%$ & Normal & 15 & $100,0 \%$ \\
\hline Total & 15 & $100,0 \%$ & Total & 15 & $100,0 \%$ \\
\hline
\end{tabular}

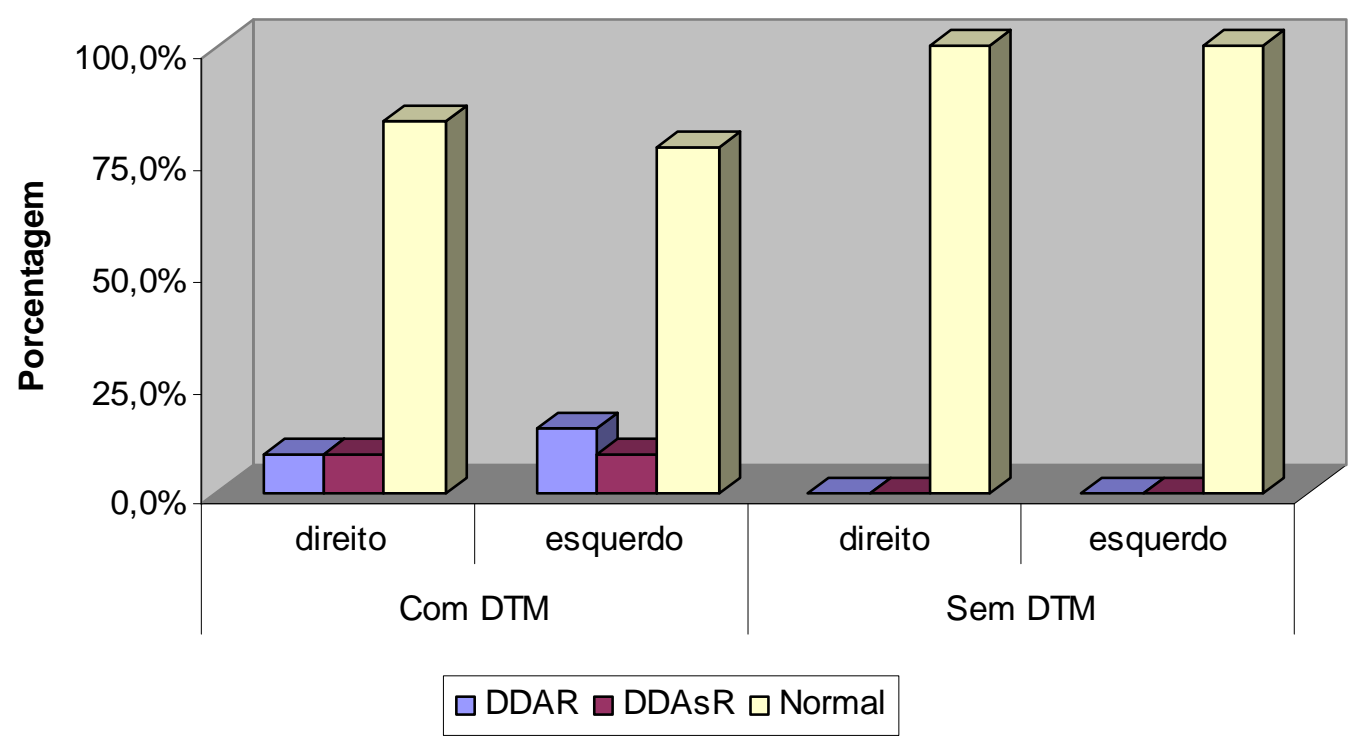

Gráfico 5.18 - Distribuição do DDA dos pacientes, segundo Grupo e Lado 
Tabela 5.13 - Distribuição da Mobilidade da Cabeça da Mandíbula dos pacientes, segundo Grupo e Lado

\begin{tabular}{l|l|l|l|l|l|}
\hline Lado direito & \multicolumn{5}{c}{ Lado esquerdo } \\
\hline Com DTM & Freqüência & Porcentagem & Com DTM & Freqüência & Porcentagem \\
\hline Hipermobilidade & 2 & $5,7 \%$ & Hipermobilidade & 6 & $17,1 \%$ \\
\hline Hipomobilidade & 5 & $14,3 \%$ & Hipomobilidade & 4 & $11,4 \%$ \\
\hline Normal & 28 & $80,0 \%$ & Normal & 25 & $71,4 \%$ \\
\hline Total & 35 & $100,0 \%$ & Total & 35 & $100,0 \%$ \\
\hline Sem DTM & Freqüência & Porcentagem & Sem DTM & Freqüência & Porcentagem \\
\hline Hipermobilidade & 1 & $6,7 \%$ & Hipermobilidade & - & - \\
\hline Hipomobilidade & - & - & Hipomobilidade & - & - \\
\hline Normal & 14 & $93,3 \%$ & Normal & 15 & $100,0 \%$ \\
\hline Total & 15 & $100,0 \%$ & Total & 15 & $100,0 \%$ \\
\hline
\end{tabular}

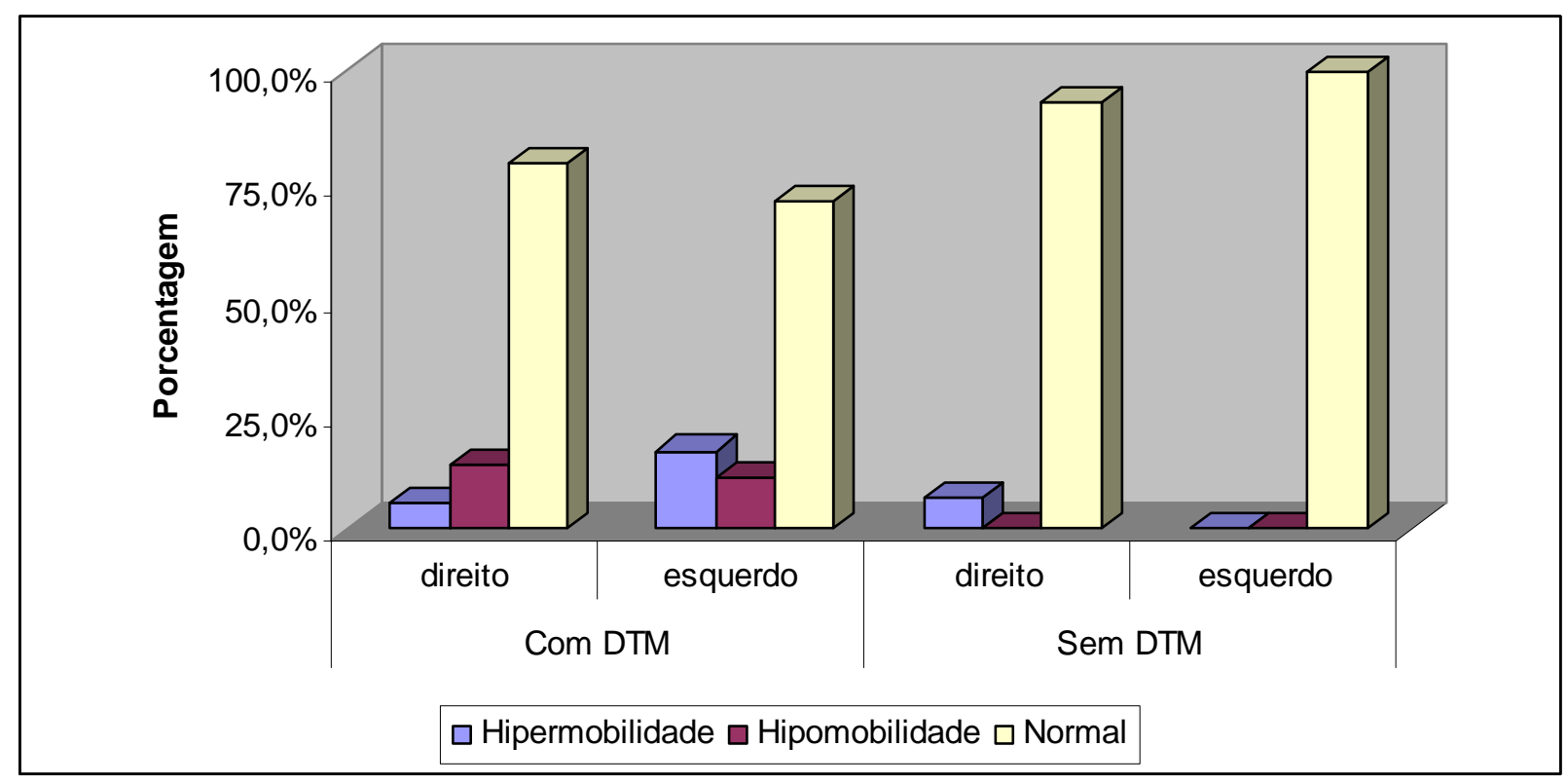

Gráfico 5.19 - Distribuição da Mobilidade da Cabeça da Mandíbula dos pacientes, segundo Grupo e Lado 
Tabela 5.14 - Distribuição da Morfologia do MPL dos pacientes, segundo Grupo e Lado

Lado direito

\begin{tabular}{|l|l|l|l|l|l|}
\hline Com DTM & Freqüência & Porcentagem & Com DTM & Freqüência & Porcentagem \\
\hline Atrofia & 1 & $2,9 \%$ & Atrofia & 1 & $2,9 \%$ \\
\hline Contratura & 1 & $2,9 \%$ & Contratura & 1 & $2,9 \%$ \\
\hline Flacidez & 1 & $2,9 \%$ & Flacidez & 1 & $2,9 \%$ \\
\hline Hipertrofia & - & - & Hipertrofia & 1 & $2,9 \%$ \\
\hline Normal & 32 & $91,4 \%$ & Normal & 31 & $88,6 \%$ \\
\hline Total & 35 & $100,0 \%$ & Total & 35 & $100,0 \%$ \\
\hline
\end{tabular}

\begin{tabular}{|l|l|l|l|l|l|}
\hline Sem DTM & Freqüência & Porcentagem & Sem DTM & Freqüência & Porcentagem \\
\hline Atrofia & - & - & Atrofia & - & - \\
\hline Contratura & - & - & Contratura & - & - \\
\hline Flacidez & - & - & Flacidez & - & - \\
\hline Hipertrofia & - & - & Hipertrofia & - & - \\
\hline Normal & 15 & $100,0 \%$ & Normal & 15 & $100,0 \%$ \\
\hline Total & 15 & $100,0 \%$ & Total & 15 & $100,0 \%$ \\
\hline
\end{tabular}

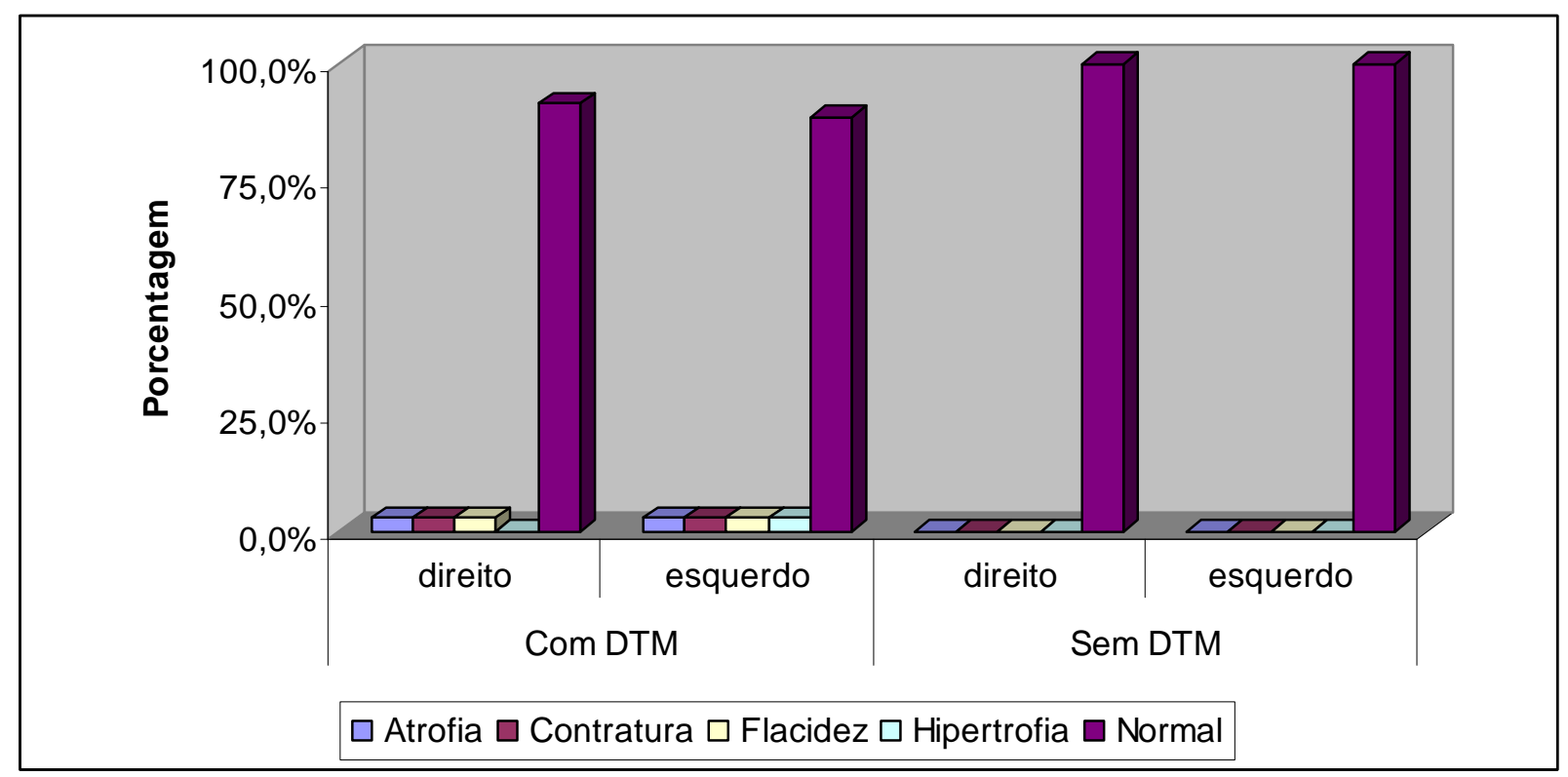

Gráfico 5.20 - Distribuição da Morfologia do MPL dos pacientes, segundo Grupo e Lado 
O estudo descritivo da associação entre as informações do DDA, Mobilidade da Cabeça da Mandíbula e Morfologia do MPL, em ambos os grupos, considerando também as informações dos lados, estão descritas nas tabelas 5.15 a 5.17 e nos gráfico 5.21 a 5.23 .

Tabela 5.15 - Distribuição do DDA dos pacientes, segundo Grupo

\begin{tabular}{|c|c|c|c|}
\hline & \multicolumn{2}{|l|}{ Grupo } & \multirow[t]{2}{*}{ Total } \\
\hline Deslocamento do disco & Com DTM & Sem DTM & \\
\hline \multirow{2}{*}{ DDAR $^{\mathrm{a}}$ em ambos os lados } & 3 & - & 3 \\
\hline & $8,6 \%$ & - & $6,0 \%$ \\
\hline \multirow[t]{2}{*}{$D_{D A s} R^{b}$ no direito e DDAR ${ }^{a}$ no esquerdo } & 1 & - & 1 \\
\hline & $2,9 \%$ & - & $2,0 \%$ \\
\hline \multirow[t]{2}{*}{ DDAsR $^{\mathrm{b}}$ em ambos os lados } & 2 & - & 2 \\
\hline & $5,7 \%$ & - & $4,0 \%$ \\
\hline \multirow[t]{2}{*}{ Normal no direito e DDAR ${ }^{\mathrm{a}}$ no esquerdo } & 1 & - & 1 \\
\hline & $2,9 \%$ & - & $2,0 \%$ \\
\hline \multirow[t]{2}{*}{ Normal no direito e DDAsR ${ }^{\mathrm{b}}$ no esquerdo } & 1 & - & 1 \\
\hline & $2,9 \%$ & - & $2,0 \%$ \\
\hline \multirow[t]{2}{*}{ Normal em ambos os lados } & 27 & 15 & 42 \\
\hline & $77,1 \%$ & $100,0 \%$ & $84,0 \%$ \\
\hline \multirow[t]{2}{*}{ Total } & 35 & 15 & 50 \\
\hline & $100,0 \%$ & $100,0 \%$ & $100,0 \%$ \\
\hline
\end{tabular}




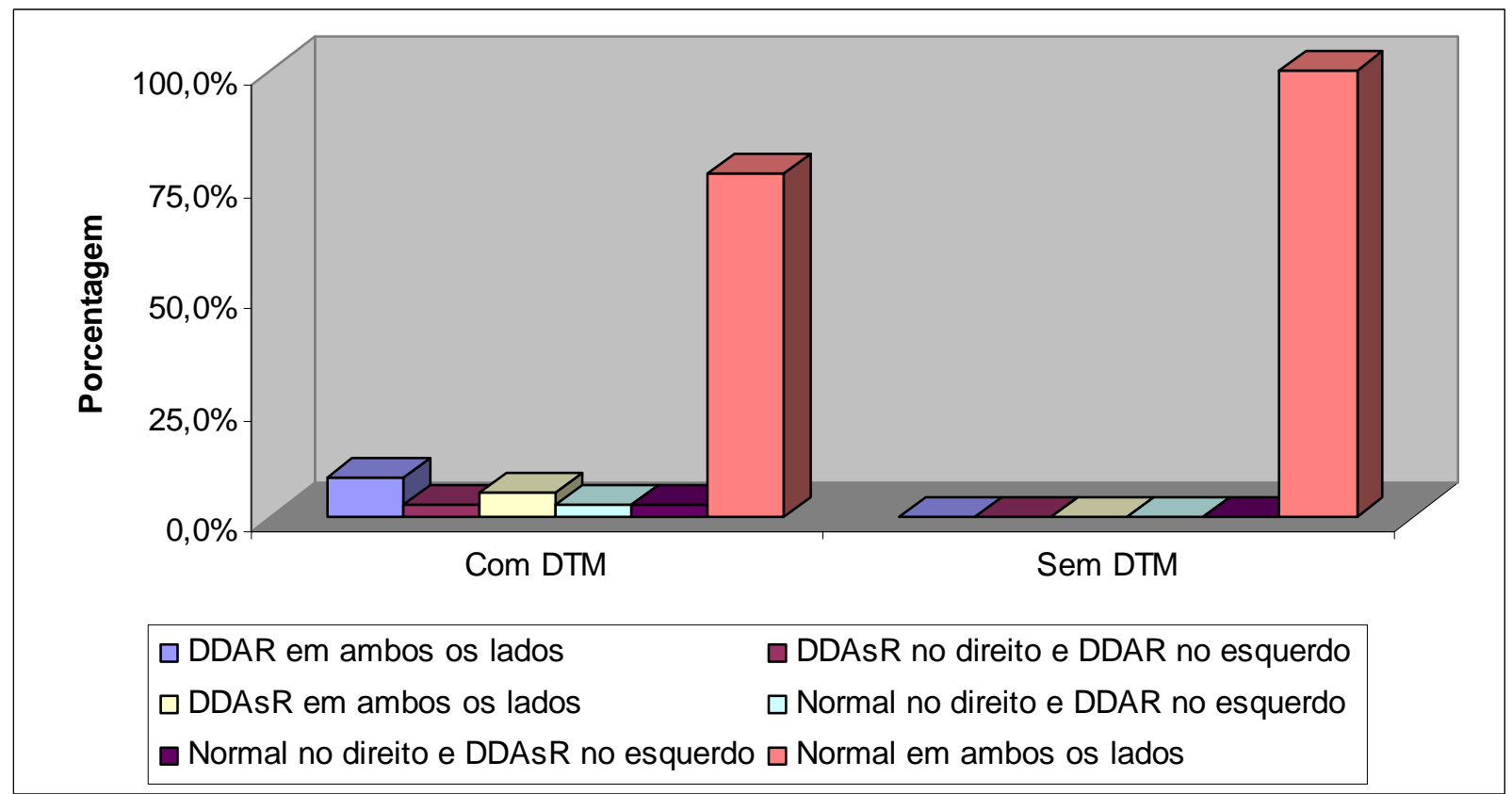

Gráfico 5.21 - Distribuição do DDA dos pacientes, segundo Grupo

Tabela 5.16 - Distribuição da Mobilidade da Cabeça da Mandíbula dos pacientes, segundo Grupo

\begin{tabular}{|c|c|c|c|}
\hline \multirow[b]{2}{*}{ Mobilidade } & \multicolumn{2}{|l|}{ Grupo } & \multirow[t]{2}{*}{ Total } \\
\hline & Com DTM & Sem DTM & \\
\hline \multirow[t]{2}{*}{ Hipermobilidade em ambos os lados } & 2 & - & 2 \\
\hline & $5,7 \%$ & - & $4,0 \%$ \\
\hline \multirow[t]{2}{*}{ Hipermobilidade no direito e Normal no esquerdo } & - & 1 & 1 \\
\hline & - & $6,7 \%$ & $2,0 \%$ \\
\hline \multirow[t]{2}{*}{ Hipomobilidade em ambos os lados } & 4 & - & 4 \\
\hline & $11,4 \%$ & - & $8,0 \%$ \\
\hline \multirow[t]{2}{*}{ Hipomobilidade no direito e Normal no esquerdo } & 1 & - & 1 \\
\hline & $2,9 \%$ & - & $2,0 \%$ \\
\hline \multirow[t]{2}{*}{ Normal no direito e Hipermobilidade no esquerdo } & 4 & - & 4 \\
\hline & $11,4 \%$ & - & $8,0 \%$ \\
\hline \multirow[t]{2}{*}{ Normal em ambos os lados } & 24 & 14 & 38 \\
\hline & $68,6 \%$ & $93,3 \%$ & $76,0 \%$ \\
\hline \multirow[t]{2}{*}{ Total } & 35 & 15 & 50 \\
\hline & $100,0 \%$ & $100,0 \%$ & $100,0 \%$ \\
\hline
\end{tabular}




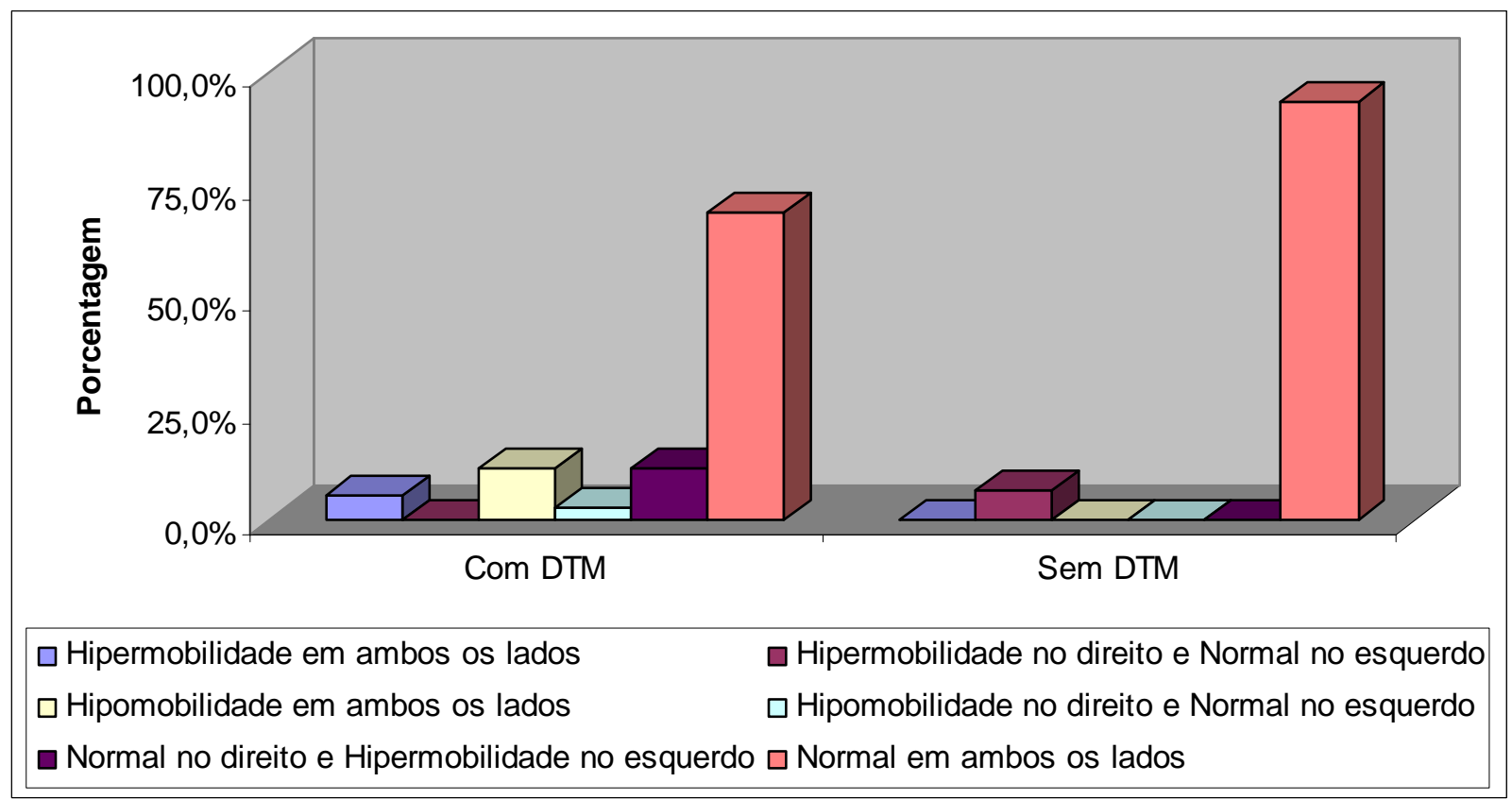

Gráfico 5.22 - Distribuição da Mobilidade da Cabeça da Mandíbula dos pacientes, segundo Grupo

Tabela 5.17 - Distribuição da Morfologia do MPL dos pacientes, segundo Grupo

\begin{tabular}{|l|l|l|l|}
\hline & Grupo & \multicolumn{2}{l|}{ Total } \\
\hline Aparência do MPL & Com DTM & Sem DTM & \\
\hline Atrofia no direito e Hipertrofia no esquerdo & 1 & - & 1 \\
\hline Contratura em ambos os lados & $2,9 \%$ & - & $2,0 \%$ \\
\hline Flacidez em ambos os lados & 1 & - & 1 \\
\hline Normal no direito e Atrofia no esquerdo & $2,9 \%$ & - & $2,0 \%$ \\
\hline & 1 & - & 1 \\
\hline Normal em ambos os lados & $2,9 \%$ & - & $2,0 \%$ \\
\hline Total & $2,9 \%$ & - & 1 \\
\hline & 31 & 15 & $2,0 \%$ \\
\hline & $88,6 \%$ & $100,0 \%$ & 96 \\
\hline & 35 & 15 & 50 \\
\hline
\end{tabular}




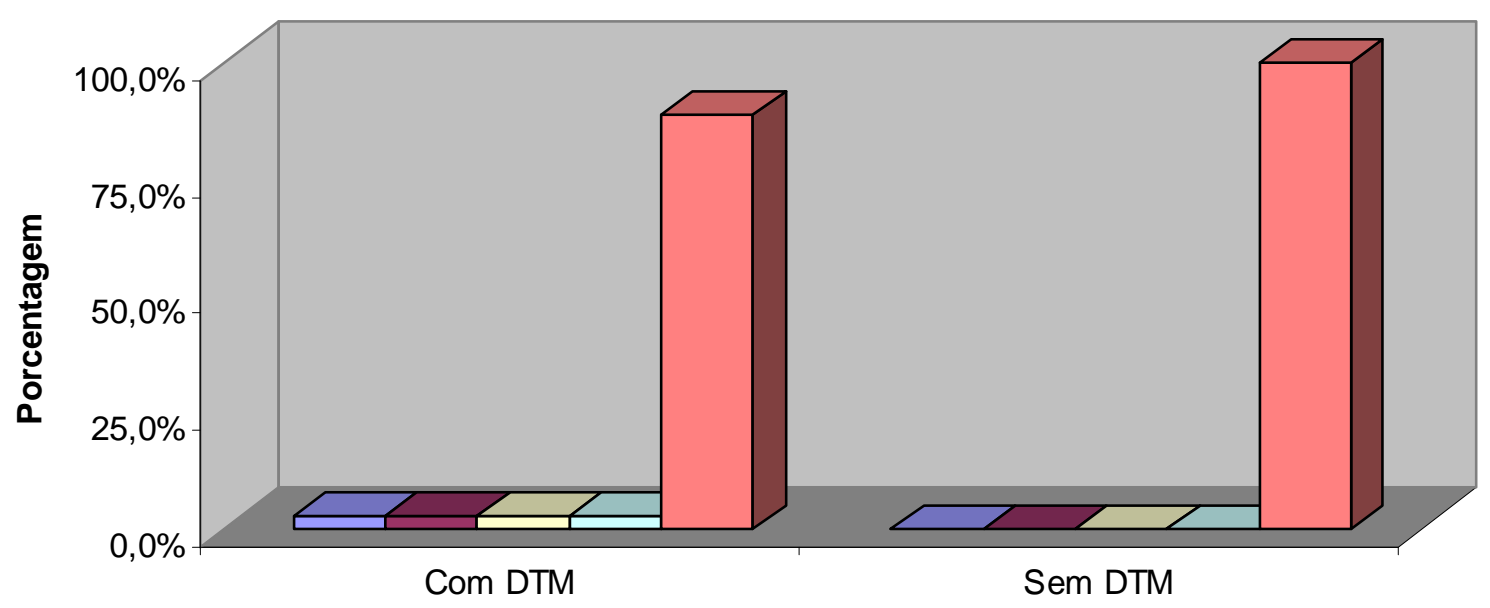

$\square$ Atrofia no direito e Hipertrofia no esquerdo $\square$ Contratura em ambos os lados $\square$ Flacidez em ambos os lados $\square$ Normal no direito e Atrofia no esquerdo $\square$ Normal em ambos os lados

Gráfico 5.23 - Distribuição da Morfologia do MPL dos pacientes, segundo Grupo

As comparações entre a Morfologia do MPL dos pacientes e os tipos de DDA e Mobilidade da Cabeça da Mandíbula foram também investigados, conforme trazem as tabelas 5.18 e 5.19 . 
Tabela 5.18 - Distribuição do DDA e Morfologia do MPL dos pacientes, segundo Grupo

Morfologia do MPL

Total

\begin{tabular}{|c|c|c|c|c|c|c|c|}
\hline & DDA & A_H $\mathrm{H}^{\mathrm{g}}$ & C_C $C^{n}$ & F_F $F^{\prime}$ & $N \_A^{\prime}$ & N_N $N^{\dagger}$ & \\
\hline \multirow[t]{14}{*}{ Com DTM } & $D^{D A R} \_D D A R^{a}$ & $\begin{array}{lll}- & - \\
\end{array}$ & - & - & - & 3 & 3 \\
\hline & & - & - & - & - & $9,7 \%$ & $8,6 \%$ \\
\hline & DDAsR_DDAR ${ }^{b}$ & - & - & - & - & 1 & 1 \\
\hline & & - & - & - & - & $3,2 \%$ & $2,9 \%$ \\
\hline & DDAsR_DDAsR & - & - & - & - & 2 & 2 \\
\hline & & - & - & - & - & $6,5 \%$ & $5,7 \%$ \\
\hline & N_DDAR ${ }^{d}$ & - & - & - & - & 1 & 1 \\
\hline & & - & - & - & - & $3,2 \%$ & $2,9 \%$ \\
\hline & N_DDAsR ${ }^{e}$ & - & - & - & - & 1 & 1 \\
\hline & & - & - & - & - & $3,2 \%$ & $2,9 \%$ \\
\hline & N_N $N^{\dagger}$ & 1 & 1 & 1 & 1 & 23 & 27 \\
\hline & & $100,0 \%$ & $100,0 \%$ & $100,0 \%$ & $100,0 \%$ & $74,2 \%$ & $77,1 \%$ \\
\hline & Total & 1 & 1 & 1 & 1 & 31 & 35 \\
\hline & & $100,0 \%$ & $100,0 \%$ & $100,0 \%$ & $100,0 \%$ & $100,0 \%$ & $100,0 \%$ \\
\hline
\end{tabular}

\begin{tabular}{|c|c|c|c|c|c|c|c|}
\hline \multirow[t]{14}{*}{ Sem DTM } & DDAR_DDAR ${ }^{a}$ & - & - & - & - & - & - \\
\hline & & - & - & - & - & - & - \\
\hline & DDAsR_DDAR ${ }^{\mathrm{b}}$ & - & - & - & - & - & - \\
\hline & & - & - & - & - & - & - \\
\hline & DDAsR_DDAsR ${ }^{\mathrm{C}}$ & - & - & - & - & - & - \\
\hline & & - & - & - & - & - & - \\
\hline & N_DDAR ${ }^{d}$ & - & - & - & - & - & - \\
\hline & & - & - & - & - & - & - \\
\hline & N_DDAsR ${ }^{e}$ & - & - & - & - & - & - \\
\hline & & - & - & - & - & - & - \\
\hline & N_N ${ }^{\dagger}$ & - & - & - & - & 15 & 15 \\
\hline & & - & - & - & - & $100,0 \%$ & $100,0 \%$ \\
\hline & Total & - & - & - & - & 15 & 15 \\
\hline & & - & - & - & - & $100,0 \%$ & $100,0 \%$ \\
\hline
\end{tabular}

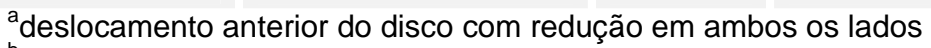
${ }^{b}$ deslocamento anterior do disco sem redução do direito e deslocamento do disco anterior com redução do esquerdo

'deslocamento anterior do disco sem redução em ambos os lados

${ }^{\mathrm{d}}$ Normal do direito e deslocamento anterior do disco com redução do esquerdo

Normal do direito e deslocamento anterior do disco sem redução do esquerdo

${ }^{f}$ Normal em ambos os lados

gatrofia do direito e hipertrofia do esquerdo

h contratura em ambos os lados

iflacidez em ambos os lados

'normal do direito e atrofia do esquerdo 
Tabela 5.19 - Distribuição da Mobilidade e Morfologia do MPL dos pacientes, segundo Grupo

\begin{tabular}{|c|c|c|c|c|c|c|c|}
\hline & & \multicolumn{5}{|c|}{ Morfologia do MPL } & \multirow[t]{2}{*}{ Total } \\
\hline & Mobilidade & A_H $H^{g}$ & C_c $c^{n}$ & F_F $F^{\prime}$ & N_A $A^{\prime}$ & N_N ${ }^{e}$ & \\
\hline \multirow[t]{14}{*}{ Com DTM } & Hiper $^{a}$ & - & - & - & - & 2 & 2 \\
\hline & & - & - & - & - & $6,5 \%$ & $5,7 \%$ \\
\hline & $\mathrm{Hipo}^{\text {b }}$ & - & - & - & 1 & 3 & 4 \\
\hline & & - & - & - & $100,0 \%$ & $9,7 \%$ & $11,4 \%$ \\
\hline & Hipo_N ${ }^{c}$ & - & - & - & - & 1 & 1 \\
\hline & & - & - & - & - & $3,2 \%$ & $2,9 \%$ \\
\hline & N_Hiper ${ }^{d}$ & - & - & - & - & 4 & 4 \\
\hline & & - & - & - & - & $12,9 \%$ & $11,4 \%$ \\
\hline & Hiper_N ${ }^{\dagger}$ & - & - & - & - & - & - \\
\hline & & - & - & - & - & - & - \\
\hline & N_N $N^{e}$ & 1 & 1 & 1 & - & 21 & 24 \\
\hline & & $100,0 \%$ & $100,0 \%$ & $100,0 \%$ & - & $67,7 \%$ & $68,6 \%$ \\
\hline & Total & 1 & 1 & 1 & 1 & 31 & 35 \\
\hline & & $100,0 \%$ & $100,0 \%$ & $100,0 \%$ & $100,0 \%$ & $100,0 \%$ & $100,0 \%$ \\
\hline \multirow[t]{14}{*}{ Sem DTM } & Hiper $^{a}$ & - & - & - & - & - & - \\
\hline & & - & - & - & - & - & - \\
\hline & Hipo $^{\text {b }}$ & - & - & - & - & - & - \\
\hline & & - & - & - & - & - & - \\
\hline & Hipo_Nc & - & - & - & - & - & - \\
\hline & & - & - & - & - & - & - \\
\hline & N_Hiper ${ }^{d}$ & - & - & - & - & - & - \\
\hline & & - & - & - & - & - & - \\
\hline & Hiper_N ${ }^{\dagger}$ & - & - & - & - & 1 & 1 \\
\hline & & - & - & - & - & $6,7 \%$ & $6,7 \%$ \\
\hline & N_N ${ }^{e}$ & - & - & - & - & 14 & 14 \\
\hline & & - & - & - & - & $93,3 \%$ & $93,3 \%$ \\
\hline & Total & - & - & - & - & 15 & 15 \\
\hline & & - & - & - & - & $100,0 \%$ & $100,0 \%$ \\
\hline \multicolumn{8}{|c|}{$\begin{array}{l}\text { ahipermobilidade em ambos os lados } \\
\text { bhipomobilidade em ambos os lados } \\
\text { chipomobilidade do direito e normal do esquerdo } \\
\text { d normal do direito e hipermobilidade do esquerdo } \\
\text { enormal em ambos os lados } \\
\text { thipermobilidade do direito e normal do esquerdo } \\
\text { ghiperofia do direito e hipertrofia do esquerdo } \\
\text { gatrofias la } \\
\text { hcontratura em ambos os lados } \\
\text { 'flacidez em ambos os lados } \\
\text { nnormal do direito e atrofia do esquerdo }\end{array}$} \\
\hline
\end{tabular}


O estudo da relação entre as medidas do MPL nos diferentes cortes (axial, T1 sagital com boca fechada e T2 sagital com boca aberta) com o DDA, Mobilidade da Cabeça da Mandíbula, além da Morfologia do MPL e presença de Estalo, em ambos os grupos, foi feito pela construção das tabelas 5.20 a 5.22 . 
Tabela 5.20 - Medidas-resumo da medida axial, T1 sagital com boca fechada e T2 sagital com boca aberta do MPL (mm), segundo Grupo, Deslocamento do Disco e Lado

\begin{tabular}{|c|c|c|c|c|c|c|c|}
\hline \multirow[b]{2}{*}{$\begin{array}{l}\text { Grupo } \\
\text { com DTM }\end{array}$} & \multirow[b]{2}{*}{ Medidas-resumo } & \multicolumn{2}{|l|}{ Axial } & \multicolumn{2}{|l|}{$\mathrm{T} 1^{\mathrm{a}}$} & \multicolumn{2}{|l|}{$\mathrm{T} 2^{\mathrm{b}}$} \\
\hline & & direito & esquerdo & direito & esquerdo & direito & esquerdo \\
\hline \multirow[t]{6}{*}{$\mathrm{DDAR}^{\mathrm{c}}$} & $\mathrm{N}$ & 3 & 5 & 3 & 5 & 3 & 5 \\
\hline & Média & 13,2 & 14,4 & 16,2 & 17,5 & 12,6 & 11,3 \\
\hline & Mediana & 13,7 & 14,6 & 14,6 & 15,6 & 12,1 & 10,6 \\
\hline & Mínimo & 11,1 & 13,6 & 12,5 & 15,2 & 11,3 & 10,1 \\
\hline & Máximo & 14,9 & 15,3 & 21,6 & 22,4 & 14,4 & 14,5 \\
\hline & Desvio-padrão & 1,9 & 0,7 & 4,8 & 3,1 & 1,6 & 1,8 \\
\hline \multirow[t]{6}{*}{$D_{D A s}{ }^{d}$} & $\mathrm{~N}$ & 3 & 3 & 3 & 3 & 3 & 3 \\
\hline & Média & 15,0 & 13,2 & 16,1 & 14,4 & 11,0 & 13,2 \\
\hline & Mediana & 15,0 & 13,4 & 14,0 & 13,3 & 9,9 & 13,8 \\
\hline & Mínimo & 14,7 & 12,0 & 13,7 & 9,9 & 8,8 & 9,2 \\
\hline & Máximo & 15,2 & 14,3 & 20,7 & 20,1 & 14,3 & 16,7 \\
\hline & Desvio-padrão & 0,3 & 1,2 & 4,0 & 5,2 & 2,9 & 3,8 \\
\hline \multirow[t]{6}{*}{ Normal } & $\mathrm{N}$ & 29 & 27 & 29 & 27 & 29 & 27 \\
\hline & Média & 16,5 & 16,1 & 17,9 & 19,5 & 13,2 & 13,2 \\
\hline & Mediana & 16,4 & 16,2 & 15,6 & 17,1 & 13,0 & 13,2 \\
\hline & Mínimo & 9,3 & 9,5 & 7,6 & 9,9 & 3,5 & 5,0 \\
\hline & Máximo & 24,8 & 22,7 & 31,9 & 31,8 & 19,3 & 19,5 \\
\hline & Desvio-padrão & 3,4 & 3,4 & 6,0 & 5,8 & 3,3 & 3,6 \\
\hline \multicolumn{8}{|l|}{$\begin{array}{l}\text { Grupo } \\
\text { sem DTM }\end{array}$} \\
\hline \multirow[t]{6}{*}{ Normal } & $N$ & 15 & 15 & 15 & 15 & 15 & 15 \\
\hline & Média & 14,0 & 15,0 & 15,5 & 15,3 & 11,1 & 11,3 \\
\hline & Mediana & 13,9 & 15,6 & 16,7 & 14,6 & 8,9 & 9,1 \\
\hline & Mínimo & 11,3 & 7,9 & 5,8 & 6,1 & 6,0 & 6,4 \\
\hline & Máximo & 18,0 & 19,0 & 25,7 & 26,0 & 24,0 & 25,0 \\
\hline & Desvio-padrão & 2,1 & 3,0 & 6,1 & 6,3 & 5,0 & 5,2 \\
\hline$p^{e}$ & & 0,037 & 0,295 & 0,644 & 0,122 & 0,366 & 0,440 \\
\hline
\end{tabular}


Tabela 5.21 - Medidas-resumo da medida axial, T1 sagital com boca fechada e T2 sagital com boca aberta do MPL ( $\mathrm{mm}$ ), segundo Grupo, Mobilidade e Lado

\begin{tabular}{|c|c|c|c|c|c|c|c|}
\hline \multirow[b]{2}{*}{$\begin{array}{l}\text { Grupo } \\
\text { DTM }\end{array}$} & \multirow[b]{2}{*}{$\begin{array}{l}\text { Medidas- } \\
\text { resumo }\end{array}$} & \multicolumn{2}{|l|}{ Axial } & \multicolumn{2}{|l|}{$\mathrm{T} 1^{\mathrm{a}}$} & \multicolumn{2}{|l|}{$\mathrm{T} 2^{\mathrm{b}}$} \\
\hline & & direito & esquerdo & direito & esquerdo & direito & esquerdo \\
\hline \multirow[t]{6}{*}{ Hipermobilidade } & $\mathrm{N}$ & 2 & 6 & 2 & 6 & 2 & 6 \\
\hline & Média & 16,7 & 18,8 & 18,3 & 20,1 & 15,6 & 14,1 \\
\hline & Mediana & 16,7 & 18,1 & 18,3 & 17,6 & 15,6 & 14,2 \\
\hline & Mínimo & 14,9 & 15,3 & 15,0 & 13,1 & 14,4 & 9,6 \\
\hline & Máximo & 18,4 & 22,4 & 21,6 & 31,8 & 16,8 & 17,2 \\
\hline & Desvio-padrão & 2,5 & 2,9 & 4,7 & 6,8 & 1,7 & 2,8 \\
\hline \multirow{6}{*}{ Hipomobilidade } & $\mathrm{N}$ & 5 & 4 & 5 & 4 & 5 & 4 \\
\hline & Média & 14,2 & 14,5 & 14,2 & 13,3 & 13,2 & 13,5 \\
\hline & Mediana & 14,7 & 14,5 & 13,7 & 12,6 & 12,1 & 12,6 \\
\hline & Mínimo & 11,1 & 13,4 & 9,2 & 9,9 & 9,9 & 9,6 \\
\hline & Máximo & 15,8 & 15,5 & 20,7 & 18,1 & 18,9 & 19,3 \\
\hline & Desvio-padrão & 1,8 & 1,0 & 4,2 & 4,1 & 3,6 & 4,2 \\
\hline \multirow[t]{6}{*}{ Normal } & $\mathrm{N}$ & 28 & 25 & 28 & 25 & 28 & 25 \\
\hline & Média & 16,4 & 15,1 & 18,1 & 19,3 & 12,7 & 12,6 \\
\hline & Mediana & 16,2 & 14,6 & 15,9 & 17,1 & 12,9 & 11,8 \\
\hline & Mínimo & 9,3 & 9,5 & 7,6 & 13,2 & 3,5 & 5,0 \\
\hline & Máximo & 24,8 & 22,7 & 31,9 & 31,3 & 19,3 & 19,5 \\
\hline & Desvio-padrão & 3,5 & 3,0 & 5,9 & 5,2 & 3,1 & 3,5 \\
\hline \multicolumn{8}{|c|}{$\begin{array}{l}\text { Grupo sem } \\
\text { DTM }\end{array}$} \\
\hline \multirow[t]{6}{*}{ Hipermobilidade } & $\mathrm{N}$ & 1 & - & 1 & - & 1 & - \\
\hline & Média & 17,3 & - & 23,4 & - & 7,8 & - \\
\hline & Mediana & 17,3 & - & 23,4 & - & 7,8 & - \\
\hline & Mínimo & 17,3 & - & 23,4 & - & 7,8 & - \\
\hline & Máximo & 17,3 & - & 23,4 & - & 7,8 & - \\
\hline & Desvio-padrão & - & - & - & - & - & - \\
\hline \multirow[t]{6}{*}{ Normal } & $\mathrm{N}$ & 14 & 15 & 14 & 15 & 14 & 15 \\
\hline & Média & 13,7 & 15,0 & 14,9 & 15,3 & 11,4 & 11,3 \\
\hline & Mediana & 13,7 & 15,6 & 16,5 & 14,6 & 9,0 & 9,1 \\
\hline & Mínimo & 11,3 & 7,9 & 5,8 & 6,1 & 6,0 & 6,4 \\
\hline & Máximo & 18,0 & 19,0 & 25,7 & 26,0 & 24,0 & 25,0 \\
\hline & Desvio-padrão & 2,0 & 3,0 & 6,0 & 6,3 & 5,1 & 5,2 \\
\hline$p^{c}$ & & 0,082 & 0,040 & 0,276 & 0,053 & 0,381 & 0,470 \\
\hline
\end{tabular}


Tabela 5.22 - Medidas-resumo da medida axial, T1, e T2 do MPL (mm), segundo Grupo, Morfologia do MPL e Lado

\begin{tabular}{|c|c|c|c|c|c|c|c|}
\hline \multirow[b]{2}{*}{$\begin{array}{l}\text { Grupo com } \\
\text { DTM }\end{array}$} & \multirow[b]{2}{*}{ Medidas-resumo } & \multicolumn{2}{|l|}{ Axial } & \multicolumn{2}{|l|}{$\mathrm{T} 1^{\mathrm{a}}$} & \multicolumn{2}{|l|}{$\mathrm{T} 2^{\mathrm{b}}$} \\
\hline & & direito & esquerdo & direito & esquerdo & direito & esquerdo \\
\hline \multirow[t]{6}{*}{ Atrofia } & $\mathrm{N}$ & 1 & 1 & 1 & 1 & 1 & 1 \\
\hline & Média & 11,5 & 15,5 & 24,0 & 18,1 & 12,5 & 19,3 \\
\hline & Mediana & 11,5 & 15,5 & 24,0 & 18,1 & 12,5 & 19,3 \\
\hline & Mínimo & 11,5 & 15,5 & 24,0 & 18,1 & 12,5 & 19,3 \\
\hline & Máximo & 11,5 & 15,5 & 24,0 & 18,1 & 12,5 & 19,3 \\
\hline & Desvio-padrão & - & - & - & - & - & - \\
\hline \multirow[t]{6}{*}{ Contratura } & $\mathrm{N}$ & 1 & 1 & 1 & 1 & 1 & 1 \\
\hline & Média & 13,6 & 12,1 & 15,6 & 18,6 & 10,9 & 9,3 \\
\hline & Mediana & 13,6 & 12,1 & 15,6 & 18,6 & 10,9 & 9,3 \\
\hline & Mínimo & 13,6 & 12,1 & 15,6 & 18,6 & 10,9 & 9,3 \\
\hline & Máximo & 13,6 & 12,1 & 15,6 & 18,6 & 10,9 & 9,3 \\
\hline & Desvio-padrão & - & - & - & - & - & - \\
\hline \multirow[t]{6}{*}{ Flacidez } & $\mathrm{N}$ & 1 & 1 & 1 & 1 & 1 & 1 \\
\hline & Média & 9,3 & 9,5 & 7,6 & 22,0 & 13,0 & 18,9 \\
\hline & Mediana & 9,3 & 9,5 & 7,6 & 22,0 & 13,0 & 18,9 \\
\hline & Mínimo & 9,3 & 9,5 & 7,6 & 22,0 & 13,0 & 18,9 \\
\hline & Máximo & 9,3 & 9,5 & 7,6 & 22,0 & 13,0 & 18,9 \\
\hline & Desvio-padrão & - & - & - & - & - & - \\
\hline \multirow[t]{6}{*}{ Hipertrofia } & $\mathrm{N}$ & - & 1 & - & 1 & - & 1 \\
\hline & Média & - & 13,5 & - & 25,2 & - & 14,3 \\
\hline & Mediana & - & 13,5 & - & 25,2 & - & 14,3 \\
\hline & Mínimo & - & 13,5 & - & 25,2 & - & 14,3 \\
\hline & Máximo & - & 13,5 & - & 25,2 & - & 14,3 \\
\hline & Desvio-padrão & & - & - & - & - & - \\
\hline \multirow[t]{6}{*}{ Normal } & $\mathrm{N}$ & 32 & 31 & 32 & 31 & 32 & 31 \\
\hline & Média & 16,5 & 16,0 & 17,8 & 18,5 & 13,0 & 12,6 \\
\hline & Mediana & 16,0 & 15,6 & 15,6 & 16,4 & 13,0 & 12,9 \\
\hline & Mínimo & 11,1 & 10,9 & 9,2 & 9,9 & 3,5 & 5,0 \\
\hline & Máximo & 24,8 & 22,7 & 31,9 & 31,8 & 19,3 & 19,5 \\
\hline & Desvio-padrão & 3,0 & 3,0 & 5,6 & 5,8 & 3,3 & 3,2 \\
\hline \multicolumn{8}{|l|}{$\begin{array}{l}\text { Grupo sem } \\
\text { DTM }\end{array}$} \\
\hline \multirow[t]{6}{*}{ Normal } & $\mathrm{N}$ & 15 & 15 & 15 & 15 & 15 & 15 \\
\hline & Média & 14,0 & 15,0 & 15,5 & 15,3 & 11,1 & 11,3 \\
\hline & Mediana & 13,9 & 15,6 & 16,7 & 14,6 & 8,9 & 9,1 \\
\hline & Mínimo & 11,3 & 7,9 & 5,8 & 6,1 & 6,0 & 6,4 \\
\hline & Máximo & 18,0 & 19,0 & 25,7 & 26,0 & 24,0 & 25,0 \\
\hline & Desvio-padrão & 2,1 & 3,0 & 6,1 & 6,3 & 5,0 & 5,2 \\
\hline$p^{c}$ & & 0,006 & 0,303 & 0,219 & 0,097 & 0,129 & 0,275 \\
\hline
\end{tabular}


Com respeito às informações do lado direito, os resultados revelaram que as medidas do T1 sagital com boca fechada $(p=0,644)$ e T2 sagital com boca aberta $(p=0,366)$ não estão relacionadas ao tipo de DDA. Apenas a medida axial está relacionada ao tipo de DDA $(p=0,037)$, conforme a tabela 5.20.

Tabela 5.23 - Resultados das comparações das medidas médias no corte AXIAL, segundo Grupo e DDA

\begin{tabular}{|l|l|}
\hline Conclusão & Nível descritivo $(\mathrm{p})$ \\
\hline com DTM e DDAR = com DTM e DDAsR & 0,887 \\
\hline com DTM e DDAR = com DTM Normal & 0,273 \\
\hline com DTM e DDAR = sem DTM Normal & 0,978 \\
\hline com DTM e DDAsR = com DTM Normal & 0,829 \\
\hline com DTM e DDAsR = sem DTM Normal & 0,951 \\
\hline com DTM Normal > sem DTM Normal & 0,048 \\
\hline
\end{tabular}


Com respeito ainda às informações do lado esquerdo, notamos que as medidas do T1 sagital com boca fechada $(p=0,053)$ e T2 sagital com boca aberta $(p=0,470)$ não estão relacionadas à Mobilidade (Tabela 5.24). Apenas a medida axial está relacionada à Mobilidade $(\mathrm{p}=0,040)$, conforme resume a tabela 5.24

Tabela 5.24 - Resultados das comparações das medidas médias no corte axial, segundo Grupo e Mobilidade

\begin{tabular}{|c|c|}
\hline Conclusão & Nível descritivo (p) \\
\hline $\begin{array}{l}\text { com DTM e Hipermobilidade }=\text { com DTM e } \\
\text { Hipomobilidade }\end{array}$ & 0,116 \\
\hline com DTM e Hipermobilidade > com DTM Normal & 0,036 \\
\hline com DTM e Hipermobilidade > sem DTM Normal & 0,050 \\
\hline com DTM e Hipomobilidade = com DTM Normal & 0,982 \\
\hline com DTM e Hipomobilidade = sem DTM Normal & 0,987 \\
\hline com DTM Normal = sem DTM Normal & $>0,999$ \\
\hline
\end{tabular}


Conforme traz a tabela 5.25 , os resultados mostraram que os indivíduos apresentaram medidas axial $(p=0,393), T 1$ sagital com boca fechada $(p=0,385)$ e T2 sagital com boca aberta $(p=0,730)$ do lado direito estatisticamente iguais ao do lado esquerdo.

Tabela 5.25 - Medidas-resumo das medidas axial, T1 sagital com boca fechada e T2 sagital com boca aberta, segundo Grupo, presença do Estalo e Lado

\begin{tabular}{|c|c|c|c|c|c|c|c|}
\hline & \multirow[b]{2}{*}{$\begin{array}{l}\text { Medidas- } \\
\text { resumo }\end{array}$} & \multicolumn{2}{|l|}{ Axial } & \multicolumn{2}{|l|}{$\mathrm{T} 1^{\mathrm{a}}$} & \multicolumn{2}{|l|}{$\mathrm{T} 2^{\mathrm{b}}$} \\
\hline $\begin{array}{l}\text { Grupo com } \\
\text { DTM }\end{array}$ & & direito & esquerdo & direito & esquerdo & direito & esquerdo \\
\hline Sem estalo & Média & 16,1 & 15,3 & 16,6 & 18,3 & 12,3 & 12,3 \\
\hline \multirow[t]{4}{*}{$(n=26)$} & Mediana & 15,8 & 14,9 & 15,4 & 16,5 & 11,8 & 11,6 \\
\hline & Mínimo & 9,3 & 9,5 & 7,6 & 9,9 & 3,5 & 5,0 \\
\hline & Máximo & 24,8 & 22,7 & 31,9 & 31,8 & 18,9 & 19,3 \\
\hline & Desvio-padrão & 3,4 & 3,1 & 5,5 & 5,3 & 3,3 & 3,4 \\
\hline \multirow{5}{*}{$(n=9)$} & Média & 16,0 & 16,6 & 20,3 & 20,1 & 14,7 & 15,0 \\
\hline & Mediana & 16,4 & 16,4 & 20,4 & 21,6 & 14,2 & 14,3 \\
\hline & Mínimo & 11,5 & 13,4 & 12,5 & 9,9 & 12,5 & 10,8 \\
\hline & Máximo & 19,7 & 22,4 & 29,7 & 31,3 & 19,3 & 19,5 \\
\hline & Desvio-padrão & 3,0 & 3,1 & 5,6 & 6,5 & 2,1 & 2,8 \\
\hline \multicolumn{8}{|l|}{$\begin{array}{l}\text { Grupo sem } \\
\text { DTM }\end{array}$} \\
\hline Sem estalo & Média & 14,0 & 15,0 & 15,5 & 15,3 & 11,1 & 11,3 \\
\hline \multirow[t]{4}{*}{$(n=15)$} & Mediana & 13,9 & 15,6 & 16,7 & 14,6 & 8,9 & 9,1 \\
\hline & Mínimo & 11,3 & 7,9 & 5,8 & 6,1 & 6,0 & 6,4 \\
\hline & Máximo & 18,0 & 19,0 & 25,7 & 26,0 & 24,0 & 25,0 \\
\hline & Desvio-padrão & 2,1 & 3,0 & 6,1 & 6,3 & 5,0 & 5,2 \\
\hline
\end{tabular}


A tabela 5.26 apresenta as informações das medidas axial, T1 sagital com boca fechada e T2 sagital com boca aberta, considerando Grupo e a presença de Dor. Vale ressaltar que, dado os resultados inferenciais, os indivíduos apresentaram medidas axial $(p=0,445)$, T1 sagital com boca fechada $(p=0,245)$ e T2 sagital com boca aberta $(p=0,713)$ do lado direito estatisticamente iguais ao do lado esquerdo.

Tabela 5.26 - Medidas-resumo das medidas axial, T1 sagital com boca fechada e T2 sagital com boca aberta, segundo Grupo, presença de Dor e

\begin{tabular}{|c|c|c|c|c|c|c|c|c|}
\hline \multirow[b]{2}{*}{$\begin{array}{l}\text { Grupo } \\
\text { DTM }\end{array}$} & \multirow[b]{2}{*}{ com } & \multirow[b]{2}{*}{$\begin{array}{l}\text { Medidas- } \\
\text { resumo }\end{array}$} & \multicolumn{2}{|l|}{ Axial } & \multicolumn{2}{|l|}{$\mathrm{T} 1^{\mathrm{a}}$} & \multicolumn{2}{|l|}{$T 2^{b}$} \\
\hline & & & direito & esquerdo & direito & esquerdo & direito & esquerdo \\
\hline Sem dor & & Média & 15,5 & 16,0 & 19,4 & 19,9 & 14,0 & 14,4 \\
\hline \multirow[t]{4}{*}{$(n=10)$} & & Mediana & 15,4 & 15,5 & 18,3 & 20,1 & 13,6 & 14,3 \\
\hline & & Mínimo & 11,5 & 12,1 & 12,5 & 9,9 & 10,9 & 9,3 \\
\hline & & Máximo & 19,7 & 22,4 & 29,7 & 31,3 & 19,3 & 19,5 \\
\hline & & Desvio-padrão & 2,8 & 3,3 & 5,7 & 6,3 & 2,4 & 3,3 \\
\hline Com dor & & Média & 16,3 & 15,5 & 16,8 & 18,3 & 12,5 & 12,4 \\
\hline \multirow[t]{4}{*}{$(n=25)$} & & Mediana & 15,9 & 15,3 & 15,4 & 16,6 & 12,3 & 11,8 \\
\hline & & Mínimo & 9,3 & 9,5 & 7,6 & 9,9 & 3,5 & 5,0 \\
\hline & & Máximo & 24,8 & 22,7 & 31,9 & 31,8 & 18,9 & 19,3 \\
\hline & & Desvio-padrão & 3,5 & 3,1 & 5,7 & 5,4 & 3,3 & 3,4 \\
\hline \multicolumn{9}{|l|}{$\begin{array}{l}\text { Grupo } \\
\text { DTM }\end{array}$} \\
\hline Sem dor & & Média & 14,0 & 15,0 & 15,5 & 15,3 & 11,1 & 11,3 \\
\hline \multirow[t]{4}{*}{$(n=15)$} & & Mediana & 13,9 & 15,6 & 16,7 & 14,6 & 8,9 & 9,1 \\
\hline & & Mínimo & 11,3 & 7,9 & 5,8 & 6,1 & 6,0 & 6,4 \\
\hline & & Máximo & 18,0 & 19,0 & 25,7 & 26,0 & 24,0 & 25,0 \\
\hline & & Desvio-padrão & 2,1 & 3,0 & 6,1 & 6,3 & 5,0 & 5,2 \\
\hline
\end{tabular}

Finalmente nas tabelas 5.27 e 5.28 podemos observar um Resumo de todos os testes estatísticos empregados e todos os valores de $\mathbf{p}$ obtidos. Em negrito estão assinalados os resultados estatisticamente significantes. 
Tabela 5.27 - Resumo das comparações realizadas, testes estatísticos aplicados e níveis descritivos ( $p$ )

Variáveis comparadas

Idade versus Grupo

Gênero versus Grupo

DDA versus Grupo

Mobilidade da cabeça da mandíbula versus Grupo

Morfologia do MPL versus Grupo

Morfologia do MLP versus DDA (no grupo com DTM)

Morfologia do MPL e Mobilidade da mandíbula (no grupo com DTM)

Queixa versus Grupo

Sintomatologia versus Grupo

Crepitação versus Grupo

Dor versus Grupo

Bruxismo versus Grupo

Cefaléia versus Grupo

Estalo versus Grupo

Limitação versus Grupo

Teste do MPL versus Grupo

Abertura de boca (quantitativa) versus Grupo

Abertura de boca (qualitativa) versus Grupo

corte axial direito versus Grupo e Deslocamento

$\mathrm{T} 1^{\mathrm{a}}$ direito versus Grupo e Deslocamento

T2 ${ }^{\mathrm{b}}$ direito versus Grupo e Deslocamento

corte axial esquerdo versus Grupo e Deslocamento

$\mathrm{T} 1^{\mathrm{a}}$ esquerdo versus Grupo e Deslocamento

$T 2^{\mathrm{b}}$ esquerdo versus Grupo e Deslocamento

corte axial direito versus Grupo e Mobilidade

$\mathrm{T} 1^{\mathrm{a}}$ direito versus Grupo e Mobilidade

T2 ${ }^{\mathrm{b}}$ direito versus Grupo e Mobilidade

corte axial esquerdo versus Grupo e Mobilidade

T1 ${ }^{a}$ esquerdo versus Grupo e Mobilidade

$T 2^{\mathrm{b}}$ esquerdo versus Grupo e Mobilidade

corte axial direito versus Grupo e Morfologia

$\mathrm{T} 1^{\mathrm{a}}$ direito versus Grupo e Morfologia

$\mathrm{T} 2^{\mathrm{b}}$ direito versus Grupo e Aparência

corte axial esquerdo versus Grupo e Morfologia

$\mathrm{T}_{1}{ }^{\mathrm{a}}$ esquerdo versus Grupo e Morfologia

$\mathrm{T}^{\mathrm{b}}$ squerdo versus Grupo e Morfologia

${ }^{a}$ medida do MPL no corte T1 sagital com boca fechada

${ }^{b}$ medida do MPL no corte T2 sagital com boca aberta

\section{Teste estatístico utilizado}

T-Student para amostras 0,214 independentes

Exato de Fisher

0,146

Extensão do teste Exato de Fisher

Extensão do teste Exato de Fisher

0,815

Extensão do teste Exato de Fisher

0,189

Extensão do teste Exato de Fisher

Extensão do teste Exato de Fisher

$>0,999$

$>0,999$

0,797

Teste Exato de Fisher

$<0,001$

Teste Exato de Fisher

$<0,001$

Teste Exato de Fisher

$>0,999$

Qui-quadrado de Pearson

$<0,001$

Teste Exato de Fisher

0,043

Teste Exato de Fisher

0,086

Teste Exato de Fisher

$\mathbf{0 , 0 4 3}$

Teste Exato de Fisher

$>0,999$

Teste Exato de Fisher

0,022

T-Student para amostras 0,438 independentes

Qui-quadrado de Pearson $\quad 0,662$

ANOVA Simples

$\mathbf{0 , 0 3 7}$

ANOVA Simples

0,644

ANOVA Simples

0,366

ANOVA Simples

0,295

ANOVA Simples

0,122

ANOVA Simples

0,440

ANOVA Simples

0,082

ANOVA Simples

0,276

ANOVA Simples

0,381

ANOVA Simples

0,040

ANOVA Simples

0,053

ANOVA Simples

0,470

ANOVA Simples

0,006

ANOVA Simples

0,219

ANOVA Simples

0,129

ANOVA Simples

0,303

ANOVA Simples

0,097

ANOVA Simples

0,275


Tabela 5.28 - Resumo das comparações realizadas, testes estatísticos aplicados e níveis descritivos ( $p$ )

\begin{tabular}{|c|c|c|c|c|c|}
\hline Variáveis comparadas & \multicolumn{3}{|c|}{ Teste estatístico utilizado } & \multirow{2}{*}{$\begin{array}{l}\mathbf{p} \text { (lado) } \\
0,383\end{array}$} & \multirow{2}{*}{$\begin{array}{l}\mathbf{p} \text { (grupo) } \\
0,129\end{array}$} \\
\hline $\begin{array}{l}\text { corte axial versus Grupo, considerando } \\
\text { lados }\end{array}$ & $\begin{array}{l}\text { ANOVA } \\
\text { repetidas }\end{array}$ & com & medidas & & \\
\hline T1 $1^{a}$ versus Grupo, considerando lado & $\begin{array}{l}\text { ANOVA } \\
\text { repetidas }\end{array}$ & com & medidas & 0,327 & 0,116 \\
\hline T2 ${ }^{\mathrm{b}}$ versus Grupo, considerando lado & $\begin{array}{l}\text { ANOVA } \\
\text { repetidas }\end{array}$ & com & medidas & 0,807 & 0,134 \\
\hline $\begin{array}{l}\text { corte axial versus Grupo e presença de } \\
\text { Estalo }\end{array}$ & $\begin{array}{l}\text { ANOVA } \\
\text { repetidas }\end{array}$ & com & medidas & 0,393 & 0,274 \\
\hline $\mathrm{T} 1^{\mathrm{a}}$ versus Grupo e presença de Estalo & $\begin{array}{l}\text { ANOVA } \\
\text { repetidas }\end{array}$ & com & medidas & 0,385 & 0,132 \\
\hline $\mathrm{T} 2^{\mathrm{b}}$ versus Grupo e presença de Estalo & $\begin{array}{l}\text { ANOVA } \\
\text { repetidas }\end{array}$ & com & medidas & 0,730 & 0,071 \\
\hline $\begin{array}{l}\text { corte axial versus Grupo e presença de } \\
\text { Dor }\end{array}$ & $\begin{array}{l}\text { ANOVA } \\
\text { repetidas }\end{array}$ & com & medidas & 0,445 & 0,316 \\
\hline $\mathrm{T} 1^{\mathrm{a}}$ versus Grupo e presença de Dor & $\begin{array}{l}\text { ANOVA } \\
\text { repetidas }\end{array}$ & com & medidas & 0,245 & 0,182 \\
\hline T2 ${ }^{\mathrm{b}}$ versus Grupo e presença de Dor & $\begin{array}{l}\text { ANOVA } \\
\text { repetidas }\end{array}$ & com & medidas & 0,713 & 0,151 \\
\hline
\end{tabular}




\section{DISCUSSÃO}

Em nosso estudo foram considerados 50 indivíduos (100 ATM), sendo 35 pacientes com sinais e sintomas de DTM e 15 voluntários assintomáticos, todos submetidos ao exame de RM da ATM.

Os exames clínicos de todos os indivíduos foram realizados pelo autor e as imagens de RM das ATM, analisadas em conjunto com um médico radiologista especialista em cabeça e pescoço.

Dos 35 pacientes com sinais clínicos de DTM, 29 (82,9\%) eram do gênero feminino e $6(17,1 \%)$ do gênero masculino, o que vai de acordo com o que encontramos na literatura, que mostra que a DTM tem maior prevalência nas mulheres (FRICTON; OKESON, 2000; MANFREDI; SILVA; VENDITI, 2001). O grupo sem DTM era composto por $9(60,0 \%)$ pacientes do gênero feminino e $6(40,0 \%)$ pacientes do gênero masculino.

Com relação às idades dos pacientes, apesar das medias das idades serem bem similares entre os grupos com e sem DTM, pudemos observar que a faixa de idade foi mais variável no grupo com DTM (entre 18 e 63 anos), media de 35,0 anos, considerados adultos jovens, como descrito por Bruno (2004), mais do que no grupo sem DTM (entre 20 e 49 anos), média de 31,1 anos.

É importante ressaltar que os grupos com e sem DTM apresentaram estatisticamente a mesma idade média $(p=0,214)$ e também a mesma distribuição quanto ao gênero $(p=0,146)$.

A respeito das queixas clínicas coletadas nas anamneses realizadas, no grupo com DTM, a distribuição dos sintomas foi bem homogênea entre os lados afetados: direito, esquerdo ou bilateralmente. Entre os sintomas relatados pelos 
pacientes, os mais comuns foram dor $(71,4 \%)$, estalo $(30,4 \%)$, bruxismo $(25,7 \%)$ e cefaléia (22,9\%), valores similares aos descritos por Abou-Atme, Zawawi e Melis (2006). Em porcentagem muito inferior encontramos crepitação e limitação de abertura da boca ao exame clínico.

Dor miofacial, localizada ou indefinida, foi sem duvida a maior queixa observada nos pacientes com DTM, sendo estatisticamente significante $(p<0,001)$, concordando com os achados de Limchaichana et a. (2007).

Ainda ao exame clínico, realizamos o Teste Muscular Anterior, chamado por nós de teste do MPL, em todos os pacientes, para se avaliar presença de dor, o que poderia significar comprometimento do MPL, segundo Research Diagnostic Criteria de Dworkin e Le Resche (1992). Pudemos observar que 100\% dos pacientes sem DTM, apresentou o teste do MPL negativo e no grupo com DTM, 28,6\% dos pacientes apresentaram o teste do MPL positivo, sugerindo que o MPL poderia apresentar alguma alteração, ou relação com a DTM. Este resultado foi estatisticamente significante, comparando-se o grupo com $(p=0,022)$ e sem DTM.

Em todos os pacientes foram realizadas as medidas da abertura máxima da boca, em milímetros (mm). É importante observar que as médias das medidas de abertura da boca de ambos os grupos são estatisticamente iguais $(p=0,438)$. Mesmo considerando a abertura da boca como anormal (menor que $40 \mathrm{~mm}$ ) e normal $(40 \mathrm{~mm}$ ou mais) conforme Agerberg (1974), notamos que os grupos têm estatisticamente a mesma distribuição $(p=0,662)$, apesar dos pacientes do grupo com DTM se queixarem de alguma dificuldade no momento da abertura máxima da boca ou incomodo no momento do posicionamento do mordedor.

Em todas as sequências de RM analisadas foi possível observar claramente as duas cabeças do MPL, comprovando a eficácia deste método diagnóstico, o que 
confirma o que já foi descrito por vários autores, como Schellhas (1989), Quemar, Revalec e Akokas (1993), Hong (1993), Liu (2000), Yang (2001; 2002), Taskaya (2002) e Goto (2002).

Após termos obtido todas as seqüências de RM da ATM, realizamos as medidas médias dos MPL, em milímetros, numa Workstation, de todos os pacientes nos cortes: axial, sagital T1 boca fechada e sagital T2 boca aberta, os quais foram selecionados por serem os cortes onde os MPL se apresentavam mais visíveis, em diferentes momentos durante o exame. Nos cortes axiais observamos a espessura do MPL e nos cortes sagitais a altura, nos momentos de boca fechada e abertura máxima.

Para cada seqüência de imagem de RM, efetuamos a comparação das medidas obtidas dos MPL entre os lados direito (D) e esquerdo (E) do mesmo paciente e entre as medidas dos músculos do grupo com e sem DTM, com o objetivo de estudarmos se estas medidas foram estatisticamente significantes nestas comparações.

Em todos os MPL analisados pudemos observar o encurtamento do músculo durante a abertura da boca, o que demonstra a diminuição de seu volume durante o movimento de abaixamento da mandíbula, como foi descrito por Gan, Ma e Wang (1994), Goto et al. (2002) e Hong (1993).

Os resultados inferenciais dos testes estatísticos revelaram que, em media, as medidas do lado $D$ são estatisticamente iguais às medidas do lado $E$ para os cortes: axial $(p=0,383)$, T1 sagital com boca fechada $(p=0,327)$ e T2 sagital boca aberta $(p=0,807)$. Os grupos com e sem DTM, apresentaram, em media, medidas estatisticamente iguais dos cortes: axial $(p=0,129)$, T1 sagital boca fechada $(p=0,116)$ e T2 sagital boca aberta $(p=0,134)$. 
De acordo com Finden, Enochs e Rao (2007), a falta de significância relativa às espessuras das cabeças dos MPL deve-se, em parte, ao alto grau de variação no tamanho das cabeças dos MPL entre os indivíduos, relacionadas às estruturas físicas das pessoas, gênero e idade dos pacientes.

Em seguida observamos a morfologia dos MPL nas imagens de RM e as alterações no tamanho dos músculos, para o mesmo paciente entre os lados $\mathrm{D}$ e $\mathrm{E}$; e entre os pacientes dos grupos com e sem DTM, seguindo os parâmetros sugeridos por Yang (2002). Os tipos de alterações morfológicas encontradas foram: atrofia, hipertrofia, contratura e flacidez musculares. Em 91,4\% dos músculos do lado D e $88,6 \%$ dos músculos do lado E, do grupo com DTM, foram observadas morfologias normais do músculo, assim como em 100\% dos músculos do grupo sem DTM.

As poucas alterações morfológicas encontradas no grupo com DTM, com prevalência da atrofia e contratura do músculo, não foram estatisticamente significantes.

Sabendo-se que Deslocamento do Disco Articular é freqüente em pacientes com DTM, em especial Deslocamento Anterior do Disco (DDA) (EMSHOFF et al., 2002; KATZBERG et al., 1996; OQURA, 2006; SENER e AKQUNLU, 2005; TASKAYA-YYLMAR et al., 2002; USUMEZ et al., 2004), analisamos a freqüência de DDA na nossa mostra, e constatamos que $100 \%$ dos indivíduos do grupo sem DTM não apresentaram imagens de DDA e apenas uma pequena porcentagem dos pacientes com DTM, entre $17,2 \%$ e $22,9 \%$, apresentaram imagem compatível com algum tipo de DDA (com ou sem redução) nos lados D ou E. Resultados estes que não foram estatisticamente significantes.

A mobilidade da cabeça da mandíbula, também foi avaliada, já que o MPL se insere principalmente na fóvea pterigóide da cabeça da mandíbula (FIGUN; 
GARINO, 1994; MADEIRA, 2001; MCDEVITT, 1989).

Observamos a existência de hipomobilidade ou hipermobilidade nas imagens de RM, nas imagens de boca aberta e fechada, inclusive nas sequências de pseudocine, que auxiliam muito na observação do comportamento de todo o conjunto desde a oclusão até a posição de abertura máxima da boca.

É importante ressaltar que, apesar da existência de pacientes, no grupo com DTM, com algum tipo de DDA, alteração na mobilidade da cabeça da mandíbula e alteração na morfologia do MPL, ambos os grupos apresentaram, estatisticamente, a mesma distribuição do DDA $(p=0,815)$ e mobilidade da cabeça da mandíbula $(p=0,189)$, além da morfologia do MPL $(p>0,999)$.

Na comparação entre posição do disco articular, mobilidade da cabeça da mandíbula e alteração na morfologia dos músculos, comparamos todos esses tipos de achados, entre o grupo com DTM, nos lados D e E e o grupo sem DTM. Não encontramos relação entre todos estes dados, apesar de serem achados predominantemente em pacientes com DTM, o que poderia indicar que as alterações encontradas em pacientes com DTM não são interligadas, isto é, são independentes. Não é necessário que ao apresentar uma alteração esta deva estar associada à outra qualquer, como já descrito anteriormente por Yang (2002), que observou alterações no MPL e alterações na mobilidade da cabeça da mandíbula em pacientes com e sem DDA.

Vale comentar que, só foi possível aplicar o teste estatístico para estudar essas comparações no grupo com DTM e neste caso, não foi detectada nenhuma associação estatisticamente significante entre a morfologia do MLP e DDA ( $p>0,999)$, assim como também entre morfologia do MPL e mobilidade da cabeça da mandíbula $(p=0,797)$. 
Segundo o trabalho de Yang (2002), hipertrofia do MPL foi a alteração mais frequentemente encontrada no seu estudo, principalmente na cabeça superior do MPL (54,9\%) e na cabeça inferior associada a alguma alteração na cabeça superior do MPL $(89,4 \%)$. Acreditamos que estes altos índices de alterações descritos por este autor se devem a parâmetros qualitativos subjetivos na definição destas alterações, baseados no tamanho e forma dos MPL observados nas imagens de RM.

Por outro lado este próprio autor (YANG, 2002) relatou que as alterações no MPL podem não estar relacionadas a outros achados observados em pacientes com DTM, quando disse que os seus resultados levaram a crer que as alterações no MPL podem ser a causa de sintomas clínicos de DTM em pacientes sem deslocamento de disco articular e com hipermobilidade da cabeça da mandíbula.

Na comparação das medidas dos MPL nos cortes: axial, T1 e T2; com DDA, hipo e hipermobilidade da mandíbula e morfologia dos MPL, constatamos que as medidas nos cortes: axial $(p=0,082)$, T1 sagital com boca fechada $(p=0,276)$ e T2 sagital com boca aberta $(\mathrm{p}=0,381)$ não estão relacionadas à mobilidade, com relação ao lado D. Já em relação à morfologia do MPL, ainda do lado $D$, foi possível comparar apenas os grupos com e sem DTM com morfologia normal do MPL. Os resultados mostraram que os grupos têm valores médios estatisticamente iguais do T1 sagital com boca fechada $(p=0,219)$ e T2 sagital com boca aberta $(p=0,129)$, mas o grupo com DTM apresentou valor médio axial maior que o grupo sem DTM $(p=0,006)$, assim como a medida axial está relacionada ao tipo de DDA $(p=0,037)$, também do lado D.

As comparações das medidas do lado esquerdo, também comparadas nesta pesquisa, mostraram que medidas axial $(p=0,295)$, T1 sagital com boca fechada 
$(p=0,122)$ e T2 sagital com boca aberta $(p=0,440)$ não estão relacionadas ao DDA. Já em relação à mobilidade, apenas a medida axial está relacionada a este tipo de alteração $(p=0,040)$.

Assim como ocorreu no lado direito, no lado esquerdo foi possível comparar apenas os grupos com e sem DTM com Morfologia Normal do MPL. Os resultados mostraram que os grupos têm valores médios estatisticamente iguais da medida axial ( $p=0,303)$, T1 sagital com boca fechada $(p=0,097)$ e T2 sagital com boca aberta $(p=0,275)$.

Concluímos que as medidas dos MPL nos cortes axiais em pacientes com DTM, do lado $D$, estão relacionadas com DDA $(p=0,037)$ e alterações morfológicas do MPL $(p=0,006)$ e as medidas axiais dos MPL do lado E estão relacionadas com hipermobilidade da cabeça da mandíbula. Estes resultados sugerem que as espessuras dos MPL encontram-se aumentadas quando relacionadas com DDA e hipermobilidade, podendo significar algum tipo de compensação, sobrecarga ou hiperatividade do músculo nos casos de presença destas disfunções.

Taskaya-Yýlmaz e Ogutcen-Toller (2002) relataram que a teoria de que DDA pode estar relacionado a hiperatividade do MPL é bem aceita, por outro lado demonstrou que atrofia ou contratura do MPL têm sido vistos como secundários a excessiva atividade muscular ou devido ao fato da DDA reduzir a função da cabeça superior do MPL, levando à atrofia muscular. $O$ que nos leva a pensar que o comportamento do MPL em relação ao disco articular, especialmente nos casos de DDA, ainda não está totalmente esclarecido.

Finden, Enochs e Rao (2007) postularam que embora o disco e a cabeça da mandíbula mantêm uma relação normal entre si, tanto em posição de boca fechada quanto boca aberta, a presença de deslocamento do disco articular pode resultar em 
forças desfavoráveis na ATM contralateral, o que poderia causar espasmo muscular, resultando em edema na cabeça superior do MPL.

Devido ao alto índice de Dor e Estalo detectados nos pacientes com DTM, ao exame clínico, tentamos relacionar as medidas realizadas dos MPL com estes dados e observamos que os valores médios dos MPL foram estatisticamente iguais para o grupo que apresentava estes sinais e para o grupo assintomático. Os três grupos (com DTM sem estalo, com DTM com estalo e sem DTM sem estalo) apresentaram valores médios das medidas axiais $(p=0,274), T 1$ sagital com boca fechada $(p=0,132)$ e T2 sagital com boca aberta $(p=0,071)$ estatisticamente iguais. Também os três grupos (com DTM sem dor, com DTM com dor e sem DTM sem dor) apresentaram valores médios das medidas axiais $(p=0,316)$, T1 sagital com boca fechada $(p=0,182)$ e T2 sagital com boca aberta $(p=0,151)$ estatisticamente iguais.

Levando-se em conta que a distribuição da ocorrência das Queixas dos pacientes foi maior bilateralmente ou do lado E, como Dor e Estalo, assim como a presença de hipermobilidade da cabeça da mandíbula, também ocorreu com mais freqüência do lado $E$, podemos pensar que o aumento da espessura do MPL, nos cortes axiais, do lado D, ocorreriam por sobrecarga muscular contralateral durante os movimentos exacerbados da cabeça da mandíbula. 


\section{CONCLUSÕES}

7.1 houve uma prevalência de DTM no gênero feminino;

7.2 as queixas mais presentes foram dor e estalo;

7.3 todos os pacientes com DTM são portadores de algum tipo de sintomatologia;

7.4 a presença de DTM pode provocar alteração na espessura do MPL;

7.5 todos os pacientes sem DTM apresentaram o teste do MPL (Teste Muscular Anterior) negativo;

7.6 os tipos de alterações morfológicas mais encontradas foram atrofia e contratura muscular. 


\section{REFERÊNCIAS ${ }^{1}$}

Abou-Atme YS, Zawawi $\mathrm{KH}$, Melis M. Prevalence, Intensity, and Correlation of Different TMJ Symptoms in Lebanese and Italian Subpopulations. J Contemp Dent Pract 2006 Sep;(7)4:071-078.

Agerberg G. Maximal mandibular movement in young men and women. Sweed Dent 1974;67:81-100.

Agresti A. Categorical data analysis. New York: Wiley Interscience; 1990.

Benito C, Casares G, Benito C. TMJ static disk: correlation between clinical findings and pseudodynamic magnetic resonance images. Cranio 1998;16(4):242-51.

Bertilsson O, Strom D. A literature survey of a hundred years of anatomic and funccional lateral pterygoid muscle research. J Orofacial Pain 1995;9(1):17-23.

Burnett KR, Davis CL, Read J. Dynamic display of the temporomandibular joint meniscus by using "fast-scan" MR imaging. AJR Am J Roentgenol 1987 Nov;149(5): 959-62.

Bruno MAD. Disfunção temporomandibular. Aspectos clínicos de interesse do cefaliatra. Migrâneas cefaléias 2004 jan./fev./mar;7(1)14-8.

Bussab WO, Morettin PA. Estatística básica. 5a. ed. São Paulo: Saraiva; 2006.

Conti PCR, Miranda JES, Ornelas F. Ruídos articulares e sinais de disfunção temporomandibular: um estudo comparativo por meio da palpação manual e vibratografia computadorizada da ATM. Rev Pesq Odontol Bras 2000 Out/Dez; 14(4)367-71.

Dworkin SF, LeResche L. Research diagnostic criteria for temporomandibular disorders: review, criteria, examinations and specifications, critique. J Craniomandib Disord 1992 Fall;6(4):301-55.

\footnotetext{
${ }^{1}$ De acordo com o Estilo Vancouver. Abreviatura de periódicos segundo base de dados MEDLINE
} 
Eberhard D, Bantelon HP, Steger W. Functional magnetic resonance imaging of temporomandibular joint disorders. Eur J Orthod 2000;22:489-97.

Emshoff R, Rudisch A, Innerhofer K, Brandlmaier I, Moschen I, Bertram S. Magnetic resonance imaging findings of internal derangement in temporomandibular joints without a clinical diagnosis of temporomandibular disorder. J Oral Rehabil 2002 Jun; 29(6):516-22.

Figun ME, Garino RR. Miologia: anatomia odontológica funcional e aplicada. 2a. ed. São Paulo: Panamericana; 1994. p 71-2.

Finden SG, Enochs WS, Rao VM. Pathologic Changes of the Lateral Pterygoid Muscle in Patients with Derangement of the Temporomandibular Joint Disk: Objective Measures at MR Imaging. AJNR 2007 Set; 28(8):1537-9.

Fricton JR, Okeson JP. Broad support evident for the emerging specially of orofacial pain. Text Dent J 2000 Jul;117(7):22-5.

Gan $\mathrm{YH}, \mathrm{MA} X \mathrm{X}$, Wang J. Magnetic resonance imaging of lateral pterygoid muscle in temporomandibular join dysfunction syndrome. Zhonghua Kou Qiang Yi Xue ZZa Zhi 1994 Nov;29(6):326-8.

Genovesi W. Centro de dor e neurocirurgia funcional. 2004. Disponível em: URL: http:// www.centrodedor.com.br/images/atm 01

Goto TK, Tokumori K, Nakamura Y, Yahagi M, Yuasak, Okamura K, et al. Volume changes in human masticatory muscles between jaw closing and opening. $J$ Dent Res 2002 Jun;81(6):428-32.

Gray H. Anatomia do corpo humano. 29a. ed. Cidade: Guanabara - Koogan; 1988.

Gray H. Anatomy of the human body. 1918. Disponível em: URL: http://www.bartleby.com

Greene CS, Laskin DM. Long-term status of TMJ clicking in patients with myofascial pain and dysfunction. J Am Dent Assoc 1988;117(3):461-5.

Heffez LB, Mafee MF, Rosenberg HM. Imaging atlas of the temporomandibular joint. Philadelphia, PA: Williams \& Wilkins; 1995. 
Helms CA, Richardson ML, Moon KL, Ware, WH. Nuclear magnetic resonance imaging of the temporomandibular joint: preliminary observations. Cranio Pract 1984; 2:219-24.

Hong L. Analysis of the image of external pterygoid muscle during close and wide opening of the jaw by condylo-pterygoid-maxillo-oblique projection in magnetic resonance. Zhonghua Kou Qiang Yi Xue ZZa Zhi 1993 Jul;28(4):200-2.

Hornak JP. The basics of MRI 1996. Rochester Institute of Technology. Disponível em: URL: http://www.cis.rit.edu/htbooks/mri/inside.htm .

Iwama $Y$, Fujii M, Shibanuma $H$, Muratsu $H$, Kurosaka M, Kawamitsu $H$, et al. Highresolution MRI using a microscopy coil for the diagnosis of recurrent lateral patellar dislocation. Radiat Med 2006 Jun; 24(5):327-34.

Katzberg RW, Bessette RW, Tallents RH, Plewes DB, Manzione JV, Schenck JF, et al. Normal and Abnormal temporomandibular joint: MR imaging with surface coil 1986 Jan;158(1)183-9.

Katzberg RW, Westesson PL. Diagnosis of the temporomandibular joint. Philadelphia, PA: WB Saunders; 1993.

Katzberg RW, Wetesson PL, Tallents RH, Drake CM. Anatomic disorders of the temporomandibular join disc in asymptomatic subjects. J Oral Maxillofac Surg 1996 Feb;54(2):147-59.

Keller P. Basic Principles of MR Imaging. Milwaukee: GE Medical Systems; 1988. Disponível em: URL: http://www.easymeasure.co.uk/principlesmri.aspx .

Laskin DM. Temporomandibular disorders: a term past its time? J Am Dent Assoc 2008 Feb;139(2):124-8.

Laskin DM, Greenfield W, Gale E. Report of the president's conference on the examination, diagnosis, and management of temporomandibular disorders J Am Dent Assoc 1983;106:75-77.

Limchaichana N, Nilsson H, Ekberg EC, Nilner M, Petersson A. Clinical diagnoses and MRI findings in patients with TMD pain. J Oral Rehabil 2007 Apr;34(4):237-45. 
Liu ZT, Yamgata K, Kuroe K, Suenaga S, Noikura T, Ito G. Morphological and positional assessments of TMJ components and lateral pterygoid muscle in relation to symptoms and occlusion of patients with temporomandibular disorders. J Oral Rehabil 2000 Oct;27(10):860-74.

Madeira MC. Bases anátomo fucionais para a prática Odontológica. Anatomia Funcional da Face. São Paulo: Sarvier; 2001. p. 82-4.

Mc Devitt WE. Prime movers of the mandible. Functional Anatomy of the Masticatory System. London: Wright; 1989. p. 30-44.

Manfredi APS, Silva AA, Vendite LL. Avaliação da sensibilidade do questionário de triagem para dor orofacial e desordens temporomandibulares recomendado pela Academia Americana de Dor Orofacial. Rev Bras Otorrinolaringol 2001 Nov;67(6):763-8.

Medeiros RB. Radiação ionizante e não ionizante. Núcleo de proteção radiológica UNIFESP. Disponível em: URL: http://cfhr.epm.br/images/aulaRM

Murray GM, Phanachet I,Ushida S, Whittle T. The human lateral pterygoid muscle: a review of some experimental aspects and possible clinical relevance. Aust Dent 2004 Mar;49(1):2-8.

Musgrave MT, Westesson PL, Tallent RH, Manzione JV, Katzberg RW. Improved magnetic resonance imaging of the temporomandibular join by oblique scanning planes. Oral Surg Oral Med Oral Pathol 1991 May;71(5):525-8.

Neter J, Kutner MH, Nachtsheim CJ, Wasserman W. Applied linear statistical models. 4th. ed. Boston: Irwin; 1996.

Okeson JP, de Kanter RJ. Temporomandibular disorders in the medical practice. J Fam Pract 1996 Oct;43(4):347-56.

Oqura I. Magnetic resonance imaging characteristics of temporomandibular joint pain during opening and biting in patients with disc displacement. Oral Surg Oral Med Oral Pathol Oral Radiol Endod 2006 Nov;102(5):669-72.

Quemar JC, Bernard AM, Akoka S, Romdane H, Simon J, Certaines JD. Magnetic resonance imaging of the TMJ: identification of anatomic elements by controlled movement and application to normal and pathologic clinical situations. J Craniomand Disord Facial Oral Pain 1998;3(1):20-4. 
Quemar JC, Ravalec X, Akoka S. Parasagital magnetic resonance imaging of the lateral pterygoid muscle: a preliminary study. J Orofac Pain 1993 Spring;7(2):169-74.

Rauhala K, Oikarinen KS, Raustia AM. Role of TMD in facial pain: occlusion, muscle and TMJ pain. Cranio 1999;17(4):254-61.

Schellhas KP. MR imaging of muscles of mastication. AJR Am J Roentgenol 1989; 153:847-55.

Schellhas KP, Wilkes $\mathrm{CH}$, Heithoff KB, Omlie MR, Block JC. Temporomandibular joint: diagnosis of internal derangements using magnetic resonance imaging. Minn Med 1986;69(9):516-9.

Schellock FG. Magnetic Resonance safety update 2002: Implants and devices. JMRI 2002;16(5):485-96.

Scherzinger AL, Hendee WR. Basic Principles of Magnetic Resonance Imaging-An Update. West J Med 1985 Dec;143(6):782-92.

Schmolke C. The relationship between the temporomandibular join capsule, articular disc and jaw muscles. J Anat 1994 Apr;184(2):335-45.

Sener S, Akounlu F. Correlation of different MRI characteristics of anterior displacement with reduction and without reduction. J Contemp Dent Pract 2005 Feb;15(6):26-36.

Sicher H, Dubrul G. Anatomia oral. Distúrbios funcionais da articulação craniomandibular. 8a. ed. São Paulo: Artes médicas; 1991. p. 355-366.

Sobotta, J. Atlas de anatomia humana. 21a. ed. Rio de Janeiro: Guanabara Koogan; 2000. Disponível em:URL: http://www.auladeanatomia.com . [2008 set. 17].

Solberg WK. Temporomandibular disorders: background and the clinical problems. Br Dent J 1986;160(5)157-61.

Stratmann U, Mokrys K, Meyer U, Kleinheinz J. Clinical anatomy and palpability of the inferior lateral pterygoid muscle. J Prosthet Dent 2000 May;83(5):548-54.

Tasaki MM, Westesson PL. Temporomandibular joint: diagnostic accuracy with sagital and coronal MR imaging. Radiology 1993;186(3):723-9. 
Taskaya-Yýlmaz N, Ceylan G, Incesu L, Muglali M. A possible etiology of the internal derangement of the temporomandibular joint based on the MRI observations of the lateral pterygoid muscle. Surg Radiol Anat 2004 March;27(1):19-24.

Taskaya-Yýlmaz N, Ogutcen-Toller M. Clinical correlation of MRI findings of internal derangements of the temporomandibular joints. Br J Oral Maxillofac Surg 2002 Aug;40(4):317-21.

Truelove EL, Sommers EE, LeResche L, Dworkin SF, Von Korff M. Clinical diagnostic criteria for TMD: new classification permits multiple diagnoses. J Am Dent Assoc 1992;123(4):47-54.

Turp JC, Minagi S. Palpation of the lateral pterygoid region in TMD--where is the evidence? J Dent 2001 Sep;29(7):475-83.

Usumez S, Oz F, Guray E. Comparison of clinical and magnetic resonance imaging diagnoses in patients with TMD history. J Oral Rehabil 2004 Jan;31(1):56-6.

Wang MQ, Yan CY, Yuan YP. Is the superior belly of the lateral pterygoid primarily a stabilizer? An EMG study. J Oral Rehabil 2001 Jun;28(6):507-9.

Westbrook C, Kaut C. Ressonância magnética prática. 2a. ed. Rio de Janeiro: Guanabara Koogan; 2000. p 1-140.

Westesson PL. Reliability and validity of imaging diagnosis of temporomandibular joint disorder. Adv Dent Res 1993;17:331-5.

Yang $X$. Magnetic Resonance Imaging of the Lateral Pterygoid Muscle in Temporomandibular Disorders. [Academic Dissertation]. Finland: University of Oulu; 2002. Disponível em: URL: http://herkules.oulu.fi/isbn9514266439 [2008 set. 17].

Yang X, Pernu H, Pyhtinen J, Tiilikainen PA, Oikarinen KS, Raustia AM. MRI findings concerning the lateral pterygoid muscle in patients with symptomatic TMJ hypermobility. Cranio 2001 Oct;19(4):260-8.

Yang X, Pernu H, Pyhtinen J, Tilikainen PA, Oikarinen KS, Raustia AM. MR abnormalities of the lateral pterygoid muscle in patients with nonreducing disk displacement of the TMJ. Cranio 2002 Jul;20(3):209-21. 


\section{Sño-11U1z \\ Estudos}

\section{PARECER FINAL \\ COMITÊ DE ÉTICA EM PESQUISA DA BENEFICÊNCIA MÉDICA BRASILEIRA SIA - HOSPITAL E MATERNIDADE SÃO LUIZ}

\section{PROJETO CAAE N $\mathbf{N}^{\circ}$ 020.0.220.017-05}

No CEP: 102/2005

TíTULO: "Avaliação do Músculo Pterigóideo Lateral por meio de Ressonância Magnética"

INVESTIGADOR PRINCIPAL: Dra. Silvia Fernandes Morgado D'Ippolito

PROFISSÃO: Dentista

PROTOCOLO: 29.09 .05

Saibam, quantos este PARECER FINAL virem, que o Comitê de Ética em Pesquisa da Beneficencia Médica Brasileira S/A Hospital e Maternidade São Luiz, em Reunião ordinária realizada em 30.11.2005, APROVOU, por unanimidade, o projeto/estudo/pesquisa em epígrafe, nos termos do relatório e voto do Relator designado.

Relatório: A proposição neste trabalho é demonstrar que a Ressonância Magnética é o método de diagnóstico por imagem ideal para a exploração muscular, pode ser de grande ajuda na avaliação da morfologia e das alterações patológicas da estrutura articular temporomandibular e dos músculos mastigatórios, mostrando-se eficaz na observação específica do Músculo Pterigóideo Lateral, que é o objetivo do nosso estudo, sua anatomia, fisiologia, alterações nos casos de Desordens Temporomandibulares, tais como hipermobilidade, deslocamento do disco articular e alteraçöes volumétricas, bem como a correlação destas alterações com as desordens do complexo temporomandibular, sua sintomatologia e os sinais e sintomas clínicos relatados pelos pacientes.

Parecer: Projeto aprovado sem reservas do ponto de vista ético.

Pelo exposto, o Comitê de Ética em Pesquisa, vem pela presente informar seu parecer FAVORÁVEL à realização do projeto/estudo/pesquisa apresentado, consignando seu necessário 
ANEXO A (cont)

\section{sño-1101z \\ Centro de \\ Estudos}

CONSENTIMENTO, conforme disposto no Parágrafo $1^{\circ}$, da Cláusula $6^{a}$, de seu Regimento Interno. Solicitamos que nos enviem relatórios semestrais e final sobre os resultados desta pesquisa.

Tudo em conformidade com a ata de Reunião ordinária, lavrada no dia 30.11.2005. Presidiu a Reunião a Dra. Maria Lúcia Borri Presidente Interina do Comitê de Ética em Pesquisa da Beneficência Médica Brasileira S/A - Hospital e Maternidade São Luiz.

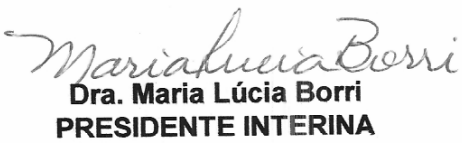

Comitê de Ética em Pesquisa Hospital e Maternidade São Luiz 
ANEXO B

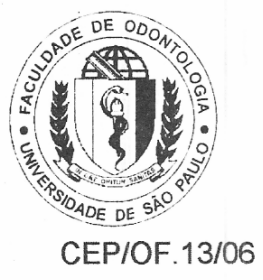

\section{UNIVERSIDADE DE SÃO PAULO}

FACULDADE DE ODONTOLOGIA

São Paulo, 28 de março de 2006

Senhora Pesquisadora

Informamos a Vossa Senhoria, que diante de Parecer do Comitê de Ética em Pesquisa da Beneficência Médica Brasileira S/A. - Hospital e Maternidade São Luiz, estamos cientes da aprovação do projeto de pesquisa intitulado "Avaliação do músculo pterigoideo lateral por meio de ressonância magnética" de sua autoria, não havendo nenhuma oposição por parte deste CEP, com relação a sua realização.

Sendo o que se nos apresentava, valemo-nos da oportunidade para reiterarthe os nossos protestos de elevada estima e distinta consideração.

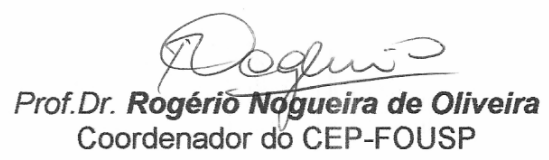

Ilustríssima Senhora

Silvia F. Morgado D'Ippolito

Departamento de Estomatologia 
ANEXO C

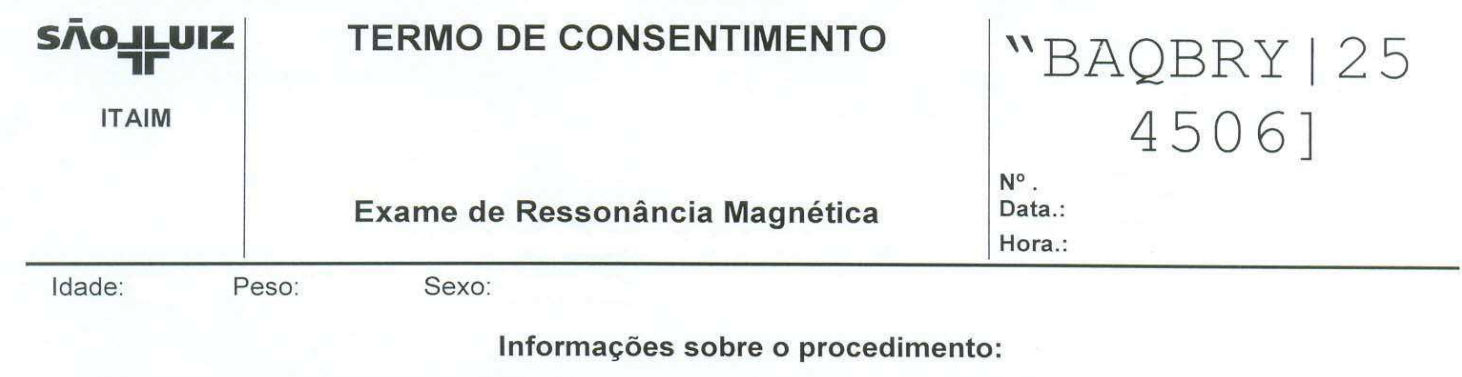

O exame de ressonância magnética (RM) não utiliza radiações ionizantes (como Rx), não tem nenhum efeito colateral sobre o organismo humano e nem provoca mal estar. O exame pode ser repetido quantas vezes for necessário. Este aparelho funciona como um grande imã que gera um campo magnético e por tal motivo alguns cuidados devem ser tomados com materiais metálicos sendo por isso necessária a resposta de um questionário que the apresentaremos a seguir. É importante permanecer totalmente imóvel durante a realização do procedimento pois as imagens são como fotografias e se houver movimento elas sairão tremidas e terão que ser repetidas. O exame pode durar em média entre 20 a 60 minutos dependendo da região a ser examinada. A critério do radiologista poderá ser indicada a administração de contraste endovenoso para melhor esclarecimento do diagnóstico. Informamos que o contraste da RM não provoca reações alérgicas. O local da punção da veia poderá ficar vermelho ou irritado problema facilmente solucionado com mediação local (pomadas). Durante todo o exame haverá um contato visual e sonoro entre a equipe médica e o paciente através de visor, microfone e campainha. O nosso serviço está equipado para qualquer atendimento num caso de emergência.

1. O Sr (a) é portador de:

Questionário de Pacientes Alérgicos

a) marca-passo cardíaco, medular ou cerebral?

b) clipe intracraniano?

c) válvula cardíaca?

d) pinos, parafusos ou próteses ortopédicas?

e) tatuagem ou maquiagem permanente?

f) DIU?

g) prótese dentária móvel?

h) A Sra está ou suspeita estar grávida?

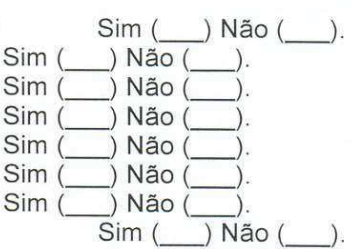

i) $\mathrm{O} \mathrm{Sr}$ (a) já foi atingido por um projétil de arma de fogo, por fagulha nos olhos ou atua em atividades de manipulação de metais?

$\operatorname{sim}(\ldots)$ Não (__

História Clínica

1. Quais problemas o (a) levaram a procurar seu médico?

2. De qual doença seu médico suspeita?

3. Há quanto tempo os sintomas iniciaram?

4. Existe algum outro problema de saúde além da suspeita do seu médico?

5. O Sr.(a) já foi submetido a algum tipo de cirurgia? Qual? Há quanto tempo?

6. O Sr(a) já fez Radioterapia Sim (__ Não (__ Há quanto tempo?

7. O $\operatorname{Sr}(a)$ já fez Quimioterapia? Sim (__ Não (__ Há quanto tempo? 


\begin{abstract}
ANEXO - Termo de Consentimento Livre e Esclarecido, de participação pósinformado, no protocolo de "Avaliação do Músculo Pterigóideo Lateral por meio de Ressonância Magnética”.
\end{abstract}

$\mathrm{Eu}$ abaixo assinado,

voluntariamente concordo em participar do estudo "Avaliação do Músculo Pterigóideo Lateral, por meio de Ressonância Magnética”. Há garantia de que minha identidade será preservada na pesquisa e nas apresentações da mesma. Ficou bem esclarecido que a pesquisa consta de coleta de dados por meio de exames de Ressonância Magnética da Articulação Temporomandibular. Declaro ter lido e compreendido esta declaração de consentimento, na qual fui informado de todos os dados importantes sobre a conduta deste estudo. Fui informado que o pesquisador responsável pelo projeto poderá ser contatado em qualquer momento que eu julgar necessário, durante todo o período deste estudo. Foi me oferecido ampla oportunidade de fazer perguntas e recebi respostas que me satisfizeram totalmente. Entendo que não haverá nenhum custo relacionado à minha inclusão neste projeto de pesquisa. No presente momento me foi apresentado o "Termo de Autorização e Responsabilidade" para exames de ressonância magnética, o qual foi por mim lido, compreendido e assinado. Estou ciente que poderei retirar o meu consentimento a qualquer momento, sem penalidades, prejuízo ou perdas de qualquer benefício que possa ter adquirido durante o meu atendimento neste serviço.

São Paulo, de. de

Nome.

RG.

Assinatura do paciente.

Investigador Principal: Dra. Silvia D'Ippolito

Telefones de contato: 9980.1023 / 3040.1458 
APÊNDICE B

NOME:

DATA NASCIMENTO:

DATA EXAME:

TELEFONE PARA CONTATO:

ANAMNESE:

- TEMPO

- REGIÃo E LAdO

- INTENSIDADE (Forte, Médio, Fraco)

- FREQUÊNCIA

- DURAÇÃo

- HORARIO DE OCORRÊNCIA

- FATOR DESENCADEANTE

- FATOR DE PIORA

- FATOR DE MELHORA

- FATOR ACOMPANHANTE

TESTES FUNCIONAIS

- TESTE MUSCULAR (ESPATULA) : 1 MIN LINHA MEDIANA

LADO D

LADO E

- ABERTURA MAXIMA - MEDIDA

- EXCURSÃo LATERAL

- PROTRUSÃo

- PALPAÇÃo (Click, PONTO GATILHO,DESLOCAMENTO) 
APÊNDICE C

O Boxplot é uma representação gráfica que nos fornece uma idéia da posição, dispersão, assimetria e dados discrepantes.

A construção é feita a partir de algumas medidas de posição:

- Primeiro quartil $\left(\mathrm{J}_{1}\right)$

- Mediana $\left(\mathrm{J}_{2}\right)$

- Terceiro quartil $\left(\mathrm{J}_{3}\right)$

Definimos inicialmente aqueles valores que estão muito distantes do primeiro ou do terceiro quartis, como sendo observações discrepantes.

Para construir o Boxplot, consideraremos um retângulo onde estão representados os quartis e a mediana. A partir do retângulo, para cima e para baixo, seguem linhas até o ponto mais remoto que não seja uma observação discrepante. Obteremos, então, uma figura que representa o conjunto dos dados, com exceção dos outlier. Estes serão representados individualmente por x.

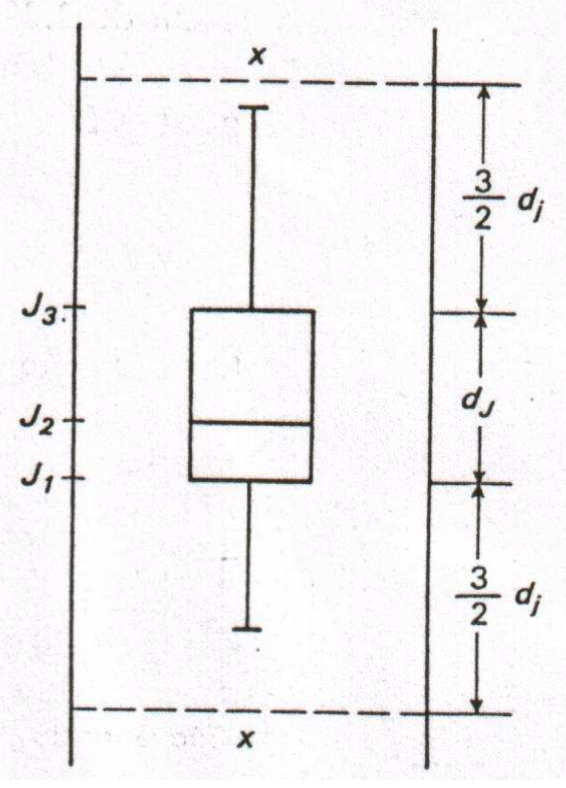

A posição central dos valores é dada pela mediana e a dispersão pela diferença entre o terceiro e o primeiro quartis. As posições relativas de $J_{1}, J_{2}$ e $J_{3}$ dão uma noção da assimetria da distribuição. 